\title{
OXIDE ELECTRODES
}

FOR $\mathrm{Pb}\left(\mathrm{Zr}_{0.52} \mathrm{Ti}_{0.48}\right) \mathrm{O}_{3}$
CAPACITORS 



\section{Oxide Electrodes \\ for $\mathrm{Pb}\left(\mathrm{Zr}_{0.52} \mathrm{Ti}_{0.48}\right) \mathrm{O}_{3}$ Capacitors}

Jun Wang 


\section{Graduation Committee}

\section{Chairman and Secretary}

Prof. dr. J.L. Herek (University of Twente)

\section{Supervisors}

Prof. dr. ing. A.J.H.M. Rijnders (University of Twente)

Prof. dr. ir. G. Koster (University of Twente)

\section{Members}

Prof. dr. F. Bijkerk (University of Twente)

Prof. dr. ir. A. Brinkman (University of Twente)

Prof. dr. W.A. Groen (TU Delft)

Prof. dr. J.Verbeeck (Antwerp University)

Prof. dr. ir. M. Huijben (University of Twente)

The research presented in this thesis was carried out at the Inorganic Materials Science group, Naonoelectronic Materials and Thin Films Cluster, Department of Science and Technology, MESA ${ }^{+}$ Institute of Nanotechnology at the University of Twente, The Netherlands. The research was financially supported by The Netherlands Organization for Scientific Research (NWO) and performed in collaboration with Océ and SolMateS.

\section{Cover}

The background of the cover shows a photograph of pulsed laser deposition system used for this work. The front cover shows the schematic of a PZT capacitor that is the main subject of this thesis. The right corner of the front cover presents the perovskite structure of oxide electrodes.

Oxide Electrodes for $\mathrm{Pb}\left(\mathrm{Zr}_{0.52} \mathrm{Ti}_{0.48}\right) \mathrm{O}_{3}$ Capacitors

$\mathrm{Ph} . \mathrm{D}$. thesis, University of Twente, Enschede, The Netherlands

Copyright $\odot 2019$ by J.Wang

DOI: $10.3990 / 1.9789036548090$

ISBN: 978-90-365-4809-0

Printed by IPSKAMP, Enschede, The Netherlands 


\section{OXIDE ELECTRODES \\ FOR $\mathrm{Pb}\left(\mathrm{Zr}_{0.52} \mathrm{Ti}_{0.48}\right) \mathrm{O}_{3}$ CAPACITORS}

\section{PROEFSCHRIFT}

ter verkrijging van

de graad van doctor aan de Universiteit Twente,

op gezag van de rector magnificus,

prof. dr. T.T.M. Palstra,

volgens besluit van het College voor Promoties

in het openbaar te verdedigen

op vrijdag 5 juli 2019 om 10.45 uur

door

Jun Wang

geboren op 7 mei 1990

te Changsha 
Dit proefschrift is goedgekeurd door de promotoren

prof. dr. ing. A.J.H.M. Rijnders

prof. dr. ir. G. Koster 


\section{Contents}

\begin{tabular}{lll}
\hline & Introduction & 1
\end{tabular}

1.1 Motivation . . . . . . . . . . . . . . . . . . . . 1

1.2 Thesis outline . . . . . . . . . . . . . . . . 6

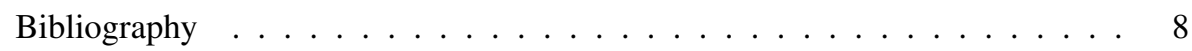

\begin{tabular}{|lll}
2 & Fabrication and characterization of epitaxial oxide thin films & 13
\end{tabular}

2.1 Fabrication . . . . . . . . . . . . . . . . . . . 14

$2.1 .1 \quad$ Pulsed laser deposition . . . . . . . . . . . . . . . . . 14

$2.1 .2 \quad$ Pulsed laser deposition setup . . . . . . . . . . . . . 15

2.1 .3 Patterning . . . . . . . . . . . . . . . 15

2.2 Characterization . . . . . . . . . . . . . . . . 17

$2.2 .1 \quad$ Atomic force microscopy . . . . . . . . . . . . . . 17

2.2 .2 X-ray diffraction $\ldots \ldots \ldots \ldots \ldots$

$2.2 .3 \quad$ Scanning transmission electron microscopy $\ldots \ldots$. . . . . . . 18

2.2 .4 Electrical transport properties . . . . . . . . . . . . 19

$2.2 .5 \quad$ Ferroelectric characterization . . . . . . . . . . . . . . 19

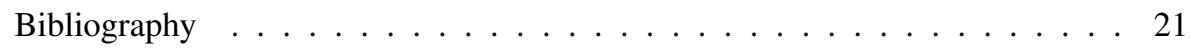


3 Growth kinetics of epitaxial La-doped $\mathrm{BaSnO}_{3}$ thin films by pulsed laser deposition

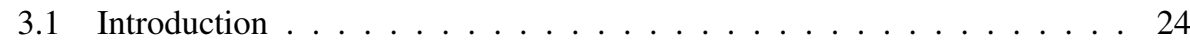

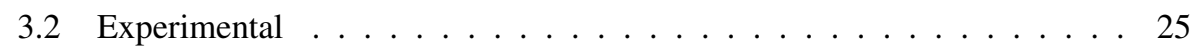

3.3 Results and discussion . . . . . . . . . . . . . . 26

3.4 Conclusion . . . . . . . . . . . . . . . 33

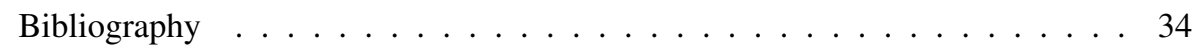

$4 \mathrm{~Pb}\left(\mathrm{Zr}_{0.52} \mathrm{Ti}_{0.48}\right) \mathrm{O}_{3}$ capacitors consisting of oxide electrodes with different work functions and carrier densities $\quad 37$

$4.1 \quad$ Introduction $\ldots \ldots \ldots \ldots$. . . . . . . . . . . . . . . . . . . . . . . 39

4.2 Capacitors on single crystal substrates $\mathrm{SrTiO}_{3} \ldots \ldots \ldots \ldots$. . . . . . . 41

$4.2 .1 \quad$ Experimental $\ldots \ldots \ldots \ldots \ldots \ldots$. . . . . . . . . . 41

4.2 .2 Results and discussion . . . . . . . . . . . . . . 42

4.3 Capacitors on silicon substrates . . . . . . . . . . . . . . . . . 55

$4.3 .1 \quad$ Experimental . . . . . . . . . . . . . . 55

4.3 .2 Results and discussion . . . . . . . . . . . . . . 56

4.4 Conclusions $\ldots \ldots \ldots \ldots \ldots \ldots$

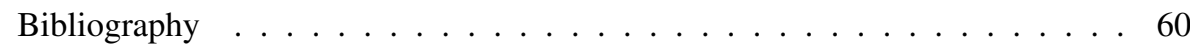

5 Complex plume stoichiometry during pulsed laser deposition of $\mathrm{SrVO}_{3}$ at low oxygen pressures $\quad 63$

5.1 Introduction . . . . . . . . . . . . . . . . 64

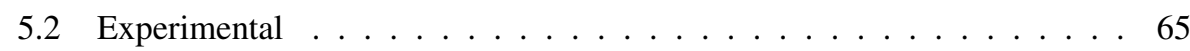

5.3 Results and discussion $\ldots \ldots \ldots \ldots \ldots 6$

5.4 Conclusion $\ldots \ldots \ldots \ldots \ldots \ldots \ldots$

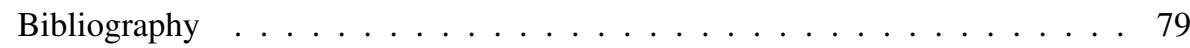


6 Dimensional-crossover-driven Metal-insulator transition in ultrathin $\mathrm{SrVO}_{3}$ films and $\mathrm{SrVO}_{3} / \mathrm{SrTiO}_{3}$ superlattices $\quad \mathbf{8 1}$

6.1 Introduction . . . . . . . . . . . . . . . . 82

6.2 Experimental $\ldots \ldots \ldots \ldots \ldots \ldots \ldots \ldots$

6.3 Results and conclusion . . . . . . . . . . . . . . . . . . 85

6.4 Conclusion . . . . . . . . . . . . . . . . . . 93

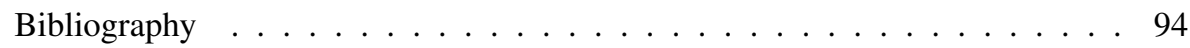

\begin{tabular}{lr}
\hline Summary & 97
\end{tabular}

\begin{tabular}{ll}
\hline Samenvatting & 101
\end{tabular}

\begin{tabular}{ll}
\hline 全文总结 & 105
\end{tabular}

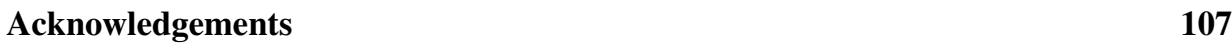





\section{Chapter 1}

\section{Introduction}

\subsection{Motivation}

Ferroelectric materials have spontaneous electric polarization that can be reversed by applying an external electric field. Because of the switchability between two states, they are used for non-volatile random access memory (NVRAM) devices [1-3]. Ferroelectric random access memory (FeRAM) was first proposed by Dudley Allen Buck in his master thesis in 1952 [4]. The ferroelectric based field effect transistor (FeFET) is the other application, which has been developed for the realization of non-destructive read out memories [5-7]. Recently, ferroelectric tunnel junction (FTJ) based devices have received a lot of interest for neuron like adaptive system and brain inspired computing [8-10]. The spontaneously electric polarization of a ferroelectric material is coupled with the material lattice. The change of spontaneously electric polarization in response to the application of an external stress is called piezoelectricity. Ferroelectric materials also have piezoelectric property. This makes ferroelectric capacitors suitable for a broad range of applications, such as sensors and actuators [4, 11, 12]. The performances, such as operating voltage, operating speed and the working stability, of these ferroelectric devices are important to be studied

Lead zirconate titanante, $\mathrm{Pb}\left(\mathrm{Zr}_{\mathrm{x}} \mathrm{Ti}_{1-\mathrm{x}}\right) \mathrm{O}_{3}$ (PZT) is a well-known ferroelectric material because of its high degree of polarization, high Curie temperature and high electromechanical coupling coefficients in a wide temperature range [13, [14]. It is a solid 


\section{Chapter 1: Introduction}

solution of material composition ranging from $\mathrm{PbTiO}_{3}$ to $\mathrm{PbZrO} 3 . \mathrm{Pb}\left(\mathrm{Zr}_{0.52} \mathrm{Ti}_{0.48}\right) \mathrm{O}_{3}$, at the morphotrobic phase boundary (MPB), is a great interesting composition to industry and research because of its remarkable polarization and piezoelectric properties [15, 16]. Typically, a layer of ferroelectric material is sandwiched between a pair of electrodes in capacitor geometry which provides charge screening to prevent the so-called depolarization field. The direction of this field is opposite to the polarization, causing the destabilization in ferroelectric polarization [16]. The effects of electrode materials on PZT ferroelectric devices have been studied intensively. A major problem for the working stability is that PZT capacitors with metal electrodes (Pt,Au) suffer a significant loss of switchable polarization when subjected to a large number of the switching pulses (called fatigue). Various explanations for this phenomenon are proposed. For example, oxygen vacancies accumulation at the metal - PZT interface, the domain wall pinning by electrons and the local phase decomposition [17- 19]. This fatigue problem was almost completely solved by using conductive oxide electrodes instead of metals. Currently, strontium Ruthenate $\mathrm{SrRuO}_{3}$ (SRO) and lanthanum nickelate $\mathrm{LaNiO}_{3}$ (LNO) are widely used as electrodes in laboratory studies for PZT devices. The widely accepted model claims that all oxide materials are regarded as an oxygen sink to suppress the oxygen vacancies accumulation at the electrode - PZT interface [20,23]. However, the effects of interface contacts between the ferroelectric layer and the oxide electrode layer are not fully understood. Besides understanding the effects induced at the ferroelectric - oxide electrode interface, there are still some remaining problems with using conductive oxide materials. First, misfit dislocations can form in the films due to the lattice mismatch between electrodes and ferroelectric layers. Second, the resistivity of widely used oxide materials is relatively large compared to metals. It is important to study alternative electrode materials that have potential to solve these issues in ferroelectric devices.

Conductive oxide materials with the perovskite structure are a suitable template to grow the subsequent ferroelectric PZT layer epitaxially. In epitaxial thin films, the misfit dislocations are usually formed at the interface to relax elastic strain caused by the lattice mismatch [24, 25]. The dislocations cause strained field coupled with polarization that leads to a local polarization gradient, suppressing the polarization in the ferroelectric thin films [26]. At MPB, PZT is a tetragonal phase with an in-plane lattice constant a = $4.06 \AA$ and an out-of-plane lattice constant $\mathrm{c}=4.11 \AA$ [27]. The widely used electrodes SRO $(\mathrm{a}=3.93 \AA)$ and LNO $(\mathrm{a}=3.84 \AA$ ) have a large lattice mismatch with PZT [28, 
29]. La-doped barium stannate $\mathrm{BaSnO}_{3}$ (LBSO) is very promising as a material for PZT ferroelectric devices since it has a cubic perovskite structure with a lattice constant $\mathrm{a}=$ $4.11 \AA$, which is perfectly matched with PZT [30]. Recently, this material also catches a lot of interest because of its transparency, its high mobility at room temperature and its chemical stability [31]. Carrier mobilities in La-doped $\mathrm{BaSnO}_{3}$ thin films grown by molecular beam epitaxy (MBE) on single crystal oxide substrates and silicon substrates have reached $183 \mathrm{~cm}^{2} \mathrm{~V}^{-1} \mathrm{~s}^{-1}$ and $128 \mathrm{~cm}^{2} \mathrm{~V}^{-1} \mathrm{~s}^{-1}$ respectively [32]. Here, pulsed laser deposition (PLD) was used for the thin film fabrication. One of the important advantages is that many kinds of material can be deposited under a broad range of gas pressures in a PLD system. It also shows potential to be used towards industrial application due to low cost and fast growth [33]. As LBSO thin films are used as a conducting layer for growth of subsequent functional layers, the structural and morphological properties of thin films are important next to the electrical and transport properties. It is very important to understand how growth kinetics affect crystallinity and surface morphology of LBSO thin films. In Chapter 3, the growth kinetics of epitaxial LBSO thin films by PLD is discussed.

The current model suggests that the conductive oxide materials can solve the fatigue problem by inhibiting the oxygen vacancies accumulation at the electrode-ferroelectric interface. Several theoretical models provide an explanation for the interface induced phenomena in the polarization response of ferroelectric thin films. For example, a passivelayer caused by incomplete screening and a depletion layer caused by the electrochemical interaction between the conductive electrodes and ferroelectric layer or the charge injection from the electrode into the ferroelectric layer. These interface phenomena both have effects on the coercive field, voltage offset and the working stability in ferroelectric devices [20, 23, 34, 35]. In addition, ferroelectric domains can be pinned by defects caused by surface roughness [36]. The advantage of all-oxide epitaxial ferroelectric devices is that the influences induced by surface roughness or polycrystalline phases can be easily ruled out by growing high quality thin films. The different contacts between PZT and electrodes can be introduced by conductive oxide materials with different work functions and carrier concentrations. It is of great importance for device performance to understand the effect of different interface contacts on the polarization response of ferroelectric devices and the relation with intrinsic characteristics of different oxide electrode materials. SRO is a conducting material which has a metallic behaviour with the working func- 
tion of $5.2 \mathrm{eV}[28]$. It has a very high carrier concentration of about $2 \times 10^{22} \mathrm{~cm}^{-3}$. $\mathrm{La}_{0.07} \mathrm{Ba}_{0.93} \mathrm{SnO}_{3}$ (LBSO) is a highly doped n-type semiconductor with a wide band gap of $3.2 \mathrm{eV}$ [30]. The carrier concentration of this material is about $4 \times 10^{20} \mathrm{~cm}^{-3}$, two orders lower than that of SRO. The different interface phenomena can be induced using SRO and LBSO electrodes. In Chapter 4, the working properties of PZT devices by using LBSO and SRO electrodes are investigated.

Finally, the resistivity of widely used oxide materials $\left(\rho_{\mathrm{SRO}}=2-5 \times 10^{-4} \Omega \mathrm{cm}\right.$, $\left.\rho_{\mathrm{LNO}}=1-4 \times 10^{-4} \Omega \mathrm{cm}\right)$ is higher than the resistivity of metal electrodes $\left(\rho_{\mathrm{Pt}}=\right.$ $1 \times 10^{-5} \Omega \mathrm{cm}$ ) [28, 37, 38]. The conductive oxide material with a much lower resistivity is still required for high frequency application to reduce the contact losses. The study on PZT devices with the bottom electrode LBSO suggests that high carrier density prevents the formation of a depletion layer, thus avoiding the fatigue problem. Strontium vanadate, $\mathrm{SrVO}_{3}(\mathrm{SVO})$ gained a lot of attention after the highly conductive $\mathrm{SrVO}_{3}$ thin film grown by $\operatorname{MBE}\left(\rho_{\mathrm{SVO}}=3 \times 10^{-5} \Omega \mathrm{cm}\right.$ ) was reported by Jarrett A. Moyer [39]. This material with a carrier density of about $10^{22} \mathrm{~cm}^{-3}$ is very promising as an electrode in PZT devices. Here, PLD was used for thin film fabrication since wide range of materials can be deposited in this system. The structural and morphological properties of thin films are important next to the electrical and transport properties, since SVO thin films are used as a conducting layer for growth of subsequent functional layers. The growth mechanism of SVO thin films in a PLD system is very important to be studied in order to control the quality of thin films. In Chapter 5, the effects of growth conditions on the SVO thin film properties are discussed. Even though highly conductive SVO is obtained, the poor stability of the desired phase in high oxygen pressure hampers its use an electrode in PZT devices because PZT prefers to be grown in high oxygen pressures, causing the degradation of SVO thin films.

As we discussed above, lattice parameter, resistivity, carrier density and work function in the conductive oxide materials are important to determine the properties of PZT devices. To compare the characteristics of oxide electrodes, the crystal structure and transport properties of SRO, LNO, SVO and LBSO are listed in Table 1.1.

The main topic we discussed is the role of oxide electrodes on the properties of PZT capacitors. All oxide electrodes are grown by pulsed laser deposition (PLD). In this thesis, the mechanism of growth by PLD are studied using two model system, SVO and LBSO. Such insights are necessary to control the growth of thin films and obtain high- 
Table 1.1: The crystalline structure and transport properties of some conductive oxides.

\begin{tabular}{ccccc} 
& SRO & LNO & SVO & LBSO \\
\hline Crystal & Orthorhombic & Cubic & Cubic & Cubic \\
lattice constant $(\AA)$ & 3.93 & 3.84 & 3.83 & 4.11 \\
$\rho_{\mathrm{RT}}(\Omega \mathrm{cm})$ & $2 \times 10^{-4}$ & $3 \times 10^{-4}[41]$ & $8 \times 10^{-5}$ & $3 \times 10^{-4}$ \\
$\mathrm{n}\left(\mathrm{cm}^{-3}\right)$ & $2 \times 10^{22}[40]$ & $3 \times 10^{22}[41]$ & $2 \times 10^{22}$ & $5 \times 10^{20}$ \\
$\mu(\mathrm{cm} / \mathrm{Vs})$ & 0.25 & & 2 & 60 \\
work function $(\mathrm{eV})$ & $5.2[42]$ & $6.1[43]$ & 5.1 & $4.4[44,45]$
\end{tabular}

quality films.

PLD is a widely used technique for the fabrication of thin films. One of the most cited reasons for its popularity is that it enables the deposition of a broad range of materials which can be stoichiometrically transferred from target to substrate. Recently, a step towards the industrial application of PLD deposition on large scale wafers was achieved [33]. PLD became more widespread with the development of high pressure reflection high energy electron diffraction (RHEED) used for monitoring the material growth process [46]. In this vapour- phase deposition technique, the high supersaturation leads to a large nucleation rate, and kinetic effects will result in different growth modes. The "step flow" growth mode will occur when the intralayer mass transport is high enough on a vicinal substrate surface. The adatoms will move to the edges of the substrate steps and nucleation on terraces is prevented. If the intralayer mass transport is not fast enough, the adatoms will nucleate on terraces. The interlayer mass transport have an affect on growth mode in this case. When a steady interlayer mass transport is present, the nucleation starts after completion of a layer, called "layer-by-layer" growth mode. The nucleation will occur on the top of the islands before the islands have coalesced. This is called "multilayer" growth mode, when the interlayer mass transport is very limited [47]. The growth process of thin films in PLD is complex. Several growth parameters, such as the substrate temperate, background gas pressure, laser spot size on the target and laser fluence, can be set and influence the growth mode. The kinetic effects controlled by growth conditions were correlated to the thin films crystallinity and surface morphology in previous works [47, 48]. The enhanced smoothness $\mathrm{La}_{1-\mathrm{x}} \mathrm{Sr}_{\mathrm{x}} \mathrm{MnO}_{3}$ (LSMO) thin film has been observed at lower background gas pressure [48]. The model suggests that the increased kinetic energy of the species at lower background gas pressures improves surface diffusion which is favourable for the crystallinity and the smoothness of the films. In contrast to this 


\section{Chapter 1: Introduction}

kinetic model, more recent work has shown that stoichiometric and smooth films were obtained at higher oxygen pressures in $\mathrm{SrTiO}_{3}$ (STO) growth at varying oxygen pressure in the range from 0.01 mbar to 0.1 mbar [49]. This work suggests that the oxidation of the arriving species also plays a role in controlling the smoothness and stoichiometry of the grown films. The models proposed in previous works have shown that the kinetic effects and oxidation of deposited species all make a contribution to determine the growth modes. Based on these works, the studies of plasma chemistry and thin film growth were conducted at relatively high absolute oxygen pressure. Whether the oxidation of species plays any role at much lower oxygen pressure is desired to understand. SVO can only be grown in very low oxygen (partial) pressure since over-oxidized $\mathrm{V}^{5+}$ hampers perovskite to be formed. This material gives a way to understand the PLD process for a material that needs low oxygen pressures. Contrary to SVO, LBSO is very stable in oxygen ambient and prefers to be grown in high oxygen pressures. Whether the kinetic effects play a dominant role on the growth mode of LBSO thin films in a high oxygen pressure is an important question. The model of growth process in PLD might be more complete by investigating the growth mechanism of SVO and LBSO thin films.

Besides the high conductivity in SVO, this material is a typical strongly correlated system with a $3 \mathrm{~d}^{1}$ electronic configuration for Vanadium. It is an interesting system to study the dimensional-crossover-driven metal insulator transition (MIT). The origin of this MIT transition has not been conclusively discussed [50-52]. Although SVO is not able to be an electrode in PZT capacitors due to its oxygen sensitivity, it is still of importance to study the properties of SVO thin films in the heterostructure for fundamental physics and its potential applications as an electrode in other electronic devices. The transport properties in SVO ultrathin films and SVO/STO superlattices are discussed in Chapter 6.

\subsection{Thesis outline}

This thesis studies the alternative conductive oxide materials, SVO and LBSO, that are promising to be used as electrodes in PZT capacitors. The PLD process is also further understood by investigating the growth mechanism of these materials.

All oxide thin films were grown by pulsed laser deposition. In Chapter 2, the work- 
ing principle and experimental setup of PLD are introduced. The techniques used for thin films characterization, including atomic force microscopy (AFM), X-ray diffraction (XRD) and scanning transmission electron microscopy (STEM) are described. The process of patterning for PZT capacitor structures is also shown.

In Chapter 3, the growth kinetics of LBSO thin films using different substrate temperatures and different laser spot sizes are investigated. The quality of the grown LBSO thin films determined by AFM, XRD, STEM are correlated to their transport properties measured by physical properties measurement system (PPMS). The kinetics effects induced by surface diffusivity and mass flux on quality of the grown thin films are discussed.

The switching properties and working stability of PZT capacitors using electrodes LBSO and SRO are shown in Chapter 4. To understand the influences of electrode on working performance of PZT, the crystalline quality in SRO/PZT/LBSO, SRO/PZT/SRO and SRO/PZT/2 nm SRO/LBSO devices was determined by XRD and STEM. The effects of phenomena at the electrode-ferroelectric interface caused by different work functions and carrier densities of the electrode materials in response to the ferroelectric properties of PZT is discussed. The PZT devices sandwiched between LBSO electrodes are also fabricated on scalable substrates silicon for industrial interest.

In Chapter 5, the studies on SVO growth at varying background argon pressures, varying partial oxygen pressures and varying target - to - substrate distance are shown. Optical emission spectroscopy measurement by using intensified charge coupled device (ICCD) camera for the plasma plume at different growth conditions are analysed, as well as the film properties determined by AFM, XRD and PPMS. The correlation between the oxidation of arriving species and the quality of the grown thin films at low oxygen pressures is described.

Chapter 6 shows the dimensional-driven metal-insulator transition (MIT) in high quality epitaxial SVO ultrathin films and SVO/STO superlattices. To gain more insight into the MIT mechanism in SVO, the thickness of the films were well-controlled by RHEED. The films were grown using the optimal growth conditions and excluding any surface effects by a STO capping layer. The origin of MIT in SVO ultrathin films and coupling effect in SVO/STO superlattices are discussed. 


\section{Bibliography}

[1] J. F. Scott and C. A. P. De Araujo, Science 246, 1400 (1989).

[2] J. Scott, L. Kammerdiner, M. Parris, S. Traynor, V. Ottenbacher, A. Shawabkeh, and W. Oliver, Journal of Applied Physics 64, 787 (1988).

[3] C. A. Paz De Araujo, L. D. McMillan, B. M. Melnick, J. D. Cuchiaro, and J. F. Scott, Ferroelectrics 104, 241 (1990).

[4] D. A. Buck, Ferroelectrics for Digital Information Storage and Switching., Tech. Rep. Massachusetts Inst of Tech Cambridge Digital Computer Lab, 1952.

[5] S. Mathews, R. Ramesh, T. Venkatesan, and J. Benedetto, Science 276, 238 (1997).

[6] Z. Wen, C. Li, D. Wu, A. Li, and N. Ming, Nature Materials 12, 617 (2013).

[7] J. Hoffman, X. Pan, J. W. Reiner, F. J. Walker, J. Han, C. H. Ahn, and T. Ma, Advanced Materials 22, 2957 (2010).

[8] A. Chanthbouala, V. Garcia, R. O. Cherifi, K. Bouzehouane, S. Fusil, X. Moya, S. Xavier, H. Yamada, C. Deranlot, N. D. Mathur, et al., Nature Materials 11, 860 (2012).

[9] A. Chanthbouala, A. Crassous, V. Garcia, K. Bouzehouane, S. Fusil, X. Moya, J. Allibe, B. Dlubak, J. Grollier, S. Xavier, et al., Nature Nanotechnology 7, 101 (2012).

[10] V. Garcia and M. Bibes, Nature Communications 5, 4289 (2014).

[11] M. D. Nguyen, H. N. Vu, D. H. Blank, and G. Rijnders, Advances in Natural Sciences: Nanoscience and Nanotechnology 2, 015005 (2011).

[12] O. Auciello, J. F. Scott, and R. Ramesh, Physics Today 51, 22 (1998).

[13] V. Nagarajan, I. Jenkins, S. Alpay, H. Li, S. Aggarwal, L. Salamanca-Riba, A. Roytburd, and R. Ramesh, Journal of Applied Physics 86, 595 (1999).

[14] D. Cox, B. Noheda, and G. Shirane, Physical Review B 71, 134110 (2005).

[15] J. Frantti, S. Ivanov, S. Eriksson, H. Rundlöf, V. Lantto, J. Lappalainen, and M. Kakihana, Physical Review B 66, 064108 (2002). 
[16] B. Noheda and D. Cox, Phase Transitions 79, 5 (2006).

[17] M. D. Nguyen, Ferroelectric and piezoelectric properties of epitaxial PZT films and devices on silicon University of Twente, 2010.

[18] M. Dawber, K. Rabe, and J. Scott, Reviews of Modern Physics 77, 1083 (2005).

[19] X. Lou, M. Zhang, S. Redfern, and J. Scott, Physical Review Letters 97, 177601 (2006).

[20] G. Le Rhun, G. Poullain, and R. Bouregba, Journal of Applied Physics 96, 3876 (2004).

[21] M.-S. Chen, T.-B. Wu, and J.-M. Wu, Applied Physics Letters 68, 1430 (1996).

[22] W. Wu, K. Wong, C. Choy, and Y. Zhang, Applied Physics Letters 77, 3441 (2000).

[23] A. K. Tagantsev, I. Stolichnov, E. Colla, and N. Setter, Journal of Applied Physics 90, 1387 (2001).

[24] H. Sun, W. Tian, X. Pan, J. H. Haeni, and D. G. Schlom, Applied Physics Letters 84, 3298 (2004).

[25] A. Vailionis, H. Boschker, W. Siemons, E. P. Houwman, D. H. Blank, G. Rijnders, and G. Koster, Physical Review B 83, 064101 (2011).

[26] S. Alpay, I. Misirlioglu, V. Nagarajan, and R. Ramesh, Applied Physics Letters 85, 2044 (2004).

[27] J. Rouquette, J. Haines, V. Bornand, M. Pintard, P. Papet, B. Bonnet, and F. Gorelli, Solid State Sciences 5, 451 (2003).

[28] G. Koster, L. Klein, W. Siemons, G. Rijnders, J. S. Dodge, C.-B. Eom, D. H. Blank, and M. R. Beasley, Reviews of Modern Physics 84, 253 (2012).

[29] A. Y. Dobin, K. Nikolaev, I. Krivorotov, R. Wentzcovitch, E. D. Dahlberg, and A. Goldman, Physical Review B 68, 113408 (2003).

[30] H. J. Kim, U. Kim, T. H. Kim, J. Kim, H. M. Kim, B.-G. Jeon, W.-J. Lee, H. S. Mun, K. T. Hong, J. Yu, et al., Physical Review B 86, 165205 (2012). 
[31] B. Luo, J. Zhang, J. Wang, and P. Ran, Ceramics International 41, 2668 (2015).

[32] H. Paik, Z. Chen, E. Lochocki, A. Seidner H, A. Verma, N. Tanen, J. Park, M. Uchida, S. Shang, B.-C. Zhou, et al., APL Materials 5, 116107 (2017).

[33] D. H. Blank, M. Dekkers, and G. Rijnders, Journal of Physics D: applied physics 47, 034006 (2013).

[34] A. Tagantsev and G. Gerra, Journal of Applied Physics 100, 051607 (2006).

[35] L. Pintilie and M. Alexe, Journal of Applied Physics 98, 124103 (2005).

[36] P. T. N. Mai, Ferroelectric composites of PZT-Pt, Ph.D. thesis, Universiteit Twente (2005).

[37] K. Satyalakshmi, R. Mallya, K. Ramanathan, X. Wu, B. Brainard, D. Gautier, N. Vasanthacharya, and M. Hegde, Applied Physics Letters 62, 1233 (1993).

[38] E. Moon, B. Gray, M. Kareev, J. Liu, S. Altendorf, F. Strigari, L. Tjeng, J. Freeland, and J. Chakhalian, New Journal of Physics 13, 073037 (2011).

[39] J. A. Moyer, C. Eaton, and R. Engel-Herbert, Advanced Materials 25, 3578 (2013).

[40] W. Siemons, G. Koster, A. Vailionis, H. Yamamoto, D. H. Blank, and M. R. Beasley, Physical Review B 76, 075126 (2007).

[41] Z. Mengwei, K. Philipp, R. Aldin, V. Mehran, W. Zhanjie, A. Lambert, Applied Physics Letters 103, 141902 (2013).

[42] Y. Hikita, Y. Kozuka, T. Susaki, H. Takagi, and H. Hwang, Applied Physics Letters 90, 143507 (2007).

[43] R. Jacobs, J. Booske, and D. Morgan, Advanced Functional Materials 26, 5471 (2016).

[44] S. A. Chambers, T. C. Kaspar, A. Prakash, G. Haugstad, and B. Jalan, Applied Physics Letters 108, 152104 (2016).

[45] H. Yang, H. Luo, H. Wang, I. Usov, N. Suvorova, M. Jain, D. Feldmann, P. Dowden, R. DePaula, and Q. Jia, Applied Physics Letters 92, 102113 (2008). 
[46] G. Koster, G. J. Rijnders, D. H. Blank, and H. Rogalla, MRS Online Proceedings Library Archive 526 (1998).

[47] A. J. Rijnders, Ph.D. thesis, Universiteit Twente, 2001.

[48] J. E. Boschker, E. Folven, A. F. Monsen, E. Wahlstrom, J. K. Grepstad, and T. Tybell, Crystal Growth \& Design 12, 562 (2012).

[49] R. Groenen, J. Smit, K. Orsel, A. Vailionis, B. Bastiaens, M. Huijben, K. Boller, G. Rijnders, and G. Koster, APL Materials 3, 070701 (2015).

[50] K. Yoshimatsu, T. Okabe, H. Kumigashira, S. Okamoto, S. Aizaki, A. Fujimori, and M. Oshima, Physical Review Letters 104, 147601 (2010).

[51] M. Gu, S. A. Wolf, and J. Lu, Advanced Materials Interfaces 1, 1300126 (2014).

[52] D. Kim, D.W. Kim, B. Kang, T. Noh, D. Lee, K.-B. Lee, and S. Lee, Solid State Communications 114, 473 (2000). 


\title{
Chapter 2
}

\section{Fabrication and characterization of epitaxial oxide thin films}

\begin{abstract}
Oxide thin films were grown using pulsed laser deposition (PLD) equipped with reflection high energy electron diffraction (RHEED). The working principle and the experimental setup of PLD are described. The structure of PZT capacitors was patterned using UV lithography and dry etching. Crystal structure and morphology of thin films were characterized by atomic force microscopy (AFM), X-ray diffraction (XRD) and scanning transmission electron microscopy (STEM). Transport properties, such as resistivity, carrier mobility, were measured with physical property measurement system (PPMS). Polarization hysteresis loops are used to obtain the ferroelectric properties.
\end{abstract}




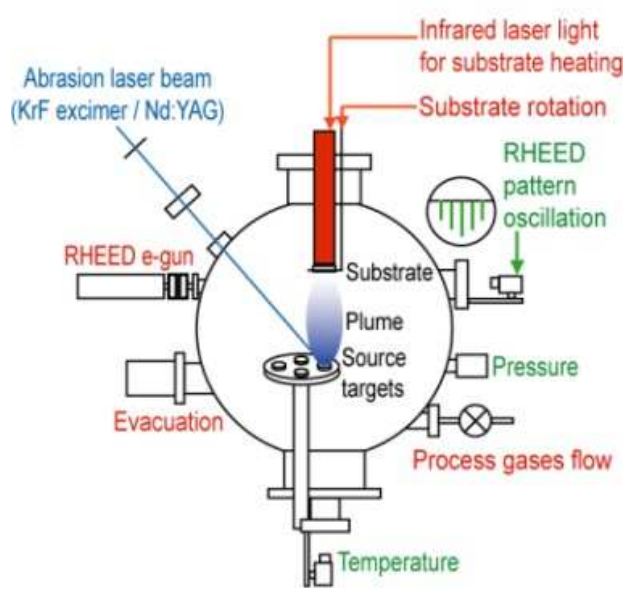

Figure 2.1: Schematic of pulsed laser deposition technique

\subsection{Fabrication}

\subsubsection{Pulsed laser deposition}

Pulsed laser deposition (PLD) is a widely used thin film deposition technique. One of the most cited reasons for its popularity is that it enables the deposition of a broad range of materials, which can be stoichiometrically transferred from a target to a substrate [1-3]. Reflection high-energy electron diffraction (RHEED) can be used at high oxygen pressure to monitor the thin film growth on unit cell level [4]. All oxide thin films discussed in this thesis were grown using PLD equipped with RHEED. Figure 2.1 shows a schematic of the pulsed laser deposition technique [5]. A high powered pulsed laser beam is focused on the target material. The absorbed energy of the laser pulse heats the material in a small region to very high temperature, creating a plasma plume of the target material. This plasma plume travels through the background gas with which it may interact and then is deposited on the heated substrate. The deposited plasma particles nucleate and grow on the surface of the substrate, forming a thin film. Epitaxial growth is properly defined as the growth of a single crystal film with the same crystal orientation as the substrate. 


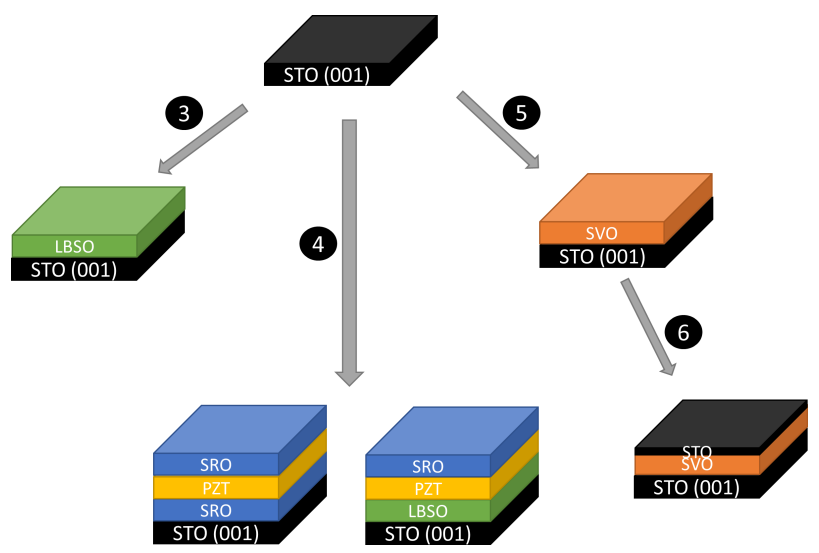

Figure 2.2: Schematic presentation of the work presented in this thesis. The numbers indicate the corresponding chapters.

\subsubsection{Pulsed laser deposition setup}

In our experimental setup a $\mathrm{KrF}$ excimer laser with a wavelength of $248 \mathrm{~nm}$ is used. The laser fluence (f) can be varied from 1 to $3 \mathrm{~J} / \mathrm{cm}^{2}$ and the laser repetition rate (r) can be tuned from $1 \mathrm{~Hz}$ to $50 \mathrm{~Hz}$. The laser beam is focused with a lens and projected at an angle of $45^{\circ}$ on the target. The spot size $S_{\text {target }}$ on the target can be adjusted in a range from $0.5 \mathrm{~mm}^{2}$ to $4 \mathrm{~mm}^{2}$ varying the position of lenses and the size of masks. In the PLD chamber, the base pressure is kept at $10^{-8}$ mbar. During the deposition, the oxygen $\left(\mathrm{P}_{\mathrm{O}_{2}}\right)$ and argon pressures $\left(\mathrm{P}_{\mathrm{Ar}}\right)$ can be varied between $10^{-7}$ mbar to 1 mbar using mass flow controllers. The substrate temperature $(\mathrm{T})$ can be heated from room temperature up to $950{ }^{\circ} \mathrm{C}$ using backside heating of the substrate with a IR laser. The growth conditions for the materials used in this thesis are listed in Table $4.1\left(\mathrm{SrVO}_{3}=\mathrm{SVO}, \mathrm{La}_{0.07} \mathrm{Ba}_{0.93} \mathrm{SnO}_{3}\right.$ $=\mathrm{LBSO}, \mathrm{SrRuO}_{3}=\mathrm{SRO}, \mathrm{Pb}\left(\mathrm{Zr}_{0.52} \mathrm{Ti}_{0.48}\right) \mathrm{O}_{3}=\mathrm{PZT}, \mathrm{SrTiO}_{3}=\mathrm{STO}, \mathrm{LaNiO}_{3}=\mathrm{LNO}$.). Figure 2.2 shows the schematic presentation of the work presented in this thesis. The numbers indicate the corresponding chapters. STO (001) was used as a substrate in this thesis and the other materials were grown on the STO.

\subsubsection{Patterning}

In order to measure the electrical and ferroelectric properties of the heterostructure, PZT-based capacitors ware patterned using photolithography and plasma dry etching 
Table 2.1: The growth conditions for the materials fabricated in this thesis.

\begin{tabular}{ccccccc} 
& SVO & LBSO & SRO & PZT & STO & LNO \\
\hline $\mathrm{f}\left(\mathrm{J} / \mathrm{cm}^{2}\right)$ & 2 & 1.3 & 2 & 2 & 2 & 2 \\
$\mathrm{r}(\mathrm{Hz})$ & 1 & 1 & 4 & 10 & 1 & 1 \\
$\mathrm{~S}_{\mathrm{target}}\left(\mathrm{mm}^{2}\right)$ & 2.3 & 0.88 & 2.3 & 2.3 & 2.3 & 2.3 \\
$\mathrm{P}_{\mathrm{O}_{2}}(\mathrm{mbar})$ & $1 \times 10^{-5}$ & 0.13 & 0.25 & 0.1 & $1 \times 10^{-5}$ & 0.13 \\
$\mathrm{P}_{\mathrm{Ar}}(\mathrm{mbar})$ & 0.025 & & & & 0.025 & \\
$\mathrm{~T}\left({ }^{\circ} \mathrm{C}\right)$ & 600 & 830 & 600 & 600 & 600 & 600
\end{tabular}

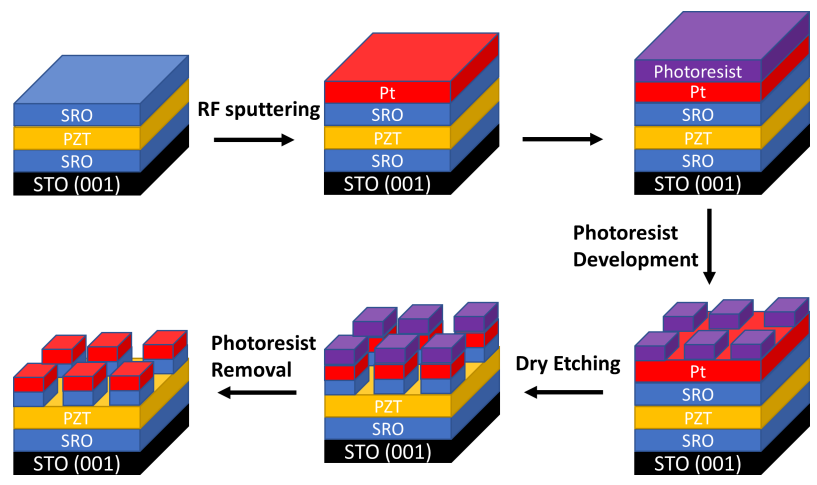

Figure 2.3: The patterning process of the SRO/PZT/SRO device. The process is the same for the other devices.

[10]. Figure 2.3 schematically shows the patterning process of the SRO/PZT/SRO device. First, a Platinum contact layer was deposited by RF sputtering on the sample made in PLD. Second, the photoresist was spun at $4000 \mathrm{rmp}$ for $30 \mathrm{sec}$ on the heterostructure sample and subsequently baked on a hot plate. Ultraviolet light (UV) source was then used with a mask to define the photoresist layer. The dry etching was performed using Argon ion beam to remove the top electrode layer. At last, the photoresist was then removed by Acetone and Ethanol. Silver paste was used at side of the sample to connect with the bottom electrode and the top electrode was connected using a metal tip probe. 

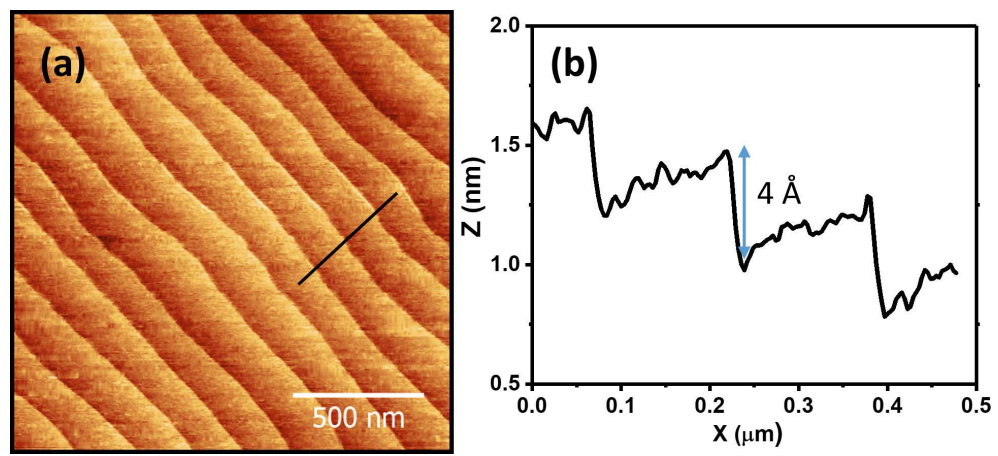

Figure 2.4: (a) AFM topology image and (b) a corresponding cross-section profile of a single terminated $\mathrm{SrTiO}_{3}$ substrate.

\subsection{Characterization}

\subsubsection{Atomic force microscopy}

The surface structure properties of substrates and thin films were measured by atomic force microscopy (AFM) (Bruker Icon). In the tapping mode a tip taps the surface close to the resonance frequency of the cantilever. The interaction between the tip and the surface can change the resonance frequency and the phase of cantilever oscillation, giving information about height changes on the sample. Figure 2.4 shows a typical AFM image of a single terminated $\mathrm{SrTiO}_{3}$ (STO) substrate [6], which is typically used in this thesis. A smooth surface with step-terrace structure is present. The corresponding cross-section profile shows that terrace step height is about $4 \AA$ corresponding with the thickness of one unit cell, indicating that the terraces have single termination $\left(\mathrm{TiO}_{2}\right)$. The surface morphology of oxide thin films is dependent on the growth conditions and will be further discussed in the Chapters 3 and 5.

\subsubsection{X-ray diffraction}

X-ray diffraction (XRD) is a commonly used tool to investigate the crystal structure. The angle and the intensity of the diffracted beam from the sample are measured to obtain information on the crystal lattice [7]. All oxide thin films were measured by XRD (Panalytical X'pert MRD) to analyse the crystallographic properties. A typical XRD spectrum 


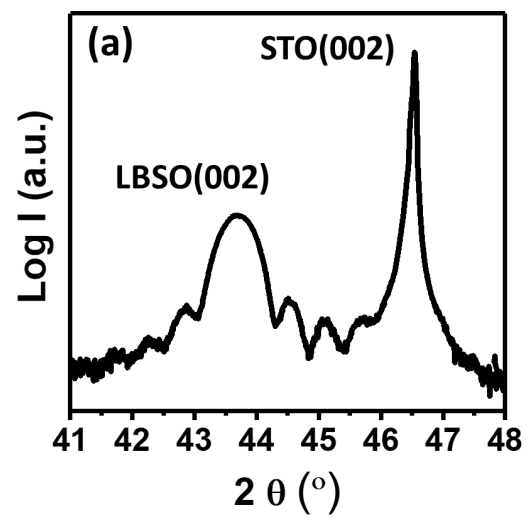

(b)

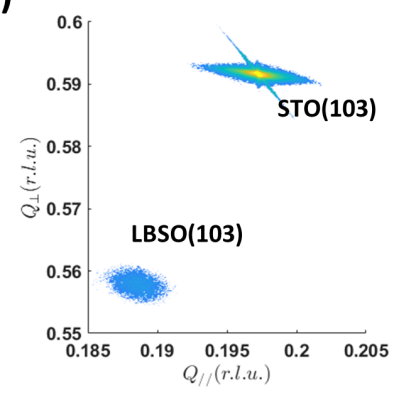

Figure 2.5: XRD 001 measurement (a) and reciprocal mapping (b) of LBSO thin film grown on the STO substrate.

obtained from a $\theta-2 \theta$ scan for the LBSO thin film grown on a STO substrate is shown in Figure 2.5 (a). The peak corresponding to the LBSO (002) is present, indicating the (001) epitaxial growth of LBSO on the (001) STO substrate. The out-of-plane lattice parameter of $4.15 \AA$ was derived from this spectrum. The Laue fringes around the film peak originating from the coherence between individual layers in the film and their period indicates that the film thickness is $15 \mathrm{~nm}$. Figure 2.5 b) is the reciprocal space mapping around the (103) reflection for the LBSO film. This shows that the LBSO thin film is fully relaxed on the STO substrate with an in-plane lattice parameter of $4.10 \AA$, as compared to 3.905 $\AA$ of STO.

\subsubsection{Scanning transmission electron microscopy}

The local structure and interface layer of thin films was probed by scanning transmission electron microscopy. Atomic resolution images can be obtained by using the annular dark-field mode [8]. The contrast of an atomic column is dependent on the atomic number. Because travelling through the sample, some electrons in the beam lose energy due to the interaction with the electrons in the sample. In STEM, electron energy loss spectroscopy (EELS) can be used for chemical mapping and elemental mapping with atomic resolution [9]. All STEM images in this thesis were taken by Nicolas Gauquelin at University of Antwerp in Belgium. Figure 2.6. (a) shows a STEM image of the LBSO thin film grown on STO substrate. Misfit dislocations caused by lattice mismatch at the 

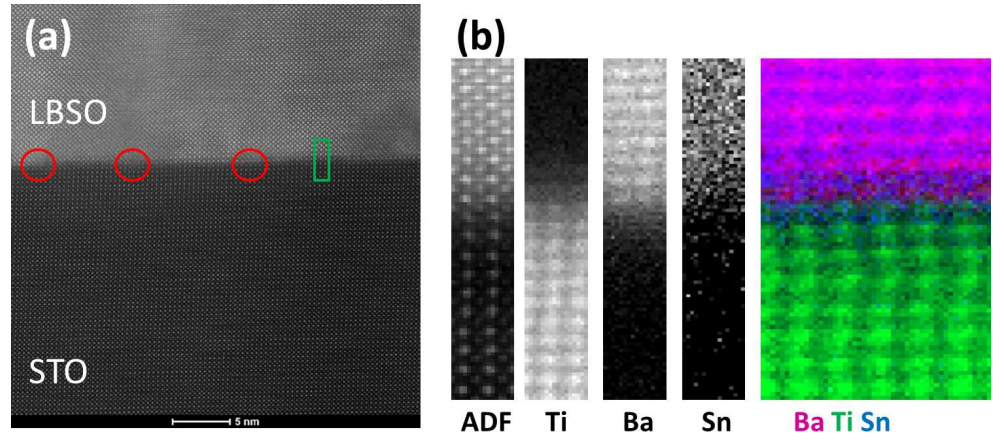

Figure 2.6: (a) High resolution scanning transmission electron microscopy (HRSTEM) image of the LBSO thin film on a STO. Misfit dislocations at interface are pointed by red circles. (b) Chemical mapping by EELS of Ti $\mathrm{L}_{2,3}, \mathrm{Ba} \mathrm{M}_{4,5}$ and $\mathrm{Sn}_{2,3}$ for the region in the green rectangle of Figure 2.6 (a) with the simultaneously acquired annular dark field (ADF) image.

STO/LBSO interface are indicated with the red circles. Figure 2.6(b) shows chemical mapping by EELS of the $\mathrm{Ti}_{2,3}, \mathrm{Ba} \mathrm{M}_{4,5}$ and $\mathrm{Sn} \mathrm{M}_{2,3}$ for the region in the green rectangle of Figure 2.6 (a) and the simultaneously acquired annular dark field (ADF) image. The atomically sharp interface indicates that there is no inter-diffusion at the interface.

\subsubsection{Electrical transport properties}

Transport properties were measured in the van der Pauw geometry [11] using a Quantum Design Physical Properties Measurement System (QD PPMS). To make good electrical contacts, titanium and gold were deposited at the four corners of the sample by sputtering with a shadow mask. The temperature dependent resistivity was measured in the range from $2 \mathrm{~K}$ to $300 \mathrm{~K}$. Hall measurements was performed in a magnetic field up to $9 \mathrm{~T}$ to obtain the carrier density and carrier mobility in the thin films.

\subsubsection{Ferroelectric characterization}

A key measurement for ferroelectric materials such as PZT is polarization hysteresis loops (P-E loops). Figure 2.7 (a) shows an example of the polarization hysteresis loop obtained from the PZT capacitor sandwiched between SRO electrodes on a STO substrate. In this measurement, a triangular voltage signal with a voltage amplitude of $\mathrm{V}_{1}$ and a scan frequency of $f_{1}$ is applied across the capacitor. (Figure 2.7 b) in blue). The direction 


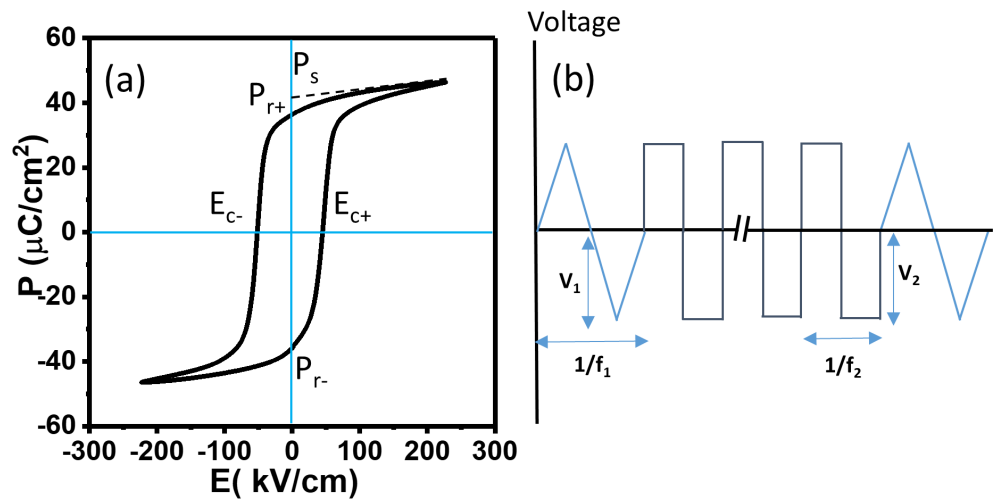

Figure 2.7: (a) Example of polarization hysteresis loop obtained from the PZT capacitor sandwiched between SRO electrodes on a STO substrate.(b) Typical voltage signal for obtaining hysteresis loops and fatigue measurements.

of the spontaneous polarization can be reversed by the externally applied electrical field. The polarization switching process is usually characterized by the saturation polarization $\mathrm{P}_{\mathrm{s}}$, the remnant polarization $\mathrm{P}_{\mathrm{r}}$ and the coercive field $\mathrm{E}_{\mathrm{c}}$ in the P-E loop, as defined in Figure 2.7 (a). The cycling stability of PZT capacitor is investigated as a function of the number of switching cycles. After measuring an initial hysteresis loop using the triangle voltage signal, a fatigue signal sequence with an amplitude $V_{2}$ and a frequency $f_{2}$ is applied (Figure 2.7.b) in grey) to the sample. The hysteresis measurements are performed at regular cycling intervals to obtain the ferroelectric properties of the device after a large number of switching cycles. The aixACCT TF2000 was used for measuring the P-E loops and the fatigue properties. 


\section{Bibliography}

[1] R. Eason, Pulsed laser deposition of thin films: applications-led growth of functional materials John Wiley \& Sons, 2007.

[2] R. Groenen, J. Smit, K. Orsel, A. Vailionis, B. Bastiaens, M. Huijben, K. Boller, G. Rijnders, and G. Koster, APL Materials 3, 070701 (2015).

[3] J. Wang, G. Rijnders, and G. Koster, Applied Physics Letters 113, 223103 (2018).

[4] G. J. Rijnders, G. Koster, D. H. Blank, and H. Rogalla, Applied Physics Letters 70, 1888 (1997).

[5] K. Wang, Advances in Graphene Science InTech, 2013.

[6] G. Koster, G. Rijnders, D. H. Blank, and H. Rogalla, Physica C: Superconductivity 339, 215 (2000).

[7] M. Birkholz, Thin film analysis by X-ray scattering John Wiley \& Sons, 2006.

[8] S. Pennycook and D. Jesson, Ultramicroscopy 37, 14 (1991).

[9] R. F. Egerton, Electron energy-loss spectroscopy in the electron microscope Springer Science \& Business Media, 2011.

[10] M. D. Nguyen, M. Dekkers, E. Houwman, R. Steenwelle, X. Wan, A. Roelofs, T. Schmitz-Kempen, and G. Rijnders, Applied Physics Letters 99, 252904 (2011).

[11] O. Philips, Philips Res. Rep 13, 1 (1958). 


\title{
Chapter 3
}

\section{Growth kinetics of epitaxial La-doped $\mathrm{BaSnO}_{3}$ thin films by pulsed laser deposition}

\begin{abstract}
The growth kinetics of epitaxial La-doped $\mathrm{BaSnO}_{3}$ thin films by pulsed laser deposition was investigated. The nucleation and growth are affected by two parameters, the diffusion coefficient and the mass flux. By varying substrate growth temperatures and varying spot sizes, the diffusion coefficient and the mass flux can be controlled, respectively. The properties of thin films were characterized by atomic force microscopy, x-ray diffraction and transport. The transport properties are dependent on both the crystalline quality as well as the surface morphology of the thin films. At room temperature, the LBSO thin film grown at the optimal conditions on the $\mathrm{BaSnO}_{3}$ buffered $\mathrm{SrTiO}_{3}$ has a resistivity of $3.5 \times 10^{-4} \Omega \mathrm{cm}$ and a mobility of $81.9 \mathrm{~cm}^{2} \mathrm{~V}^{-1} \mathrm{~s}^{-1}$.
\end{abstract}




\section{Chapter 3: Growth kinetics of epitaxial La-doped $\mathrm{BaSnO}_{3}$ thin films by pulsed laser deposition}

\subsection{Introduction}

Transparent oxide materials (TCO) are in increasing demand for a wide range of optoelectronic and electronic devices, such as solar cells and transparent logic devices [1]. Several materials, such as F-doped $\mathrm{SnO}_{2}$ and $\mathrm{Al}$-doped $\mathrm{ZnO}$ have been widely investigated [2, 3]. The most well-known TCO is Sn-doped $\operatorname{In}_{2} \mathrm{O}_{3}$ (ITO), which has been used for more than six decades, due to its high conductivity and its transparency [4, 5]. However, low abundance of Indium results in an increase in the price of Indium. Alternative materials with a lower price are needed. In recent years, oxides with the perovskite structure have received a lot of interest due to their broad range of properties, such as metal-to-insulator transitions, ferroelectricity and superconductivity [6]-8]. Such varied physical properties have been used in the form of thin film heterostructrues for realization of functionalities. Perovskite TCO materials are highly desired because they can provide a suitable template for epitaxial growth of heterostructure. The perovskite oxide La-doped $\mathrm{BaSnO}_{3}$ has received a lot of interest due to its transparency, its high mobility at room temperature and its chemical stability [9, 10].

The carrier mobility is an important parameter for developing fast logic devices because the carrier mobility limits the operation speed across electronic devices. A mobility of $320 \mathrm{~cm}^{2} \mathrm{~V}^{-1} \mathrm{~s}^{-1}$ at room temperature for La-doped $\mathrm{BaSnO}_{3}$ (LBSO) single crystals at a mobile electron concentration of $\mathrm{n}=10^{19} \mathrm{~cm}^{-3}$ has been reported [10]. The other advantage is the structural and chemical compatibility of La-doped $\mathrm{BaSnO}_{3}$ with functional perovskite oxides. The integration of LBSO with other perovskite oxides provides opportunities for hybrid devices by exploiting emergent phenomena of all oxide heterostructrues [11]. For example the integration of LBSO with ferroelectrics, such as $\mathrm{Pb}(\mathrm{Zr}, \mathrm{Ti}) \mathrm{O}_{3}$ and $0.5 \mathrm{Ba}\left(\mathrm{Zr}_{0.2} \mathrm{Ti}_{0.8}\right) \mathrm{O}_{3}-0.5\left(\mathrm{Ba}_{0.7} \mathrm{Ca}_{0.3}\right) \mathrm{TiO}_{3}$ [12, 13] can potentially be used for ferroelectric devices, including ferroelectric field-effect transistors and ferroelectric resistive memory. The lattice mismatch between La- doped $\mathrm{BaSnO}_{3}$ (cubic, $\mathrm{a}=4.11$ $\AA)$ and $\mathrm{Pb}(\mathrm{Zr}, \mathrm{Ti}) \mathrm{O}_{3}(\mathrm{a}=4.06 \AA, \mathrm{c}=4.11 \AA)$ is smaller than the lattice mismatch between the commonly used oxide electrode material, such as $\mathrm{SrRuO}_{3}(3.93 \AA)$ and $\mathrm{LaNiO}_{3}(3.84$ $\AA$ ) [14, 15]. LBSO is very promising as an electrode in PZT-based devices to reduce the defects induced by lattice mismatch in PZT.

Recently, the transport properties of La-doped $\mathrm{BaSnO}_{3}$ thin films have been widely studied. Several studies claimed that the origin of the relatively poor mobility in thin films 
compared to the bulk is the presence of misfit dislocations resulting from the lattice mismatch between the substrates [16-[18]. The properties of deposited LBSO thin films on different substrates or on introduced buffer layers has been widely reported. To date, the highest mobility of $183 \mathrm{~cm}^{2} \mathrm{~V}^{-1} \mathrm{~s}^{-1}$ in a LBSO thin film grown by molecular beam epitaxy (MBE) on a $\mathrm{DyScO}_{3}$ substrate has been obtained by Paik et al. [19]. The thickness dependence on mobilities of LBSO thin films grown by pulsed laser deposition (PLD) has been investigated by Sanchela et al. [20]. The carrier mobility in LBSO thin films increases with the thickness of thin films increasing up to $200 \mathrm{~nm}$. As LBSO thin films are used as a conducting layer for growth of subsequent functional layers, the structural and morphological properties of thin films are important next to the electrical and transport properties. The carrier mobility of thin films could also be affected by charged point defects, crystallinity and surface morphology, which are highly determined by the thin film growth process. Here, pulsed laser deposition (PLD) was used for thin film fabrication since it enables to deposit many kinds of material in a broad range of gas pressures. The most generally adopted model suggested that the growth mode in a PLD synthesis is mostly determined by the kinetic energy of the arriving species [21-23]. The effect of growth kinetics on crystallinity and surface morphology, which in turn affects transport properties of thin films, is a very important factor to investigate. In a PLD system, The nucleation and growth are affected by two kinetic parameters, the diffusion coefficient and the mass flux [21, 23,-25]. By varying substrate growth temperatures and varying spot sizes, the diffusion coefficient and the mass flux can be controlled, respectively. In this chapter, the growth kinetics of LBSO thin films was studied by varying the substrate growth temperatures and varying the spot sizes.

\subsection{Experimental}

A target of $7 \%$ La doping $\mathrm{BaSnO}_{3}$ was used in this work. $\mathrm{La}_{0.07} \mathrm{Ba}_{0.93} \mathrm{SnO}_{3}$ thin films were grown by pulsed laser deposition (PLD) equipped with high energy electron diffraction (RHEED) on single $\mathrm{TiO}_{2}$ terminated $\mathrm{SrTiO}_{3}$ (100) (STO) substrates. A thermal and chemical treatment was applied to achieve the single termination [26]. Nucleation and growth of 2d-islands are two processes during the epitaxial thin film growth on a flat surface. The surface diffusion coefficient of the surface and the mass flux of atoms are likely to be very important kinetic parameters. To study the diffusion coefficient, a first set of 
samples was grown at temperatures in the range from $750{ }^{\circ} \mathrm{C}$ to $850{ }^{\circ} \mathrm{C}$ while using a fixed spot size of $0.88 \mathrm{~mm}^{2}$. The flux of atoms was controlled by varying the spot sizes. In a second set, the spot size was varied from $2.3 \mathrm{~mm}^{2}, 1.18 \mathrm{~mm}^{2}, 0.88 \mathrm{~mm}^{2}$ to $0.59 \mathrm{~mm}^{2}$ with a constant substrate temperature of $830^{\circ} \mathrm{C}$. $\mathrm{A} \mathrm{KrF}$ excimer laser $(\lambda=248 \mathrm{~nm})$ at fluency of $1.3 \mathrm{~J} / \mathrm{cm}^{2}$ and $1 \mathrm{~Hz}$ repetition rate was used for all samples, and the oxygen pressure was kept at 0.13 mbar. The thickness of the films in these two sets was kept at about $15 \mathrm{~nm}$.

All films were monitored during growth using reflection high energy electron diffraction (RHEED) to study the growth kinetics, surface morphology, and in-plane crystal structure. Topography and roughness were investigated by atomic force microscopy (AFM) (Bruker Icon) in a tapping mode. We investigated the structural properties of the thin film by X-ray diffraction (XRD) (panalytical MRD). The crytallinite quality of thin films and the interface between LBSO thin film and STO substrate were visualized by atomically resolved scanning transmission electron microscopy (STEM) equipped with a Gatan Enfina spectrometer for Electron Energy Loss Spectroscopy (EELS). The electrical properties were measured by using van der Pauw geometry in a Quantum Design Physical Properties Measurement System (PPMS)(Quantum Design). To make good electrical contacts, titanium and gold were deposited at the four corners of the sample by sputtering with a shadow mask. The resistivity was measured in the range from $2 \mathrm{~K}$ to $300 \mathrm{~K}$. Hall measurements were performed in a magnetic field up to $9 \mathrm{~T}$ to obtain the carrier density and carrier mobility in the thin films.

\subsection{Results and discussion}

Figure 3.1 shows AFM images of the thin films grown at the temperature in the range from $750{ }^{\circ} \mathrm{C}$ to $850{ }^{\circ} \mathrm{C}$ with the fixed spot size of $0.88 \mathrm{~mm}^{2}$. The films grown at $750{ }^{\circ} \mathrm{C}$ and $790{ }^{\circ} \mathrm{C}$, as shown in Figure 3.1 a) and (b), do not show complete wetting. Holes with the height of about $1 \mathrm{~nm}$ are shown in the corresponding cross-section profiles. The film grown at $830{ }^{\circ} \mathrm{C}$ exhibits complete wetting and is very smooth (Figure 3.1.(c)). Holes are absent in the film grown at this condition. The corresponding cross-section profile shows that the roughness is about $0.8 \mathrm{~nm}$. The small white dots with height of about $5 \mathrm{~nm}$ are observed at the surface of the thin film grown at $850^{\circ} \mathrm{C}$ (Figure 3.1(d)). This might be caused by metallic tin diffusion and segregating at a such high temperature. 

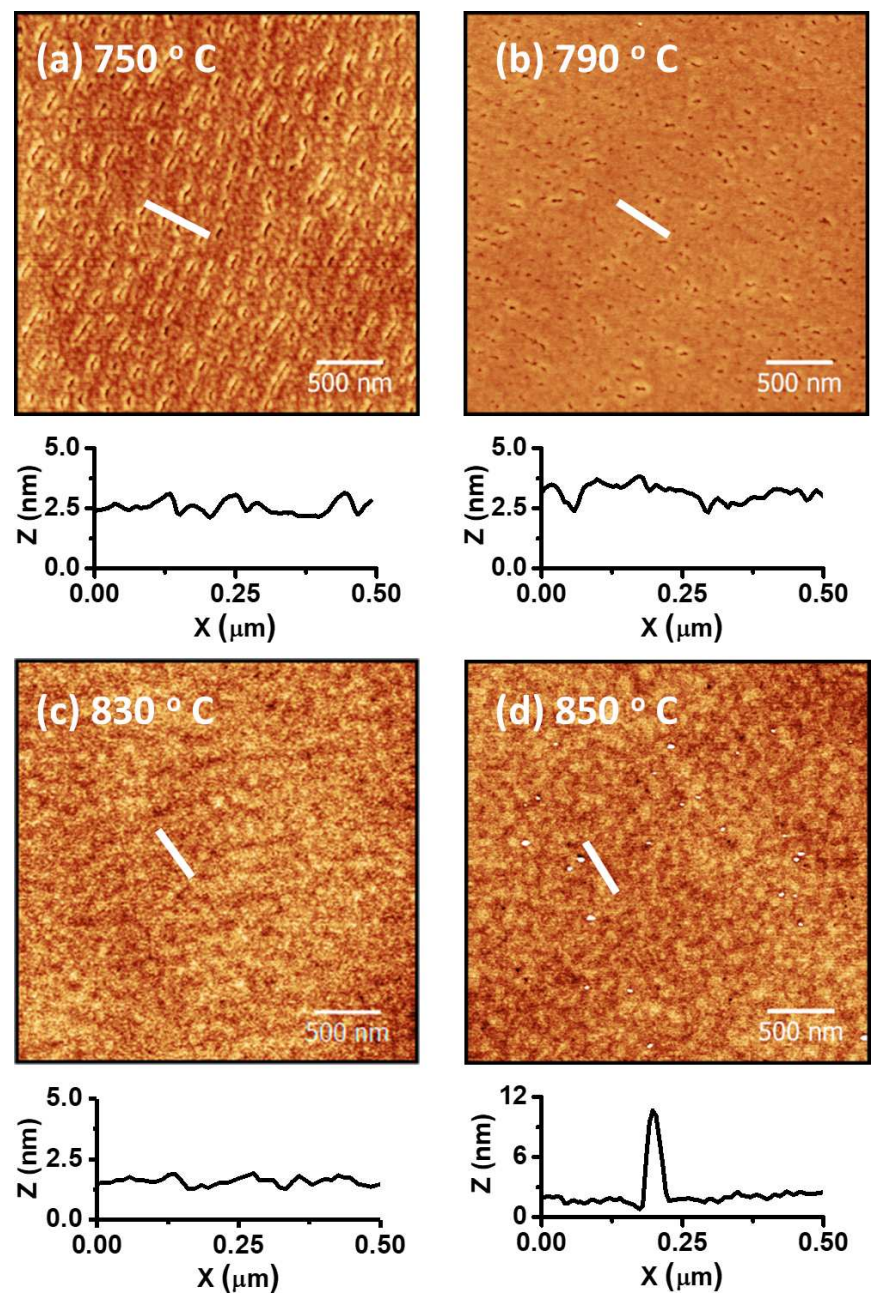

Figure 3.1: AFM topology images and the corresponding cross-section profiles of the thin films grown at temperature of (a) $750{ }^{\circ} \mathrm{C}$, (b) $800^{\circ} \mathrm{C}$, (c) $830^{\circ} \mathrm{C}$ and (d) $850{ }^{\circ} \mathrm{C}$. 


\section{Chapter 3: Growth kinetics of epitaxial La-doped $\mathrm{BaSnO}_{3}$ thin films by pulsed laser deposition}

The AFM topology images and the corresponding cross-section profiles of the thin films grown at the varying spot size of $2.3 \mathrm{~mm}^{2}, 1.18 \mathrm{~mm}^{2}, 0.88 \mathrm{~mm}^{2}$ and $0.59 \mathrm{~mm}^{2}$ with the constant temperature of $830{ }^{\circ} \mathrm{C}$ are shown in Figure 3.2. In Figure 3.2 a), the surface of the thin film consists of islands with a height of about $7 \mathrm{~nm}$ using spot size above $2.3 \mathrm{~mm}^{2}$ (the thickness of this film is $50 \mathrm{~nm}$ ). Figure 3.2 (b) shows that the grown film is not complete wetting using spot size above $1.18 \mathrm{~mm}^{2}$. The corresponding crosssection profile shows that the depth of holes is about $7 \mathrm{~nm}$. The films grown using spot size $0.88 \mathrm{~mm}^{2}$ (Figure 3.2 (c), the same as Figure 3.1 (c)) and $0.59 \mathrm{~mm}^{2}$ (Figure 3.2. d)) are complete wetting and are very smooth. The roughness of about $0.8 \mathrm{~nm}$ is shown in the corresponding cross-section profiles. Presumably, a layer-by-layer growth mode has occurred at these conditions.

The XRD (001) symmetric scan for the film grown at $830{ }^{\circ} \mathrm{C}$ with the spot size of $0.88 \mathrm{~mm}^{2}$ is shown in the Figure 3.3 a) (optimal condition). The peak corresponding to the thin film LBSO (002) is shown and this peak was present for all the films in this work. The Laue fringes around the film peak originating from the coherence between the individual layers in the film are also observed in Figure 3.3 (a), indicating a high degree of crystallinity. The thickness of $15 \mathrm{~nm}$ for the thin film can be derived from the period of Laue fringes. The inset in Figure 3.3 a) shows that full width at half maximum (FWHM) in the rocking curve of LBSO (002) is about $0.1^{\circ}$, supporting a high degree of crystallinity in this epitaxial film. The FWHM in the rocking curve of LBSO (002) peak for thin films grown at different conditions are listed in Table 3.1. At the constant temperature, the FWHM decreased with the spot size. This indicates that the crystallinity of the films grown at a small spot size was improved.

Figure 3.3 (b) shows a reciprocal space map around the (103) reflection for the film grown at $830{ }^{\circ} \mathrm{C}$ with a spot size of $0.88 \mathrm{~mm}^{2}$. The grown LBSO thin film on the STO is relaxed with an in-plane lattice parameter of $4.10 \AA$ as shown in Figure 3.3 .b). A highly crystalline LBSO thin film with the atomic ordering sharp interface of LBSO/STO are observed in the high resolution scanning transmission electron microscopy (HRSTEM) image, as shown in Figure 3.3 (c). Because of the large lattice mismatch of $4.99 \%$ between LBSO and STO (3.905 ̊), misfit dislocations, indicated with the red circles, are observed at the interface. Chemical mapping by EELS of the Ti $\mathrm{L}_{2,3}, \mathrm{Ba} \mathrm{M}_{4,5}$ and $\mathrm{Sn}$ $\mathrm{M}_{2,3}$ for the region in the green rectangle of Figure 3.3 (c) are shown in Figure 3.3 d) with the simultaneously acquired annular dark field (ADF) image. The sharp interface clearly 

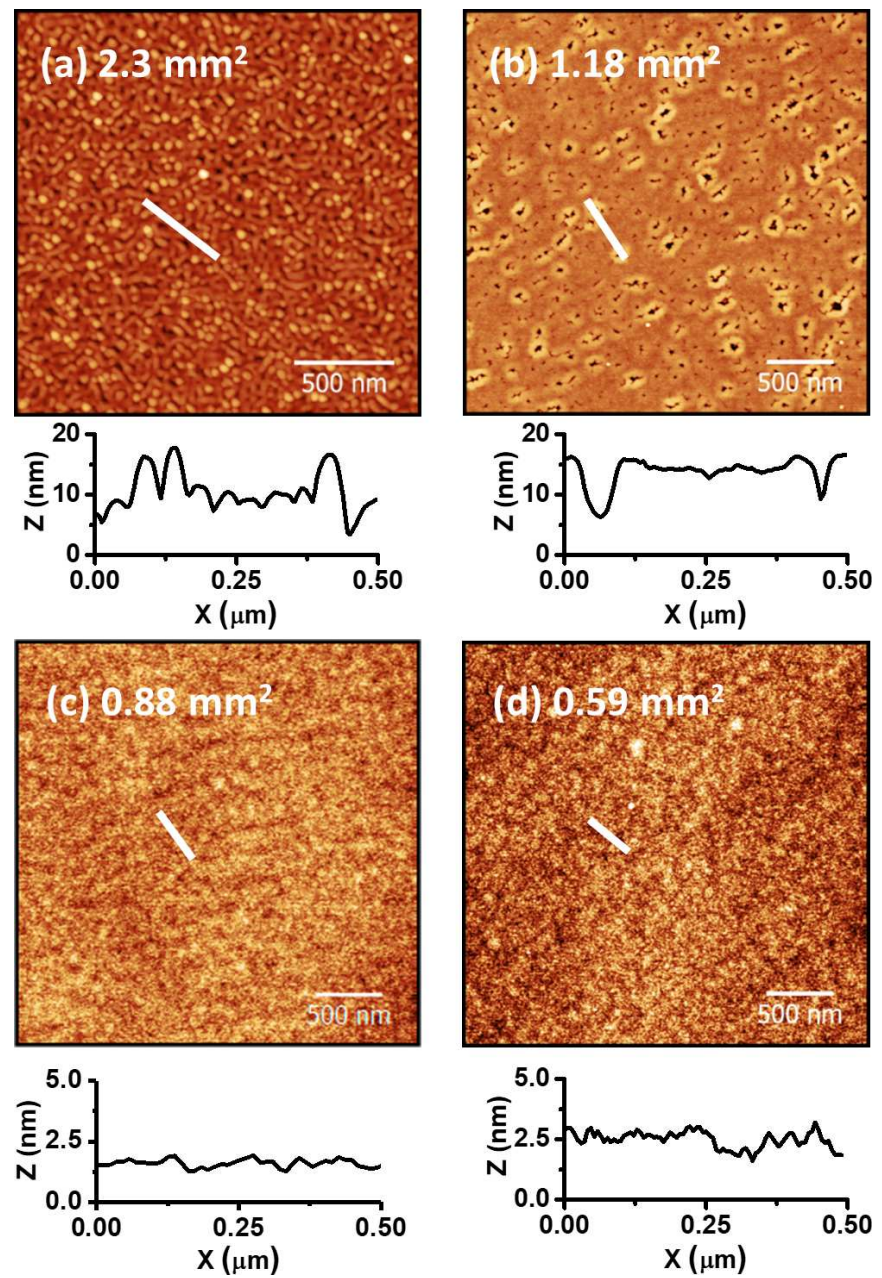

Figure 3.2: AFM topology images and the corresponding cross-section profiles of the thin films grown at the varying spot sizes of (a) $2.3 \mathrm{~mm}^{2}$ (b) $1.19 \mathrm{~mm}^{2}$, (c) $0.88 \mathrm{~mm}^{2}$ and (d) $0.59 \mathrm{~mm}^{2}$. 


\section{Chapter 3: Growth kinetics of epitaxial La-doped $\mathrm{BaSnO}_{3}$ thin films by pulsed laser deposition}

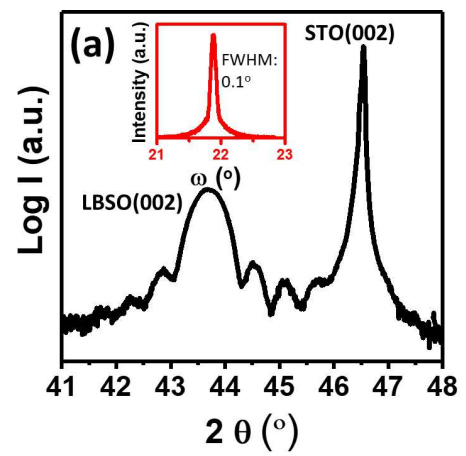

(b)
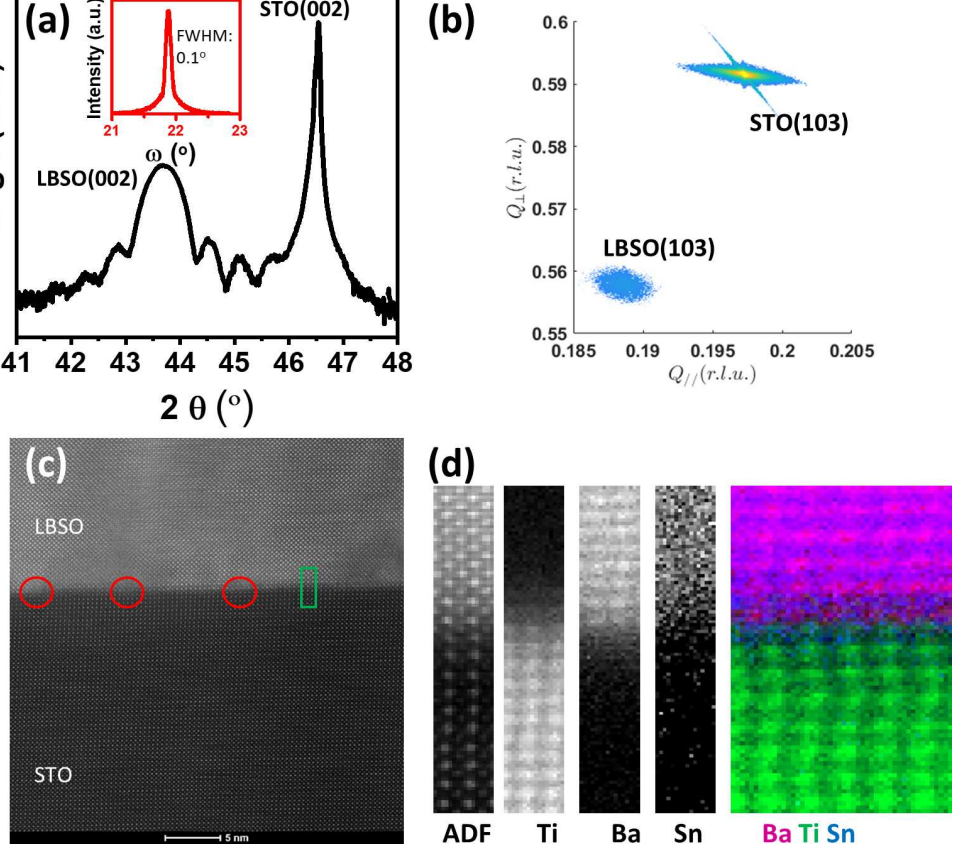

Figure 3.3: (a) XRD 001 measurement of the LBSO thin film grown at $830^{\circ} \mathrm{C}$ with the spot size of $0.88 \mathrm{~mm}^{2}$. The inset is the rocking curve of the LBSO (002) peak. (b) Reciprocal space map around the (103) reflection for the film grown at $830^{\circ} \mathrm{C}$ with the spot size of $0.88 \mathrm{~mm}^{2}$. (c) High resolution transmission electron microscopy (HRSTEM) image of the LBSO thin film on the STO. Misfit dislocations at interface are indicated by the red circles. (d) Chemical mapping by EELS of the Ti $\mathrm{L}_{2,3}, \mathrm{Ba} \mathrm{M}_{4,5}$ and $\mathrm{Sn} \mathrm{M}_{2,3}$ for the region in the green rectangle of Figure 3.3 (c) with the simultaneously acquired annular dark field (ADF) image.

shows that there is no perceptible atomic inter-diffusion at the LBSO/STO interface.

The temperature dependence of electrical resistivity was measured in the temperature range $2 \mathrm{~K}-300 \mathrm{~K}$, as shown in Figure 3.4 (a) and (b). All the samples show metallic behaviour: the resistivity decreased with decreasing temperature. The lowest resistivity was obtained for the films grown with the smoothest surface and the best crystallinity, which were grown at the temperature of $830{ }^{\circ} \mathrm{C}$ with the spot size of $0.88 \mathrm{~mm}^{2}$. The film grown at $850^{\circ} \mathrm{C}$ has higher resistivity than the film grown at $830^{\circ} \mathrm{C}$, presumably because tin has segregated at $850{ }^{\circ} \mathrm{C}$. The carrier density $\mathrm{n}$ and the mobility $\mu$ of the LBSO thin films grown at different conditions are listed in Table 3.2 At room temperature, the optimal LBSO thin film with the resistivity of $3.3 \times 10^{-4} \Omega \mathrm{cm}$ was obtained. The carrier density and carrier mobility of this film are $4.3 \times 10^{20} \mathrm{~cm}^{-3}$ and $42.7 \mathrm{~cm}^{2} \mathrm{~V}^{-1} \mathrm{~s}^{-1}$ 
Table 3.1: Full width at half maximum (FWHM) in the rocking curve of the film LBSO (002) grown at different conditions.

\begin{tabular}{ccc} 
Spot size $\left(\mathrm{mm}^{2}\right)$ & Temperature $\left({ }^{\circ} \mathrm{C}\right)$ & FWHM $\left({ }^{\circ}\right)$ \\
\hline 0.88 & 750 & 0.10 \\
0.88 & 800 & 0.10 \\
0.88 & 830 & 0.10 \\
0.88 & 850 & 0.08 \\
2.30 & 830 & 0.17 \\
1.18 & 830 & 0.12 \\
0.59 & 830 & 0.10
\end{tabular}
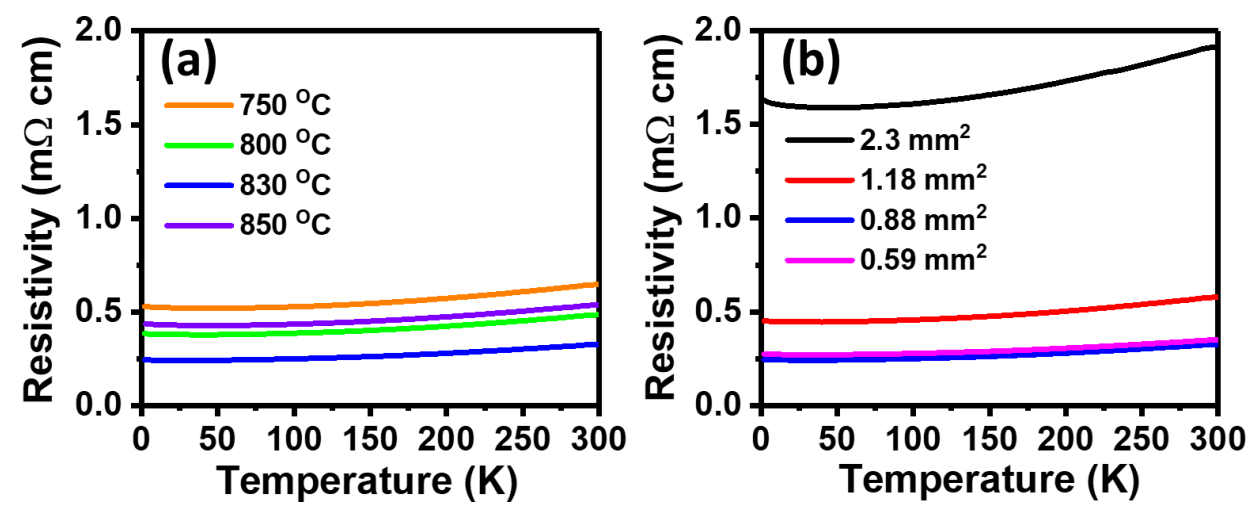

Figure 3.4: Temperature dependent resistivity $\rho$ for deposited LBSO thin films grown at (a) the varying growth temperatures and (b) the varying spot sizes.

respectively.

Two processes, the nucleation and the growth of $2 \mathrm{~d}$-islands, take place during the thin film epitaxial growth on a flat surface. They are both determined by the kinetic effects. The surface diffusion, which is an important kinetic parameter determines the average distance an atom can diffuse on a flat surface before being trapped (diffusion length) [21]. If the diffusion length $l_{\mathrm{D}}$ is larger than the average terrace width $1_{\mathrm{T}}$, adatoms have high enough mobility to travel towards the terrace step edge. The deposited adatoms nucleate at the terrace steps and the nucleation on the terraces is prevented. The steps will propagate, leading to the step-flow growth. This intralayer mass transport (diffusivity) at substrate is determined by the diffusion coefficient $D_{s}$, which is proportional to the substrate temperature. If the intralayer mass transport (diffusivity) is not fast enough, nucleation on the terrace will occur. Initially, small nuclei will be formed until one saturation density is reached. After the saturation, the probability for atoms to attach to an 


\section{Chapter 3: Growth kinetics of epitaxial La-doped $\mathrm{BaSnO}_{3}$ thin films by pulsed laser deposition}

Table 3.2: Carrier density and mobility at room temperature of the film LBSO (002) grown at different conditions.

\begin{tabular}{cccc} 
Spot size $\left(\mathrm{mm}^{2}\right)$ & Temperature $\left({ }^{\circ} \mathrm{C}\right)$ & $\mathrm{n}\left(\times 10^{20} \mathrm{~cm}^{-3}\right)$ & $\mu\left(\mathrm{cm}^{2} \mathrm{~V}^{-1} \mathrm{~s}^{-1}\right)$ \\
\hline 0.88 & 750 & 3.8 & 25.3 \\
0.88 & 790 & 4.4 & 28.7 \\
0.88 & 830 & 4.3 & 42.7 \\
0.88 & 850 & 3.1 & 35.7 \\
2.3 & 830 & 7.8 & 4.1 \\
1.18 & 830 & 4.5 & 24.3 \\
0.59 & 830 & 4.5 & 39.2
\end{tabular}

existing nucleus is higher than the probability of forming a new nucleus. The interlayer mass transport have a effect on the growth modes. Two growth modes can be classified. If the interlayer mass transport is limited, nucleation will occur on top of the initial islands, leading to the multilayer deposition. When the interlayer mass transport is steady, layerby-layer growth is obtained and the nucleation starts after completion of a layer. A mass flux is the other kinetic parameter to affect the nucleation and the growth. W. Hong et al. [24] described that a low mass flux is required to avoid the island formation, because the low mass flux leads to a slow nucleation rate. In the model described by Tersoff et al [23], growth modes could be affected by a critical size of nucleation islands at which second layer nucleation starts to occur. The layer-by-layer growth is more likely to occur when the size of nucleation islands is smaller than the critical size. The low mass flux is required since it can lead to the a large critical size of nucleation islands.

With a fixed spot size, the LBSO film grown at $750{ }^{\circ} \mathrm{C}$ (Figure 3.1 (a)) does not show complete wetting. Small holes are observed on the surface of this film. The film grown at $830^{\circ} \mathrm{C}$ exhibits complete wetting and is very smooth (Figure 3.1 (c)). Presumably, a layer-by-layer growth has occurred at this condition. It clearly shows that the temperature is an important parameter to determine the diffusion coefficient, which in turn affects the growth mode. With the growth temperature increasing, the surface diffusivity (interlayer mass transport) increases to be high enough to make the film in a layer-by-layer growth mode. A similar trend is also shown in the films grown with different spot sizes. The rough surface of the film grown using the spot size of $2.3 \mathrm{~mm}^{2}$ (Figure 3.2 (a)) indicates very limited interlayer mass transport at this condition. The smooth surface for the film grown by using spot size smaller than $0.88 \mathrm{~mm}^{2}$ (Figure 3.2 (c) and (d)) were obtained. The crystallinity of the film grown using a small spot size is also improved. Here, the 
small spot size leads to relatively low mass flux. The thin films are more likely to be grown in a layer-by-layer mode with a low mass flux. The results clearly show that two kinetic parameters, the surface diffusivity of the surface and the mass flux, play an important role in determining the growth mode of LBSO thin films.

Besides the growth conditions, the properties of thin films are determined by different parameters. Sanchela et al. [20] have shown that the carrier mobility of LBSO thin films increases with the thickness increasing up to $200 \mathrm{~nm}$. Here, at the optimal growth conditions, the carrier mobility of LBSO thin films reaches up to $60.0 \mathrm{~cm}^{2} \mathrm{~V}^{-1} \mathrm{~s}^{-1}$ when the thickness was increased to $50 \mathrm{~nm}$. The large amount of the misfit strain between the STO substrate and LBSO thin film (4.99\%) can introduce the defects in LBSO thin films (Figure 3.3 (c)), suppressing the carrier mobility. The carrier mobility of the LBSO thin film $(50 \mathrm{~nm})$ grown on a $\mathrm{BaSnO}_{3}(30 \mathrm{~nm})$ buffered STO substrate with the optimal growth conditions can reach up to $81.9 \mathrm{~cm}^{2} \mathrm{~V}^{-1} \mathrm{~s}^{-1}$.

\subsection{Conclusion}

Two sets of thin films were grown by varying growth temperature and varying laser spot size with constant oxygen pressure of 0.13 mbar. The first set of samples show that the surface morphology of LBSO thin films was improved by increasing the temperature up to $830{ }^{\circ} \mathrm{C}$. The white dots observed on the surface of thin film grown at $850^{\circ} \mathrm{C}$ is an indication of tin evaporation and segregation. The second set of samples show that a small spot size is favourable for the crystallinity and smoothness of the films. At the optimal conditions, the epitaxial LBSO thin film with a smooth surface and good crystallinity shows the best transport properties. We conclude that two kinetic parameters, diffusion coefficient controlled by growth temperature and mass flux tuned by spot size, affect the crystallinity and surface morphology of the films, which in turn control the properties of thin films. 


\section{Bibliography}

[1] H. Hosono, Thin Solid Films 515, 6000 (2007).

[2] T. Makino, Y. Segawa, A. Tsukazaki, A. Ohtomo, and M. Kawasaki, Applied Physics Letters 87, 022101 (2005).

[3] K. Nomura, H. Ohta, K. Ueda, T. Kamiya, M. Hirano, and H. Hosono, Science 300, 1269 (2003).

[4] K. Ellmer, Nature Photonics 6, 809 (2012).

[5] H. Ohta, M. Orita, M. Hirano, H. Tanji, H. Kawazoe, and H. Hosono, Applied Physics Letters 76, 2740 (2000).

[6] M. Imada, A. Fujimori, and Y. Tokura, Reviews of Modern Physics 70, 1039.

[7] I. H. Inoue and M. J. Rozenberg, Advanced Functional Materials 18, 2289 (2008)

[8] H. W. Jang, A. Kumar, S. Denev, M. D. Biegalski, P. Maksymovych, C. W. Bark, C. T. Nelson, C. M. Folkman, S. H. Baek, N. Balke, C. M. Brooks, D. A. Tenne, D. G. Schlom, L. Q. Chen, X. Q. Pan, S. V. Kalinin, V. Gopalan, and C. B. Eom, Phys. Rev. Lett. 104, 197601 (2010).

[9] X. Luo, Y. S. Oh, A. Sirenko, P. Gao, T. Tyson, K. Char, and S.-W. Cheong, Applied Physics Letters 100, 172112 (2012).

[10] H. J. Kim, U. Kim, H. M. Kim, T. H. Kim, H. S. Mun, B.-G. Jeon, K. T. Hong, W.-J. Lee, C. Ju, K. H. Kim, et al., Applied Physics Express 5, 061102 (2012).

[11] K. Krishnaswamy, L. Bjaalie, B. Himmetoglu, A. Janotti, L. Gordon, and C. G. Van de Walle, Applied Physics Letters 108, 083501 (2016).

[12] J. Rouquette, J. Haines, V. Bornand, M. Pintard, P. Papet, B. Bonnet, and F. Gorelli, Solid State Sciences 5, 451 (2003).

[13] J. P. Silva, J. Wang, G. Koster, G. Rijnders, R. Negrea, C. Ghica, K. C. Sekhar, J. A. Moreira, and M. J. Gomes, ACS Applied Materials \& Interfaces 10, 15240 (2018). 
[14] G. Koster, L. Klein, W. Siemons, G. Rijnders, J. S. Dodge, C.-B. Eom, D. H. Blank, and M. R. Beasley, Reviews of Modern Physics 84, 253 (2012).

[15] A. Y. Dobin, K. Nikolaev, I. Krivorotov, R. Wentzcovitch, E. D. Dahlberg, and A. Goldman, Physical Review B 68, 113408 (2003).

[16] S. Raghavan, T. Schumann, H. Kim, J. Y. Zhang, T. A. Cain, and S. Stemmer, APL Materials 4, 016106 (2016).

[17] A. Prakash, P. Xu, A. Faghaninia, S. Shukla, J. W. Ager III, C. S. Lo, and B. Jalan, Nature Communications 8, 15167 (2017).

[18] J. Shin, Y. M. Kim, Y. Kim, C. Park, and K. Char, Applied Physics Letters 109, 262102 (2016).

[19] H. Paik, Z. Chen, E. Lochocki, A. Seidner H, A. Verma, N. Tanen, J. Park, M. Uchida, S. Shang, B.-C. Zhou, et al., APL Materials 5, 116107 (2017).

[20] A. V. Sanchela, M. Wei, H. Zensyo, B. Feng, J. Lee, G. Kim, H. Jeen, Y. Ikuhara, and H. Ohta, Applied Physics Letters 112, 232102 (2018).

[21] A. J. Rijnders, Ph.D. thesis, Universiteit Twente, 2001.

[22] J. E. Boschker, E. Folven, A. F. Monsen, E. Wahlstrom, J. K. Grepstad, and T. Tybell, Crystal Growth \& Design 12, 562 (2012).

[23] J. Tersoff, A. D. van der Gon, and R. Tromp, Physical Review Letters 72, 266 (1994).

[24] W. Hong, H. Lee, M. Yoon,H.M. Hans,D.H. Lowndes,Z. Suo, and Z. Zhang, Physical Review Letters 95, 095501 (2005).

[25] H.M. Christen, and E. Gyula, Jornal of Physics: Condensed Matter 20, 264005 (2008).

[26] G. Koster, B. L. Kropman, G. J. H. M. Rijnders, D. H. A. Blank, and H. Rogalla, Applied Physics Letters 73, 2920 (1998). 


\title{
Chapter 4
}

\section{$\mathrm{Pb}\left(\mathrm{Zr}_{0.52} \mathrm{Ti}_{0.48}\right) \mathrm{O}_{3}$ capacitors \\ consisting of oxide electrodes}

\section{with different work functions}

\section{and carrier densities}

\begin{abstract}
We report on the effects of the (transparent) oxide $\mathrm{La}_{0.07} \mathrm{Ba}_{0.93} \mathrm{SnO}_{3}$ (LBSO) as electrode material for an all oxide $\mathrm{PbZr}_{0.52} \mathrm{Ti}_{0.48} \mathrm{O}_{3}$ (PZT) ferroelectric capacitor, as compared to the common $\mathrm{SrRuO}_{3}$ (SRO) electrode. SRO(top)/PZT/SRO (bottom), SRO /PZT/LBSO and SRO/PZT/2 nm SRO/LBSO, devices have been fabricated by pulsed laser deposition on (001)-oriented $\mathrm{SrTiO}_{3}$ substrates. The crystalline structures of the PZT devices were determined by X-ray diffraction and the atomic structure at the PZT/ LBSO interface has been investigated by scanning transmission electron microscopy. Only marginal differences in crystalline properties were found.

High quality polarization loops were obtained, but with a much larger coercive field for the SRO/PZT/LBSO device at the PZT/LBSO interface. Contrary to the SRO/PZT/ SRO device, the polarization decreases gradually with increasing field cycling (fatigue).
\end{abstract}


Chapter 4: $\mathrm{Pb}\left(\mathrm{Zr}_{0.52} \mathrm{Ti}_{0.48}\right) \mathrm{O}_{3}$ capacitors consisting of oxide electrodes with different work functions and carrier densities

This fatigue problem can be remedied by inserting an only $2 \mathrm{~nm}$ thick SRO layer between PZT and LBSO.

It is argued that charge injection into the PZT occurs at the bottom interface, because of the low PZT/LBSO interfacial barrier as compared to the SRO/PZT barrier and the low carrier density in the LBSO as compared to that in the SRO. This creates a trapped space charge, which is the cause for the difference in fatigue behaviour.

To take advantage of well-developed fabrication process in semiconductor industry. Symmetric devices LBSO/2 nm SRO/PZT/2 nm SRO/LBSO and LBSO/2 nm $\mathrm{LaNiO}_{3}$ (LNO) /PZT/2 nm LNO/LBSO were grown on scalable silicon substrates. LNO is similar to SRO with a high work function and a high carrier density but low price. It was used to support the charge injection model. The devices grown on silicon substrates are fatigue resistant. 


\subsection{Introduction}

Ferroelectric thin films have been widely studied to understand fundamental physics and for applications because of their ferroelectric non-volatile memory and fast switching characteristics [1]. Recently, also memristor like devices, such as ferroelectric resistive memory showing neuron like adaptive characteristics, received great attention [2-7]. The performances, such as operating voltage, operating speed and the working stability, of these ferroelectric devices are important to be studied [8, 9].

Lead zirconate titanante $\mathrm{Pb}\left(\mathrm{Zr}_{0.52} \mathrm{Ti}_{0.48}\right) \mathrm{O}_{3}$ (PZT) is one of the best known materials for ferroelectric non-volatile memories applications because of its large polarization and high Curie temperature [10, 11]. Typically, a layer of ferroelectric material is sandwiched between a pair of electrodes to realize the functionalities in capacitors. The influence of electrode materials on polarization properties is important and has been extensively discussed in literatures [12-22]. By using metal electrodes, commonly Pt, the switchable polarization of the PZT suffers significant decrease under the switching pulses (fatigue behaviour). Various models, such as oxygen vacancies accumulation at the metal - PZT interface and domain wall pinning, have been proposed to understand this polarization degradation [12,14].

With the development of thin film material growth techniques, such as pulsed laser deposition, all-oxide epitaxial heterostructure based ferroelectric devices can be fabricated [15]. Conductive oxide materials, such as $\mathrm{SrRuO}_{3}$ (SRO) and $\mathrm{LaNiO}_{3}(\mathrm{LNO})$, are now widely used as electrodes in the laboratory to solve the fatigue problem. A commonly used explanation for the fatigue resistance is that oxide electrodes act as oxygen sink that suppress oxygen vacancy accumulation [16-18].

Several theoretical models provide explanations for the interface induced phenomena in the polarization response of ferroelectric thin films. For example a passive layer (causing incomplete polarization screening), a depletion layer at the interface or charge injection from the electrode into the ferroelectric layer. These phenomena all have effects on the coercive field, voltage offset and the working stability of ferroelectric devices [19-22]. In all-oxide devices, different types of contacts can be created by using oxide electrode materials with different work functions and carrier concentrations. It is of great importance for device performance to understand the effect of different interface contacts 
on the polarization response of ferroelectric devices.

Recently, La-doped $\mathrm{BaSnO}_{3}$ (LBSO), that has a cubic perovskite structure, has gained a lot of attention because of its optical transparency, its high electron mobility at room temperature and its chemical stability [23, 24]. Since the lattice constant of $4.11 \AA$ is quite well matched with those of PZT ( $\mathrm{a}=4.046 \AA$, $\mathrm{c}=4.145 \AA$ [25]), LBSO is a promising electrode material for PZT ferroelectric devices. It is expected to prevent the build up of a dislocation strain field caused by misfit dislocations [26] and may replace the often used expensive $\mathrm{SrRuO}_{3}$ (SRO). The conductivity of this material arises from the partial replacement of $\mathrm{Ba}^{2+}$ by $\mathrm{La}^{3+}$, changing the average charge on the Sn-sites. This changes the material from an insulator into a metal, by shifting the Fermi level from the top of the oxygen p-bands into the conduction band formed by the hybridizid s and $\mathrm{p}$ states of the $\mathrm{Sn}$ and $\mathrm{O}$ atoms respectively [27]. It has a wide band gap of $3.2 \mathrm{eV}$ [28], a low carrier concentration of about $4 \times 10^{20} \mathrm{~cm}^{-3}$ and a work function of about 4.4 $\mathrm{eV}$ [29, 30]. SRO, a commonly used oxide electrode, is a metal with a work function of $5.2 \mathrm{eV}$ [31]. It has a very high carrier concentration of about $2 \times 10^{22} \mathrm{~cm}^{-3}$ [32] , two orders higher than that of LBSO. The differences between SRO and LBSO lead to different interface contacts at the PZT/SRO and the PZT/LBSO interfaces. Since LBSO is an optical transparent material, understanding the performance of PZT devices with a LBSO electrode may also give the opportunity to use non-volatile ferroelectric memories in optical applications [33].

PZT devices grown on single oxide crystal substrates is difficult to take advantage of the efficient fabrication processes in the semiconductor industry because single oxide crystal substrates are limited to small size. The integration of PZT devices on the scalable substrate silicon is of interest for many applications, such as actuators and sensors. 
Table 4.1: The growth conditions of each material in ferroelectric capacitors

\begin{tabular}{cccc} 
Growth conditions & LBSO & PZT & SRO \\
\hline Background pressure $\mathrm{P}_{\mathrm{O}_{2}}(\mathrm{mbar})$ & 0.13 & 0.1 & 0.25 \\
Substrate temperature $\mathrm{T}\left({ }^{\circ} \mathrm{C}\right)$ & 830 & 600 & 600 \\
Laser fluence $\mathrm{F}\left(\mathrm{J} / \mathrm{cm}^{2}\right)$ & 1.3 & 2.0 & 2.0 \\
Laser frequency f $(\mathrm{Hz})$ & 1 & 10 & 4 \\
Spot size $\mathrm{S}\left(\mathrm{mm}^{2}\right)$ & 0.59 & 2.3 & 2.3
\end{tabular}

\subsection{Capacitors on single crystal substrates $\mathrm{SrTiO}_{3}$}

\subsubsection{Experimental}

Oxide heterostructures, SRO(top)/PZT/SRO(bottom) and SRO/PZT/LBSO, were fabricated on $\mathrm{TiO}_{2}$ terminated (001)-oriented $\mathrm{SrTiO}_{3}$ (STO) substrates using pulsed laser deposition with a $248 \mathrm{~nm} \mathrm{KrF}$ excimer laser [34]. The growth conditions were optimized with respect to surface morphology, crystalline quality and functional properties. Table 4.1 gives the growth conditions for each material. The thickness of the SRO and LBSO layers is approximately $50 \mathrm{~nm}$ and the thickness of PZT layer is $440 \mathrm{~nm}$ for all capacitors. To further clarify the role of the interface on polarization switching and the fatigue of the PZT thin films, for some devices a thin SRO layer $(2 \mathrm{~nm})$ between the PZT and the bottom electrode LBSO (SRO/PZT/2 nm SRO/LBSO) was introduced. In order to measure the electrical properties, capacitor structures were patterned by photolithography and etching.

The structural and chemical properties of the interfaces between the electrodes and PZT were visualized by Cs-corrected scanning transmission electron microscopy (STEM), equipped with a Gatan Enfina spectrometer for Electron Energy Loss Spectroscopy (EELS). The microscope was operated at $300 \mathrm{kV}$ with a $20 \mathrm{mrad}$ convergence angle. Crystallographic properties of the thin films were investigated by X-ray diffraction (XRD) (Panalytical MRD). Surface morphology was investigated by atomic force microscopy (AFM) (Bruker). The out-of-plane polarization hysteresis loop (P-E) was measured with the aixACCT TF2000. The applied field range was $-225 \mathrm{kV} / \mathrm{cm}$ to $225 \mathrm{kV} / \mathrm{cm}$. Fatigue measurements were performed using bipolar rectangular field pulses of $160 \mathrm{kV} / \mathrm{cm}$ with a repetition frequency of $100 \mathrm{kHz}$. The capacitance of the PZT heterostructure reflects the 
Chapter 4: $\mathrm{Pb}\left(\mathrm{Zr}_{0.52} \mathrm{Ti}_{0.48}\right) \mathrm{O}_{3}$ capacitors consisting of oxide electrodes with different work functions and carrier densities

interaction of free carriers at the interface between PZT and the electrodes. A DC bias voltage in the range from $-340 \mathrm{kV} / \mathrm{cm}$ to $340 \mathrm{kV} / \mathrm{cm}$ and a low-field $\left(1.1 \mathrm{kV}_{\mathrm{pp}} / \mathrm{cm}\right) \mathrm{AC}$ modulation with a frequency of $100 \mathrm{kHz}$ were applied to measure the field dependence of the (AC) capacitance across the heterostructure.

\subsubsection{Results and discussion}

The interface between the PZT thin film grown on SRO has been well studied in previous work [35, 36], showing that atomic inter-diffusion is absent. However, there are no reports on the properties of the interface between PZT and a LBSO electrode. High resolution scanning transmission electron microscopy (HRSTEM) was performed on the SRO/PZT/LBSO device. High crystallinity of the LBSO and PZT thin films and an atomically sharp ordered PZT/LBSO interface are observed in the HRSTEM image, as shown in Figure 4.1 a). Chemical maps obtained by EELS of the $\mathrm{Ti} \mathrm{L}_{2,3}, \mathrm{Ba} \mathrm{M}_{4,5}$ and $\mathrm{Sn}$ $\mathrm{M}_{2,3}$ edge for the region in the red rectangle of Figure 4.1 a), are shown in Figure 4.1. b) with the simultaneously acquired annular dark field (ADF) image. The sharp interface, indicated by the green arrows, clearly shows that there is no perceptible atomic interdiffusion at the interface between LBSO and PZT. The initial growth layer of PZT on the LBSO shows hardly any growth defects, which is to be expected from the relatively small lattice mismatch. A similar growth is obtained for PZT on the $2 \mathrm{~nm}$ SRO layer on the LBSO, since SRO is fully epitaxially strained to the LBSO (see Figure 4.1. (c)).

Figure 4.2 (a) and (c) show XRD scans of SRO/PZT/SRO and SRO/PZT/LBSO thin films respectively. The (001) peaks from each layer are clearly present. In Figure 4.2(a), the peak of SRO (002) corresponds to the bottom electrode. Because the SRO top electrode is strained by PZT, causing a smaller out-of-plane lattice constant, the SRO top electrode reflection peak shifts to higher angle and is visible as a shoulder on the left side of the STO peak (Figure 4.2 (c)). Since a large part of the SRO top electrode layer was etched away to make the capacitor structure, the intensity of the corresponding peak is much reduced compared to that of the bottom electrode. The XRD spectra indicate that all the PZT thin films are epitaxially grown with (001) orientation and show that no secondary phase is formed. The insets give the corresponding rocking curves of the PZT(002) reflections. The full width at half maximum (FWHM) is $0.14^{\circ}$ for the PZT on SRO bottom electrode (Figure 4.2 a) ) and $0.13^{\circ}$ for the PZT on a LBSO bottom electrode 

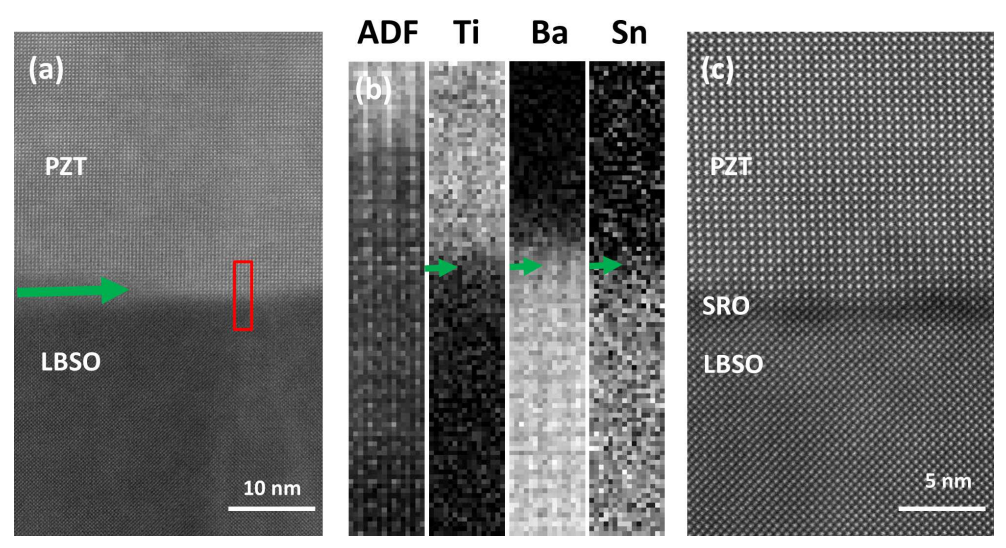

Figure 4.1: (a) STEM image at low magnification showing PZT/LBSO structure. (b) Chemical maps obtained by EELS of the Ti $\mathrm{L}_{2,3}, \mathrm{Ba} \mathrm{M}_{4,5}$ and $\mathrm{Sn} \mathrm{M}_{2,3}$ edge for the region in the red rectangle of Figure 4.1 a) with the simultaneously acquired annular dark field (ADF) image. (c) STEM image of the PZT/2 nm SRO/LBSO structure.

(Figure 4.2(c)), indicating that all PZT thin films have a high crystallinity.

To further characterize the crystalline quality and strain state of the PZT thin films, reciprocal space maps on the (103) reflections of SRO/PZT/SRO and SRO/PZT/LBSO thin films are shown in Figure 4.2 b) and (d) respectively. The bottom electrode SRO, as shown in Figure 4.2 (b), is coherently grown on the STO substrate with an in-plane coherently strained lattice constant $\mathrm{a}=3.905 \AA$ (for bulk SRO the pseudocubic lattice constant is $3.93 \AA$ ). The LBSO bottom electrode, shown in Figure 4.2 ,d), is nearly fully relaxed on the STO substrate with an in-plane lattice constant $\mathrm{a}=4.098 \AA$, almost the same to that in bulk LBSO. Due to the large in-plane lattice mismatch between PZT and strained SRO, the PZT thin film on the SRO bottom electrode is fully relaxed by defects in the first few unit cell layers and has an average, measured in-plane lattice constant $\mathrm{a}_{\mathrm{m}}$ $=4.057 \AA$ (index $\mathrm{m}$ for measured) and an (average) out-of-plane lattice constant $\mathrm{c}_{\mathrm{m}}=$ $4.113 \AA\left(\mathrm{c}_{\mathrm{m}} / \mathrm{a}_{\mathrm{m}}=1.014\right)$ (Figure 4.2 b) ). The PZT thin film on LBSO has an in-plane lattice constant $\mathrm{a}_{\mathrm{m}}=4.079 \AA$ and an out-of-plane lattice constant $\mathrm{c}_{\mathrm{m}}=4.105 \AA\left(\mathrm{c}_{\mathrm{m}} / \mathrm{a}_{\mathrm{m}}\right.$ $=1.006$ ) (Figure 4.2 (d)). The XRD scan and reciprocal space map of the SRO/PZT/2 $\mathrm{nm}$ SRO/LBSO device are shown in Figure 4.2 (c). The PZT thin film in the latter device has an in-plane lattice constant $\mathrm{a}_{\mathrm{m}}=4.080 \AA$ and an out-plane lattice constant $\mathrm{c}_{\mathrm{m}}=$ $4.104 \AA\left(\mathrm{c}_{\mathrm{m}} / \mathrm{a}_{\mathrm{m}}=1.006\right)$, equal to those of the SRO/PZT/LBSO device. This indicates that the average strain state of the PZT in both devcies is the same and that the $2 \mathrm{~nm}$ 
SRO layer is fully epitaxially strained to the LBSO. This is also evidenced by the defects at the SRO/LBSO interface in STEM image shown in Figure 4.1(c). We note that the mentioned lattice parameters are domain fraction averaged over the in-plane respectively out-of-plane lattice parameters in the nano-sized c and a domains [37]. In the bulk of the PZT film the domain fraction adapts to obtain zero stress and with that a lowest energy state in the film [38]. Both capacitor structures are subjected to the same thermal strain arising from the difference in thermal expansion coefficients of substrate and PZT. Hence in principle the domain fractions and with that the average lattice parameters should be the same in all three devices. The slight differences in measured average lattice parameters are attributed to differences in the thickness of the initial growth layer of PZT. We think that at the PZT/SRO bottom interface the lattice mismatch is so large that most epitaxial strain is relaxed by defects within a few nanometer of the PZT, whereas the small lattice mismatch at the PZT/(2nm SRO)/LBSO interface causes a relatively thick strain relaxation layer at this interface (note that the thickness of the interfacial strain relaxation layer scales inversely with the lattice mismatch [39].).

AFM images of the surfaces of the SRO and LBSO bottom electrodes are shown in Figure 4.3 (a) and (b) respectively and the insets give corresponding cross-sectional profiles. In Figure 4.3 a), the step-terrace structure is clearly observed, indicating coherent growth and a very smooth surface. Peak-to-peak height differences are about $0.4 \mathrm{~nm}$. Although the LBSO thin film is not atomically smooth and the imprint of the substrate step-terrace structure is absent, the LBSO is still very smooth and the peak-to-peak height difference is less than $0.5 \mathrm{~nm}$ (Figure $4.3 \mathrm{~b}$ )). Again we attribute these differences in surface morphology to the large lattice mismatch between LBSO and STO as compared to the full epitaxially strained growth of SRO on STO. The chemically sharp interface between PZT and LBSO, as shown by EELS-STEM (Figure 4.1) and the smooth surface of the bottom electrodes, as shown by AFM, suggest that chemical inter-diffusion effects and surface roughness effects can be ruled out in these systems.

From the structural measurements we conclude that the main difference between PZT grown on LBSO/STO and on SRO/STO is the rapid strain relaxation by a high defect density in the first few unit cells of PZT in the latter case, whereas in the cases of LBSO/STO and $2 \mathrm{~nm} \mathrm{SRO/LBSO/STO}$ the defect density is low and the strain relaxation is expected to extend over a larger thickness (of the order of $10 \mathrm{~nm}$ ).

The polarization hysteresis (P-E) loops of SRO/PZT/SRO, SRO/PZT/LBSO and SRO 

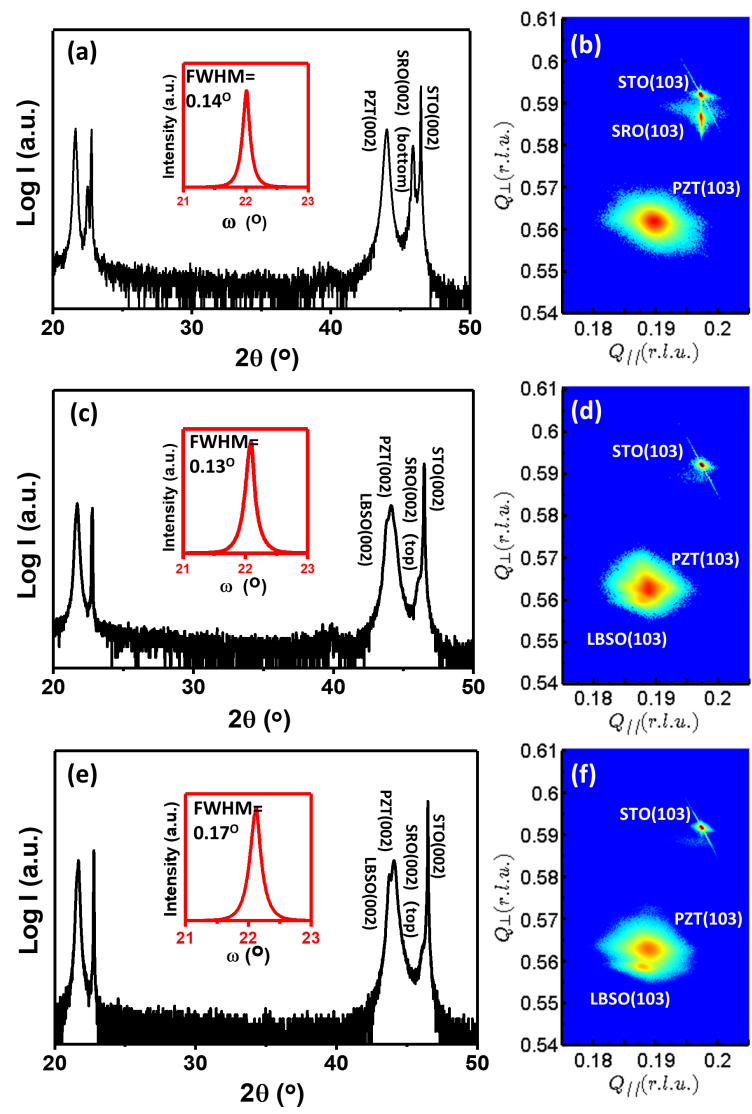

Figure 4.2: XRD 001 measurement of (a) SRO/PZT/SRO, (c) SRO/PZT/LBSO and (e) SRO/PZT/2 nm SRO/LBSO thin films on STO substrates and the reciprocal maps around the (103) peaks of (b) SRO/PZT/SRO, (d) SRO/PZT/LBSO and (f) SRO/PZT/2 $\mathrm{nm}$ SRO/LBSO thin films on STO substrates.
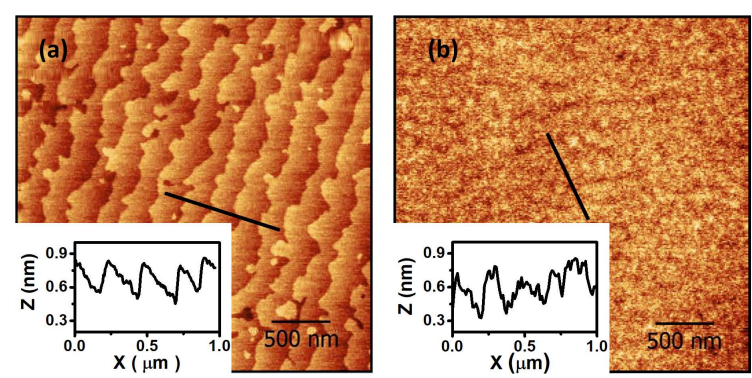

Figure 4.3: AFM images of bottom electrodes (a) SRO thin film and (b) LBSO thin film on STO substrates. 
Chapter 4: $\mathrm{Pb}\left(\mathrm{Zr}_{0.52} \mathrm{Ti}_{0.48}\right) \mathrm{O}_{3}$ capacitors consisting of oxide electrodes with different work functions and carrier densities

Table 4.2: Positive and negative remnant polarization, measured coercive fields, calculated intrinsic coercive field and net intrinsic self bias field values for the three capacitors.

\begin{tabular}{cccc} 
& $\mathrm{SRO} / \mathrm{PZT} / \mathrm{SRO}$ & $\mathrm{SRO} / \mathrm{PZT} / \mathrm{LBSO}$ & $\mathrm{SRO} / \mathrm{PZT} / 2 \mathrm{~nm}$ SRO/LBSO \\
\hline & initial (after 10 & \\
& & cycles $)$ & \\
$\mathrm{P}_{\mathrm{r}}^{+}\left(\mu \mathrm{C} / \mathrm{cm}^{2}\right)$ & 36.3 & $34.6(9.4)$ & 35.9 \\
$\mathrm{P}_{\mathrm{r}}^{-}\left(\mu \mathrm{C} / \mathrm{cm}^{2}\right)$ & -34.8 & $-36.2(-11.8)$ & -34.4 \\
\hline $\mathrm{E}_{\mathrm{cm}}^{+}(\mathrm{kV} / \mathrm{cm})$ & 45.9 & $72.5(52.8)$ & 40.8 \\
$\mathrm{E}_{\mathrm{cm}}^{-}(\mathrm{kV} / \mathrm{cm})$ & -50.5 & $-71.5(-29.9)$ & -48.9 \\
$\mathrm{E}_{\mathrm{cm}}(\mathrm{kV} / \mathrm{cm})$ & 48.2 & $72.0(41.4)$ & 44.9 \\
$\mathrm{E}_{\mathrm{sbm}}(\mathrm{kV} / \mathrm{cm})$ & -2.3 & $0.5(11.45)$ & -4 \\
\hline $\mathrm{E}_{\mathrm{ci}}^{+}(\mathrm{kV} / \mathrm{cm})$ & 48.2 & $48.2(48.2)$ & 48.2 \\
$\mathrm{E}_{\mathrm{ci}}^{-}(\mathrm{kV} / \mathrm{cm})$ & -48.2 & $-95.8(-34.5)$ & -41.5 \\
$\mathrm{E}_{\mathrm{sbi}}(\mathrm{kV} / \mathrm{cm})$ & 2.3 & $-24.3(-4.6)$ & 7.4
\end{tabular}

/PZT/2 nm SRO/LBSO capacitors, measured at $1 \mathrm{kHz}$, are shown in Figure 4.4(a). The typical ferroelectric behaviour is clearly present for all three systems. They show a similar saturation polarization value $\mathrm{P}_{\mathrm{s}}$ of about $40 \mu \mathrm{C} / \mathrm{cm}^{2}$. The measured positive and negative remnant polarization $\left(\mathrm{P}_{\mathrm{rm}}^{+}, \mathrm{P}_{\mathrm{rm}}^{-}\right)$and coercive field $\left(\mathrm{E}_{\mathrm{cm}}^{+}, \mathrm{E}_{\mathrm{cm}}^{-}\right)$values are listed in Table 4.2 (index $\mathrm{m}$ for measured). The average coercive field, $\mathrm{E}_{\mathrm{cm}}=\left(\mathrm{E}_{\mathrm{cm}}^{+}-\mathrm{E}_{\mathrm{cm}}^{-}\right) / 2$, of the $\mathrm{SRO} / \mathrm{PZT} / \mathrm{LBSO}$ device $(72.0 \mathrm{kV} / \mathrm{cm})$ is larger than that of the SRO/PZT/SRO device $(48.2 \mathrm{kV} / \mathrm{cm})$. The $2 \mathrm{~nm}$ SRO layer, inserted between the PZT and the bottom electrode LBSO, reduces the average coercive field to a value similar to that of the SRO/PZT/SRO device. Somewhat surprisingly, the imprint or self-bias field $\mathrm{E}_{\mathrm{sbm}} \equiv\left(\mathrm{E}_{\mathrm{cm}}^{+}+\mathrm{E}_{\mathrm{cm}}^{-}\right) / 2 \approx 0$ is the same for symmetric (SRO/PZT/SRO) and asymmetric (SRO/PZT/LBSO) devices.

When a positive voltage is applied to the top electrode, coming from negative poling, the polarization is more likely to point away from the top electrode, and reverse domain nucleation is likely to occur at the interface between PZT and the top electrode. We therefore assume that the positive coercive field corresponds to reverse domain nucleation at the top interface. Analogously, the negative coercive field corresponds to reverse domain nucleation at the interface between the PZT and the bottom electrode. The intrinsic coercive fields $\mathrm{E}_{\mathrm{ci}}^{+}$and $\mathrm{E}_{\mathrm{ci}}^{-}$at the PZT - electrode interfaces (index i for intrinsic) can therefore be written as:

$$
\begin{aligned}
& \mathrm{E}_{\mathrm{ci}}^{+}=\mathrm{E}_{\mathrm{cm}}^{+}+\mathrm{E}_{\mathrm{sbi}} \\
& \mathrm{E}_{\mathrm{ci}}^{-}=\mathrm{E}_{\mathrm{cm}}^{-}+\mathrm{E}_{\mathrm{sbi}}
\end{aligned}
$$



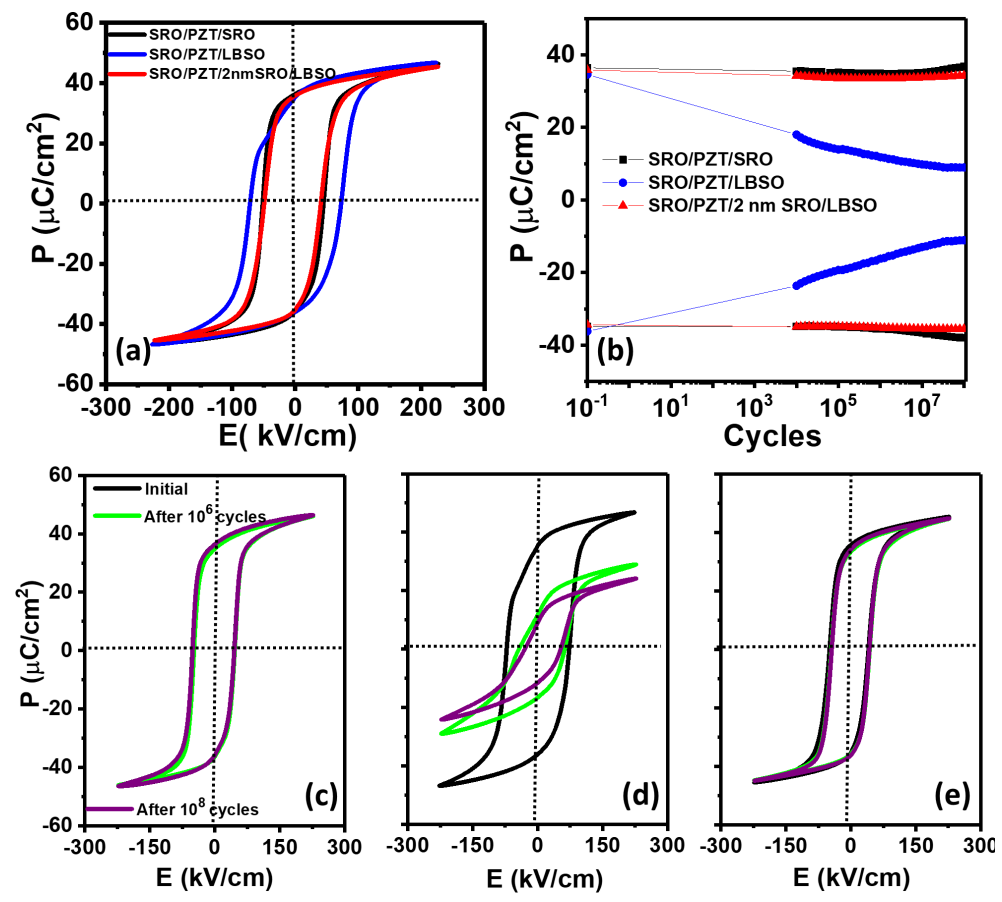

Figure 4.4: (a) Initial P-E loops of the PZT thin film in SRO/PZT/SRO, SRO/PZT/LBSO and SRO/PZT/2nm SRO/LBSO capacitors. (b) Remanent polarization during fatigue measurement for three devices performed under bipolar switching pulse of $160 \mathrm{kV} / \mathrm{cm}$ and frequency of $100 \mathrm{kHz}$. P-E loops in initial state, after $10^{6}$ and after $10^{8}$ switching cycles for the (c) SRO/PZT/SRO, (d)SRO/PZT/LBSO and (e) $\mathrm{SRO} / \mathrm{PZT} / 2 \mathrm{~nm} \mathrm{SRO} / \mathrm{LBSO}$ capacitors. 
$\mathrm{E}_{\mathrm{sbi}}$ is a net intrinsic self bias field present in the system. In the SRO/PZT/SRO capacitor, the interfaces at both sides are between SRO and PZT. We expect that in this symmetric case the values of positive and negative intrinsic coercive field $\mathrm{E}_{\mathrm{ci}}^{+}$and $\mathrm{E}_{\mathrm{ci}}^{-}$can be assumed to be the same. The intrinsic coercive field of the PZT - SRO interface $\mathrm{E}_{\mathrm{ci}-\mathrm{SRO}}^{+}=-\mathrm{E}_{\mathrm{ci}-\mathrm{SRO}}^{-}$ is then obtained as $48.2 \mathrm{kV} / \mathrm{cm}$ (see Table 4.2) and the net intrinsic self bias field as 2.3 $\mathrm{kV} / \mathrm{cm}$. In the SRO/PZT/LBSO capacitor, the above deduced intrinsic coercive field of the PZT/SRO interface $\mathrm{E}_{\mathrm{ci}-\mathrm{SRO}}^{+}$can be used for the intrinsic coercive field of the top interface. The intrinsic coercive field of the PZT/LBSO interface at negative side $\mathrm{E}_{\mathrm{ci}-\mathrm{LBSO}}^{-}$ is then derived as $-95.8 \mathrm{kV} / \mathrm{cm}$ from Equation 4.2. The large difference with the coercive field of the PZT/SRO interface hints towards a significant difference in the properties of the LBSO/PZT and SRO/PZT interfaces. In the model of interface-stimulated nucleation of reverse domains [39] the interfacial energy per unit area of the interface of the reverse domain with the electrode, $\gamma=\zeta \mathrm{P}_{\mathrm{s}}$, determines largely the coercive field value. In this expression $\zeta$ is the surface analogon of the field for the free energy per unit volume $\mathrm{EP}_{\mathrm{s}}$. Furtheron we show that there is a static field at the LBSO/PZT interface that varies strongly with field cycling. We think that this field may determine the value of $\zeta$ and is the reason behind the large value of $\mathrm{E}_{\mathrm{ci}-\mathrm{LBSO}}^{-}$as compared to $\mathrm{E}_{\mathrm{ci}-\mathrm{SRO}}^{+}$. Also the different strain state of the initial growth layer of PZT on LBSO as compared to PZT on SRO, due to the different defect density, may play a role in the reverse domain nucleation. Although this can not explain the change of the coercive field with cycling, since it is not expected that cycling changes the strain, it may be the reason for the large initial coercive field at the PZT/LBSO interface. The intrinsic self bias field in this asymmetric device is calculated as $-24.3 \mathrm{kV} / \mathrm{cm}$. The nearly symmetric P-E loop shown in Figure 4.4 a) for this asymmetric system seems therefore coincidental and caused by the large difference in intrinsic coercive fields and the large net intrinsic self bias field. By introducing the $2 \mathrm{~nm}$ SRO layer inbetween the PZT and the LBSO the coercive field of this interface is nearly fully restored to that of the top SRO/PZT interface, again demonstrating the large difference in interface properties for the different electrode materials. Also the intrinsic self bias field has nearly fully restored to the values of the SRO/PZT/SRO device.

Figure 4.4 b) shows the polarization as function of the number of switching cycles for the three different devices. As in previous work [13], it shows that SRO/PZT/SRO is highly resistant to fatigue up to at least $10^{8}$ switching cycles. However, the remnant polarization decreases approximately logarithmically with cycle number for the PZT on the 


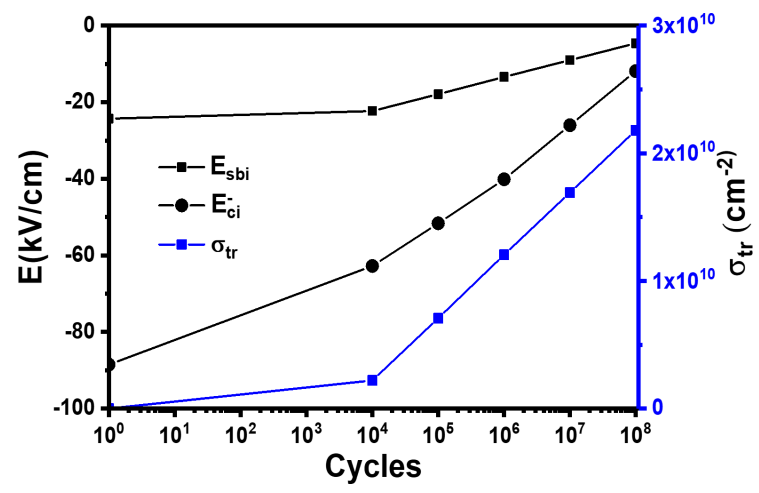

Figure 4.5: Intrinsic self bias field $\mathrm{E}_{\mathrm{sbi}}$, negative coercive filed $\mathrm{E}_{\mathrm{ci}}^{-}(\mathrm{LBSO} / \mathrm{PZT}$ interface) and trapped charge density $\sigma_{\text {tr }}$ in the SRO/PZT/LBSO device with increasing cycle number.

LBSO bottom electrode. This fatigue behaviour is completely suppressed by adding the $2 \mathrm{~nm}$ SRO layer between PZT and LBSO. This again shows the difference in interfacial properties between the LBSO/PZT and the SRO/PZT interfaces. The P-E loops at different fatigue stages, the initial loop and after $10^{6}$ and $10^{8}$ cycles, for the SRO/PZT/SRO, $\mathrm{SRO} / \mathrm{PZT} / \mathrm{LBSO}$ and SRO/PZT/2 $\mathrm{nm}$ SRO/LBSO devices are shown in Figure 4.4.c), (d) and (e) respectively. For the SRO/PZT/LBSO capacitor (Figure 4.4(d)) the loops become more asymmetric after many switching cycles (green and purple lines in Figure 4.4(d)). Based on Equations (4.1) and 4.2), the intrinsic coercive field of the PZT - LBSO interface decreases from $-95.8 \mathrm{kV} / \mathrm{cm}$ in the initial stage to $-34.5 \mathrm{kV} / \mathrm{cm}$ after $10^{8}$ switching cycles. The net intrinsic self bias field in PZT also changes from $-24.3 \mathrm{kV} / \mathrm{cm}$ in the initial stage to $-4.6 \mathrm{kV} / \mathrm{cm}$ after $10^{8}$ switching cycles. Figure 4.5 shows the intrinsic self bias field $\mathrm{E}_{\mathrm{sbi}}$, the negative coercive filed $\mathrm{E}_{\mathrm{ci}}^{-}$(LBSO/PZT interface) and the estimated trapped charge density $\sigma_{\text {tr }}$ (discussed below) in the SRO/PZT/LBSO device derived from P-E loops with increasing number of fatigue cycles. With the cycling, the (absolute values of the) intrinsic bias and the negative coercive field decrease as the trapped charge density increases with cycling. Below we discuss a plausible physical mechanism that explains this fatigue behaviour as well as the change in coercive field and self bias field with cycling. Finally we noted a 'sloped' section in the second quadrant of the P-E loop, which is not discussed further here.

Figures 4.6(a-c) depict the capacitance-voltage $(\mathrm{C}-\mathrm{V})$ measurements for the various devices in the initial stage and after $10^{6}$ switching cycles with the characteristic anti- 

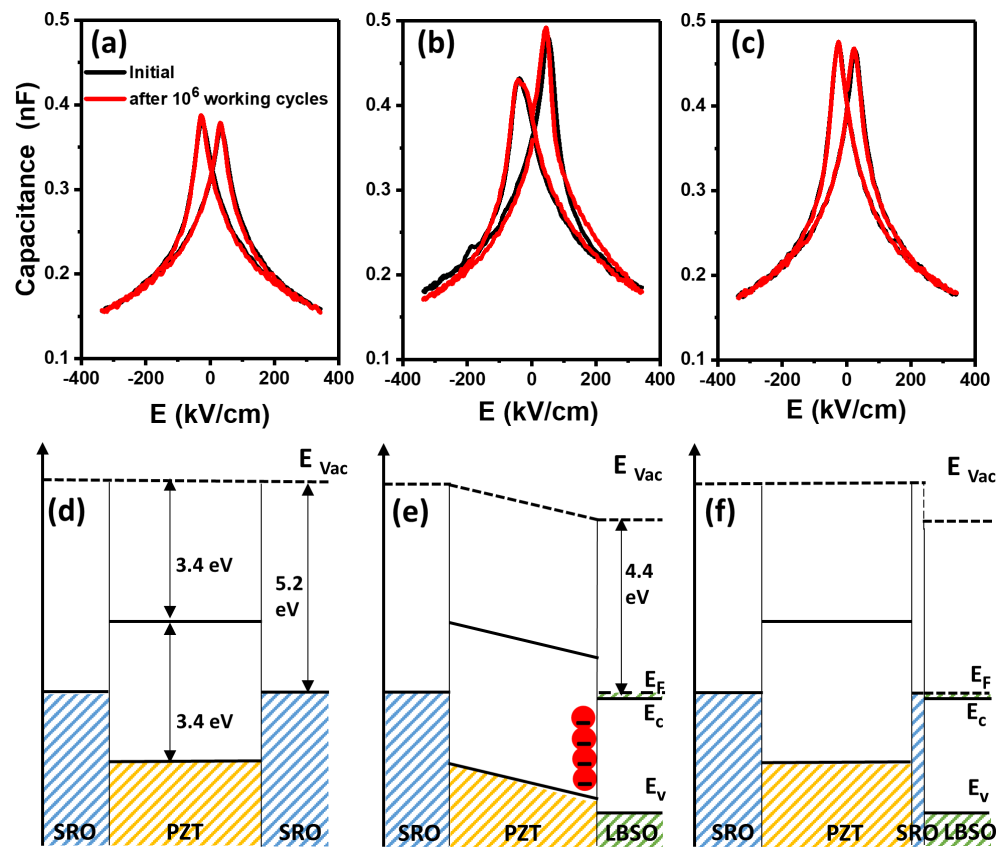

Figure 4.6: Capacitance-voltage (C-V) curves of (a) SRO/PZT/SRO and (b) $\mathrm{SRO} / \mathrm{PZT} / \mathrm{LBSO}$ and (c) SRO/PZT/2 nm SRO/LBSO capacitors at the initial stage and after $10^{6}$ switching cycles. Schematic band diagrams of (d) SRO/PZT/SRO, (e) $\mathrm{SRO} / \mathrm{PZT} / \mathrm{LBSO}$, and (e) SRO/PZT/2 nm SRO/LBSO heterostructure. Red dots with a negative sign in Figure (e) indicate that charge injection is more likely to happen at the PZT/LBSO interface. 
clockwise butterfly loops. The peaks are associated with the polarization reversal. In the SRO/PZT/SRO device (Figure 4.6 (a)), the initial capacitance is equal for both high field polarities. The $\mathrm{C}-\mathrm{V}$ curve after $10^{6}$ switching cycles is the same as the initial curve, reflecting the stability against field cycling. In the SRO/PZT/LBSO device, the initial capacitance is approximately equal to $0.180 \mathrm{nF}$ at $-340 \mathrm{kV} / \mathrm{cm}$ and $0.185 \mathrm{nF}$ at $340 \mathrm{kV} / \mathrm{cm}$. The capacitance difference for both high field side polarities indicates the imperfect screening at the PZT/LBSO interface since the LBSO is a heavily doped semiconductor with a low carrier density. At positive voltage, the polarization points towards the bottom electrode creating a positive polarization charge at the LBSO/PZT interface and a negative screening charge in the electrode. In this case the screening layer thickness is negligible. In the case of negative bias on the top electrode the positive charge in the bottom electrode screening the negative polarization charge extends over a finite screening length into the LBSO electrode. Assuming that for positive bias the interfacial capacitance is negligible, then in this case the total capacitance $\mathrm{C}_{\text {tot }}^{+}$is determined by the PZT layer only: $\mathrm{C}_{\text {tot }}^{+}=\mathrm{C}_{\text {PZT }}$. For negative voltage the total capacitance $\mathrm{C}^{-}$is then given by $1 / \mathrm{C}_{\text {tot }}^{-}=1 / \mathrm{C}_{\mathrm{PZT}}+1 / \mathrm{C}_{\mathrm{D}}$ where $\mathrm{C}_{\mathrm{D}}$ is the interfacial capacitance. By combining these relations we obtain

$$
\mathrm{C}_{\mathrm{D}}=\frac{1}{1 / \mathrm{C}_{\text {tot }}^{-}-1 / \mathrm{C}_{\mathrm{PZT}}}=\varepsilon_{0} \varepsilon_{\mathrm{d}} \mathrm{A} / \mathrm{d}
$$

The thickness of the space charge region $\mathrm{d}$ at the LBSO/PZT interface is about $1.06 \mathrm{~nm}$ assuming a dielectric constant of $\mathrm{BaSnO}_{3} \varepsilon_{\mathrm{d}}=20$ [28] and a capacitor area $\mathrm{A}=4 \times 10^{-8}$ $\mathrm{m}^{2}$. This agrees well with the Thomas-Fermi screening length $\mathrm{r}_{\text {LBSO }}=\frac{1}{2}\left(\frac{\mathrm{a}_{0}^{3}}{\mathrm{n}}\right)^{1 / 6}=0.95$ $\mathrm{nm}$, where the Bohr radius $\mathrm{a}_{0}=\left(\frac{0.53 \varepsilon}{\mathrm{m}_{\mathrm{e}}}\right) \AA=26.5 \AA$ is that of BSO, for $\varepsilon_{\mathrm{d}}=20$, effective mass $\mathrm{m}_{\mathrm{e}}=0.4 \mathrm{~m}_{0}$ [28] and carrier density $\mathrm{n}=4 \times 10^{20} \mathrm{~cm}^{-3}$. The screening length of SRO is only $0.70 \AA$ due to the high carrier density of $2 \times 10^{22} \mathrm{~cm}^{-3}$. This explains the difference in the $\mathrm{C}-\mathrm{V}$ loops of the SRO/PZT/SRO capacitor and the SRO/PZT/LBSO capacitor. (Figure 4.2 a) and (b)). After $10^{6}$ switching cycles, the SRO/PZT/LBSO capacitance at $-340 \mathrm{kV} / \mathrm{cm}$ reduces slightly to $0.170 \mathrm{nF}$ and at $-340 \mathrm{kV} / \mathrm{cm}$ reduces to 0.180 $\mathrm{nF}$ (Fig 4.6(b)), indicating the formation of an additional (interfacial) capacitance layer in series with the PZT capacitance. This result implies that any interfacial capacitance that might already have been present in the initial state has changed by the amount $C_{D}$ due to cycling. In the following we will argue that this is due to electron injection from the LBSO into the PZT upon cycling.

Interestingly the introduced $2 \mathrm{~nm}$ SRO intermediate layer is able to suppress the for- 
Chapter 4: $\mathrm{Pb}\left(\mathrm{Zr}_{0.52} \mathrm{Ti}_{0.48}\right) \mathrm{O}_{3}$ capacitors consisting of oxide electrodes with different work functions and carrier densities

Table 4.3: Band diagram parameters for SRO/PZT/SRO and SRO/PZT/LBSO capacitor structures

\begin{tabular}{ccccc} 
& $\begin{array}{c}\text { Workfunction } \\
\mathrm{W}(\mathrm{eV})\end{array}$ & $\begin{array}{c}\text { Electron affinity } \\
\chi(\mathrm{eV})\end{array}$ & $\begin{array}{c}\text { Bandgap } \\
\mathrm{E}_{\mathrm{g}}(\mathrm{eV})\end{array}$ & $\begin{array}{c}\text { Barrier } \\
\Phi_{\mathrm{B}}(\mathrm{eV})\end{array}$ \\
\hline SRO [31] & 5.2 & & & \\
LNO[42, 43] & 6.1 & & & \\
LBSO [29, 30] & 4.4 & & 3.2 & \\
PZT [41] & & 3.4 & 3.4 & \\
SRO/PZT & & & & 1.8 \\
LNO/PZT & & & & 2.7 \\
LBSO/PZT & & & & 1.0 \\
\hline
\end{tabular}

mation of a finite thickness depletion layer, because of the high electron density of SRO. As can be seen from Figure 4.6 (c) the $\mathrm{C}-\mathrm{V}$ curve after $10^{6}$ cycles remains the same as that of the initial stage, indicating that th effect of the interfacial capacitance is negligible.

The capacitance, especially at low fields, is much higher in the devices with a $(2 \mathrm{~nm}$ SRO)/LBSO electrode, than for the symmetric SRO/PZT/SRO device. We think that this indicates that domain wall motion in response to a small amplitude AC-field is much less in the latter. We speculate that this is due to the slightly different (average) strain state of the PZT films grown on (2 $\mathrm{nm} \mathrm{SRO)/LBSO} \mathrm{versus} \mathrm{growth} \mathrm{on} \mathrm{SRO.} \mathrm{There} \mathrm{is} \mathrm{also} \mathrm{a}$ significant asymmetry in peak height at the negative and positive coercive field of the $\mathrm{C}-\mathrm{V}$ loops for the SRO/PZT/LBSO device, which is largely removed by the additional 2 $\mathrm{nm}$ SRO layer. This asymmetry again reflects the difference in domain nucleation and domain growth at the different electrode interfaces.

Figures 4.6 (d-f) show schematically the band diagrams of the various capacitors using the data of Table 4.3. The screening length of the positive screening charges in the LBSO is negligible small, therefore no band bending in the LBSO taken into account. Vice versa the electron density in PZT is expected to be so low that the screening length is much larger than the film thickness, so that the potential drop in the PZT can be assumed to be linear. The $0.8 \mathrm{eV}$ difference in workfunction between the SRO and LBSO electrodes results in the slope in the band edges that can be translated into an intrinsic self bias field $\mathrm{E}_{\mathrm{sbi}-\mathrm{LBSO}}^{-}=\left(\mathrm{W}_{\mathrm{LBSO}}-\mathrm{W}_{\mathrm{SRO}}\right) / \mathrm{d}_{\mathrm{PZT}}=-18.2 \mathrm{kV} / \mathrm{cm}$, directed from the bottom to the top electrode. This agrees in sign and fairly well in value with the intrinsic self bias field of $-24.3 \mathrm{kV} / \mathrm{cm}$ determined from the P-E loop of the SRO/PZT/LBSO device. (Vice versa 
the deduced $\mathrm{E}_{\mathrm{sbi}}=-24.3 \mathrm{kV} / \mathrm{cm}$ would translate into a workfunction difference of 1.1 $\mathrm{eV}$. This would correspond to an even lower LBSO/PZT interfacial barrier height of 0.7 eV.)

Inserting the $2 \mathrm{~nm}$ SRO layer reduces the self bias field again significantly to a value that corresponds to an effective workfunction difference $\mathrm{W}_{\text {top }}-\mathrm{W}_{\text {bot }}=0.3 \mathrm{eV}$ (calculated from the determined $\mathrm{E}_{\mathrm{sbi}}$-value), which is close to that measured for the symmetric device $(0.1 \mathrm{eV})$. This indeed suggests that the effective workfunction at the bottom PZT/2 nm SRO/LBSO interface is nearly that of SRO. The small discrepancies might be due to uncertainties in the work function values and/or the effect of Fermi level pinning at the interface by defects.

The fatigue cycling changes the properties of the LBSO/PZT interface. We explain this in terms of the electron injection model described in literature.[12, 40]. During switching reverse domains are nucleating at the interface, leading to an extremely large temporary local electrical field in the reversal domains of the value $\mathrm{E}_{\mathrm{loc}} \sim \mathrm{P}_{\mathrm{s}} / \varepsilon_{0} \varepsilon_{\mathrm{i}}$, where $\varepsilon_{\mathrm{i}}$ is a dielectric constant of the electrode/PZT interface[12, 40]. Electrons are injected from the electrode into the ferroelectric by this local field and defect states, introduced during the fabrication, can trap these injected electrons near the interfaces. The finite screening length of the LBSO creates a depleted, low dielectric constant layer, during switching, enhancing the local field at the PZT/LBSO. In the Fowler-Nordheim model the tunnel/injection current $J=\mathrm{C}_{\mathrm{FN}} \mathrm{E}_{\mathrm{loc}}^{2} \exp \left[-\frac{8 \pi \sqrt{2 \mathrm{~m}_{\mathrm{e}}}\left(\mathrm{q} \Phi_{\mathrm{B}}\right)^{3 / 2}}{3 \mathrm{qE} \mathrm{E}_{\mathrm{loc}}}\right]$, where $\mathrm{C}_{\mathrm{FN}}=\frac{\mathrm{q}^{2}}{8 \pi \mathrm{h} \Phi_{\mathrm{B}}}$. The symmetric SRO/PZT/SRO has high interfacial barrier potentials of $\Phi_{\mathrm{B}}=1.8 \mathrm{eV}$, preventing easy charge injection into possible gap states in the PZT. For the LBSO/PZT interface this barrier is much lower $(1.0 \mathrm{eV})$ thus charge injection to trap states is much more likely to take place. In drawing the band diagram of the SRO/PZT/2nm SRO/LBSO device we have assumed that the full SRO/PZT barrier height is restored by the insertion of the $2 \mathrm{~nm}$ SRO layer, which would imply that the charge injection chance is reduced again significantly. Secondly, the low dielectric layer that enhances the local field in LBSO is not present. Since the local electrical field induced by reversal domains is large and the interfacial barrier is much lower at the LBSO/PZT than at the SRO/PZT interface, we expect that electron injection and subsequent trapping is much more likely to happen at the LBSO/PZT interface (noted in Figure 4.6(e)). Thus with the number of switching cycles the amount of trapped charge (per unit area), $\sigma_{\text {tr }}$, increases and creates an electric field $\mathrm{E}_{\sigma}$ directed from the top electrode to the bottom electrode in the PZT (opposite to 
the self bias field induced by the work function difference) at the LBSO/PZT interface. This increasing electric field $\mathrm{E}_{\sigma}$ can ultimately pin the polarization, causing the observed fatigue.

The injected charge changes the self bias field in the areas that are still switchable and thus observable in the fatigue hysteresis loop, as well as in the non-switchable areas. For the switchable fraction of the polarization in the fatigued SRO/PZT/LBSO device the self bias field can be estimated from the P-E loops (Figure 4.4(d)), using Equations (4.1) ) and (4.2) $)$ as $\mathrm{E}_{\mathrm{sbi}}^{\mathrm{fat}}=-4.6 \mathrm{kV} / \mathrm{cm}$. This field is the net effect of the intrinsic self bias field of the initial stage, $\mathrm{E}_{\mathrm{sbi}}^{\mathrm{in}}$, and the electric field arising from the trapped electrons, $\mathrm{E}_{\sigma}^{\mathrm{sw}}$,

$$
\mathrm{E}_{\mathrm{sbi}}^{\mathrm{fat}}=\mathrm{E}_{\mathrm{sbi}}^{\mathrm{in}}+\mathrm{E}_{\sigma}^{\mathrm{sw}}
$$

From this one can estimate $\mathrm{E}_{\sigma}^{\mathrm{sw}}=19.7 \mathrm{kV} / \mathrm{cm}$ (after $10^{8}$ cycles), directed from the top to the bottom electrode. Using Gauss' law $\mathrm{E}_{\sigma}^{\mathrm{sw}}=\sigma_{\mathrm{sw}} / 2 \varepsilon_{0}=\mathrm{n}_{\mathrm{tr}} \mathrm{e} / 2 \varepsilon_{0}$ the trapped electron charge density, $n_{t r}$, is estimated as $2.2 \times 10^{14} \mathrm{~m}^{-2}$ (or $3.6 \times 10^{-5}$ electron per unit cell area, or $3.5 \times 10^{-5} \mathrm{C} / \mathrm{m}^{2}$ ). If one assumes that the field created by trapped charge causes the polarization to be non-switchable in the non-switchable areas of the capacitor, than the trapped charge density, $\sigma_{\text {nonsw }}$, is much larger. In that case $E_{\sigma}^{\text {nonsw }}$ has to be larger than at least the maximum applied field plus measured coercive field $(\approx 300 \mathrm{kV} / \mathrm{cm})$, and the associated minimum trapped charge density is estimated as $\sigma_{\text {nonsw }} \approx 3.3 \times 10^{15} \mathrm{~m}^{-2}$ (or $5.4 \times 10^{-4}$ electron/UC-area). The change in the depletion layer at the PZT/LBSO interface, as indicated by the $\mathrm{C}-\mathrm{V}$ measurement (Figure 4.6(b)), is expected to be caused by the charge injection. An alternative mechanism may be that a high $\sigma_{\text {nonsw }}$ value pins the domain walls and in that way prevents switching.

To further substantiate the electron injection and trapping model, the fatigued device $\mathrm{SRO} / \mathrm{PZT} / \mathrm{LBSO}$ was illuminated with white light for 1.5 hours or alternatively stored in the dark for 1.5 hours. Figure 4.7 shows that the remnant polarization increases significantly after illumination, but the polarization does not recover in the dark. This indicates that the trapped electrons in the PZT are removed by the light, leading to the polarization recovery. This result also supports the charge injection and relaxation model. 


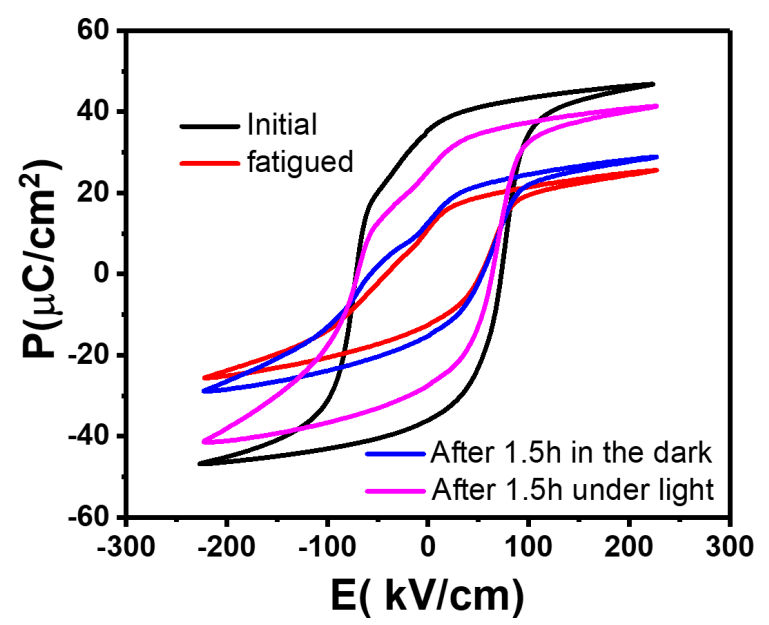

Figure 4.7: $\mathrm{P}-\mathrm{E}$ loops of the SRO/PZT/LBSO device at the initial stage (black line) and after fatigue (red line).The fatigued sample was illuminated by the white light for 1.5 hours and alternatively placed in the dark for 1.5 hours. P-E loops of the fatigued sample after 1.5 hours under light (blue line) and after 1.5 hours in the dark (purple line) are shown.

\subsection{Capacitors on silicon substrates}

It is important to understand the structure - property relations of PZT capacitors with oxide electrodes on silicon substrates. Because the devices grown on silicon can take advantage of efficient fabrication process in the semiconductor industry and is of interest for many applications, such as actuators and sensors. The other commonly used oxide electrode $\mathrm{LaNiO}_{3}$ (LNO) is similar to SRO with a high work function of $6.1 \mathrm{eV}$ and a high carrier density in the order of $10^{22} \mathrm{~cm}^{3}$ [42, 43]. It was used in PZT devices grown on silicon substrates to further substantiate the charge injection and trapping model we discussed above.

\subsubsection{Experimental}

Oxide heterostructures, LBSO/2 nm SRO/PZT/2 nm SRO/LBSO and LBSO/2 nm $\mathrm{LNO} / \mathrm{PZT} / 2 \mathrm{~nm}$ LNO/LBSO were grown on STO buffered silicon substrates. LNO is similar to SRO with a high work function and a high carrier density but low price. It was used to support the charge injection model. The growth conditions of SRO, PZT, LBSO 
Chapter 4: $\mathrm{Pb}\left(\mathrm{Zr}_{0.52} \mathrm{Ti}_{0.48}\right) \mathrm{O}_{3}$ capacitors consisting of oxide electrodes with different work functions and carrier densities

Table 4.4: The growth conditions of each material in ferroelectric capacitors

\begin{tabular}{ccccc} 
Growth conditions & LBSO & PZT & SRO & LNO \\
\hline Background pressure $\mathrm{P}_{\mathrm{O}_{2}}(\mathrm{mbar})$ & 0.13 & 0.1 & 0.25 & 0.1 \\
Substrate temperature $\mathrm{T}\left({ }^{\circ} \mathrm{C}\right)$ & $\begin{array}{c}750 \text { (bottom) } \\
600 \text { (top) }\end{array}$ & 600 & 600 & 600 \\
Laser fluence $\mathrm{F}\left(\mathrm{J} / \mathrm{cm}^{2}\right)$ & 1.3 & 2.0 & 2.0 & 2.0 \\
Laser frequency f $(\mathrm{Hz})$ & 1 & 10 & 4 & 1 \\
Spot size $\mathrm{S}\left(\mathrm{mm}^{2}\right)$ & 0.59 & 2.3 & 2.3 & 2.3
\end{tabular}

and LNO are shown in Table 4.4. The initial $2 \mathrm{~nm}$ thick STO was deposited by molecular beam epitaxy (MBE) on silicon. Before we grew the PZT capacitors, an additional $30 \mathrm{~nm}$ STO layer was deposited on the buffered silicon substrate at temperature of $650{ }^{\circ} \mathrm{C}$ and a low oxygen pressure of 0.01 mbar to prevent the reaction of the silicon with the high oxygen pressure used for the subsequent LBSO growth.

\subsubsection{Results and discussion}

XRD scans of capacitors LBSO/2 nm SRO/PZT/2 nm SRO/LBSO and LBSO/2 nm LNO/PZT/2 nm LNO/LBSO are shown in Figure4.8 (a) and (c) respectively. Peaks corresponding to the LBSO (002) and PZT(002) are clearly present in both devices. These indicate that the thin films are grown on the silicon with (001) orientation and no secondary phase is formed. The remnant polarization $\mathrm{P}_{\mathrm{r}}$ of $12.5 \mu \mathrm{C} / \mathrm{cm}^{2}$ and saturated polarization $\mathrm{P}_{\mathrm{s}}$ of $22.0 \mu \mathrm{C} / \mathrm{cm}^{2}$ are shown in the polarization hysteresis (P-E) loop of LBSO/2 nm SRO/PZT/2 nm SRO/LBSO (Figure 4.8 b)). Figure 4.8 (d) shows that the remnant polarization is $16.8 \mu \mathrm{C} / \mathrm{cm}^{2}$ and the saturated polarization is $26.5 \mu \mathrm{C} / \mathrm{cm}^{2}$ for the device LBSO/2 nm LNO/PZT/2 nm LNO/LBSO. The different thermal expansion of PZT on silicon and single crystal STO substate causes compressive strain for the PZT on STO and tensile strain for the PZT on silicon. These different strain states of PZT result in devices on the silicon substrate to have a smaller value of remnant and saturated polarization than PZT devices on the STO substrate. This observation agrees with PZT capacitors sandwiched between SRO electrodes on YSZ buffered silicon in previous work [44].

Figures 4.9 (a) and (b) show the remnant polarization as function of the number of switching cycles for devices LBSO/2 nm SRO/PZT/2 nm SRO/LBSO and LBSO/2 nm 

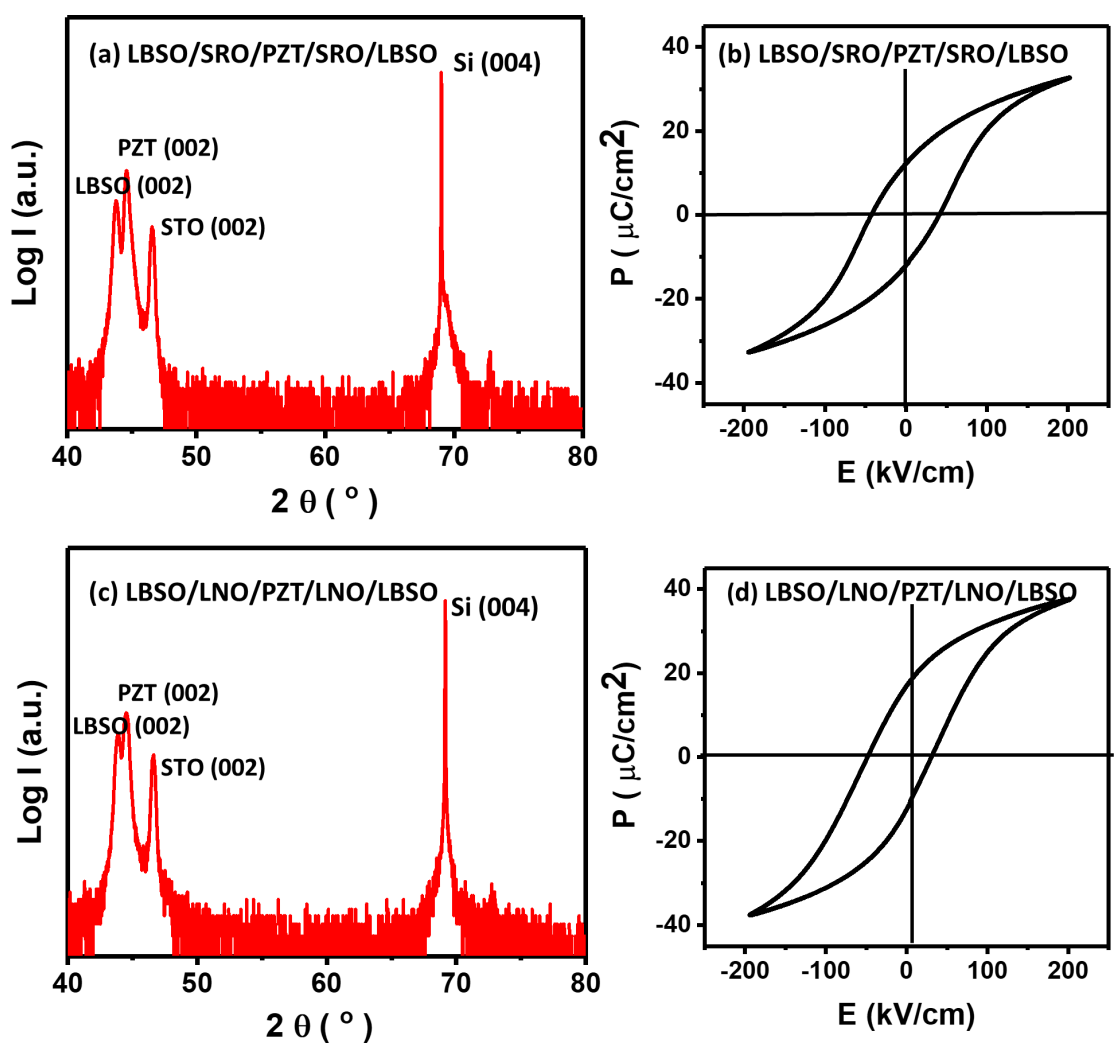

Figure 4.8: XRD measurement of the device (a) LBSO/2 nm SRO/PZT/2 nm $\mathrm{SRO} / \mathrm{LBSO}$ and (c) $\mathrm{LBSO} / 2 \mathrm{~nm} \mathrm{LNO/PZT/2} \mathrm{nm} \mathrm{LNO} / \mathrm{LBSO}$. P-E loops of the PZT thin film in the (b)LBSO/2 nm SRO/PZT/2 nm SRO/LBSO and (d) LBSO/2 nm LNO/PZT/2 $\mathrm{nm} \mathrm{LNO} / \mathrm{LBSO}$ capacitors. 
Chapter 4: $\mathrm{Pb}\left(\mathrm{Zr}_{0.52} \mathrm{Ti}_{0.48}\right) \mathrm{O}_{3}$ capacitors consisting of oxide electrodes with different work functions and carrier densities
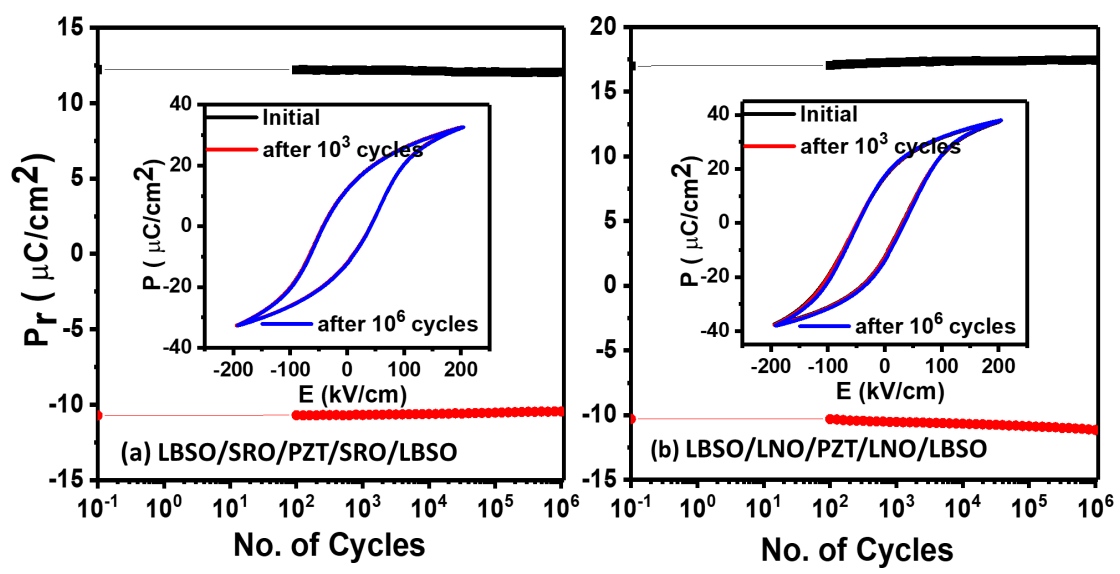

Figure 4.9: Fatigue measurement of the devices (a) LBSO/2 nm SRO/PZT/2 nm $\mathrm{SRO} / \mathrm{LBSO}$ and (b) LBSO/2 nm LNO/PZT/2 nm LNO/LBSO, performed with bipolar switching pulse of $160 \mathrm{kV} / \mathrm{cm}$ at $1 \mathrm{kHz}$. The insets are corresponding P-E loops at initial, after $10^{3}$ switching cycles and after $10^{6}$ switching cycles.

LNO/PZT/2 nm LNO/LBSO devices respectively. The devices are fatigue resistant, the remnant polarization value stays constant with the cycling number up to $10^{6}$ cycles. The insets give the corresponding P-E loops at initial, after $10^{3}$ and after $10^{6}$ switching cycles, showing that the loops are stable against switching. The inserted layer LNO is a conductive material with metallic behaviour with a high work function of $6.1 \mathrm{eV}$ and high carrier density in the order of $10^{22} \mathrm{~cm}^{-3}$ [42, 43]. The very high work function is the reason that no charge injection is expected. Secondly, the high carrier density of LNO prevents the formation of a screening layer. The fatigue resistance behaviour in the $\mathrm{LBSO} / 2 \mathrm{~nm} \mathrm{LNO} / \mathrm{PZT} / 2 \mathrm{~nm} \mathrm{LNO} / \mathrm{LBSO}$ device also supports the charge injection and relaxation model we described above.

\subsection{Conclusions}

In conclusion, PZT thin films with excellent crystalline quality and chemical sharp interfaces of the bottom electrodes LBSO respectively SRO with the ferroelectric PZT layer were obtained.

In contract with the device with PZT on SRO, a large coercive field and strong fatigue behaviour are observed for PZT with a LBSO bottom electrode. The observed fatigue 
behaviour is explained by charge injection and subsequent trapping at the PZT/LBSO interface into the ferroelectric layer up to a depth corresponding to the size of the reverse domain.

Ultimately, the electric field induced by injected charge leads to polarization fatigue. The fatigue can be resolved by introducing an only $2 \mathrm{~nm}$ thick SRO layer between PZT and LBSO. It is argued that the introduced SRO layer suppresses the charge injection, because of its large carrier density as compared to LBSO and the large interfacial barrier with PZT. The PZT capacitors sandwiched between electrodes LBSO with a thin SRO or LNO inserted layer on silicon substrates are working properly and are resistant to fatigue.

This work clearly shows that the work function and carrier density of oxide electrodes in ferroelectric devices play an important role in the polarization switching and fatigue properties of the ferroelectric layer. 


\section{Bibliography}

[1] K. M. Rabe, C. H. Ahn, and J.-M. Triscone, Physics of ferroelectrics: a modern perspective, Vol. 105 Springer Science \& Business Media, 2007.

[2] T. Choi, S. Lee, Y. Choi, V. Kiryukhin, and S.-W. Cheong, Science 324, 63 (2009).

[3] D. S. Jeong, R. Thomas, R. Katiyar, J. Scott, H. Kohlstedt, A. Petraru, and C. S. Hwang, Reports on Progress in Physics 75, 076502 (2012).

[4] Y. Nishitani, Y. Kaneko, M. Ueda, E. Fujii, and A. Tsujimura, Japanese Journal of Applied Physics 52, 04CE06 (2013).

[5] V. Garcia and M. Bibes, Nature Communications 5, 4289 (2014).

[6] A. Ghosh, G. Koster, and G. Rijnders, Advanced Functional Materials 26, 5748 (2016).

[7] J. Junquera and P. Ghosez, Nature 422, 506 (2003).

[8] J. F. Scott and C. A. P. De Araujo, Science 246, 1400 (1989).

[9] O. Auciello, J. F. Scott, and R. Ramesh, Physics Today 51, 22 (1998).

[10] C. Ahn, J.-M. Triscone, and J. Mannhart, Nature 424, 1015 (2003).

[11] V. Nagarajan, I. Jenkins, S. Alpay, H. Li, S. Aggarwal, L. Salamanca-Riba, A. Roytburd, and R. Ramesh, Journal of Applied Physics 86, 595 (1999).

[12] X. Lou, M. Zhang, S. Redfern, and J. Scott, Physical Review Letters 97, 177601 (2006).

[13] M. D. Nguyen, Ferroelectric and piezoelectric properties of epitaxial PZT films and devices on silicon University of Twente, 2010.

[14] M. Dawber, K. Rabe, and J. Scott, Reviews of Modern Physics 77, 1083 (2005).

[15] G. Rijnders and D. H. Blank, Nature 433, 369 (2005).

[16] M.-S. Chen, T.-B. Wu, and J.-M. Wu, Applied Physics Letters 68, 1430 (1996). 
[17] H. T. Vu, M. D. Nguyen, E. Houwman, M. Boota, M. Dekkers, H. N. Vu, and G. Rijnders, Materials Research Bulletin 72, 160 (2015).

[18] J. Lee, C. Thio, and S. B. Desu, Journal of Applied Physics 78, 5073 (1995).

[19] A. K. Tagantsev, I. Stolichnov, E. Colla, and N. Setter, Journal of Applied Physics 90, 1387 (2001).

[20] A. Tagantsev and G. Gerra, Journal of Applied Physics 100, 051607 (2006).

[21] L. Pintilie and M. Alexe, Journal of Applied Physics 98, 124103 (2005).

[22] G. Le Rhun, G. Poullain, and R. Bouregba, Journal of Applied Physics 96, 3876 (2004).

[23] H. Paik, Z. Chen, E. Lochocki, A. Seidner H, A. Verma, N. Tanen, J. Park, M. Uchida, S. Shang, B.-C. Zhou, et al., APL Materials 5, 116107 (2017).

[24] H. J. Kim, U. Kim, H. M. Kim, T. H. Kim, H. S. Mun, B.-G. Jeon, K. T. Hong, W.-J. Lee, C. Ju, K. H. Kim, et al., Applied Physics Express 5, 061102 (2012).

[25] B. Noheda, J. Gonzalo, L. Cross, R. Guo, S.-E. Park, D. Cox, and G. Shirane, Physical Review B 61, 8687 (2000).

[26] S. Alpay, I. Misirlioglu, V. Nagarajan, and R. Ramesh, Applied Physics Letters 85, 2044 (2004).

[27] H.-R. Liu, J.-H. Yang, H. Xiang, X. Gong, and S.-H. Wei, Applied Physics Letters 102, 112109 (2013).

[28] H. J. Kim, U. Kim, T. H. Kim, J. Kim, H. M. Kim, B.-G. Jeon, W.-J. Lee, H. S. Mun, K. T. Hong, J. Yu, et al., Physical Review B 86, 165205 (2012).

[29] S. A. Chambers, T. C. Kaspar, A. Prakash, G. Haugstad, and B. Jalan, Applied Physics Letters 108, 152104 (2016).

[30] H. Yang, H. Luo, H. Wang, I. Usov, N. Suvorova, M. Jain, D. Feldmann, P. Dowden, R. DePaula, and Q. Jia, Applied Physics Letters 92, 102113 (2008).

[31] Y. Hikita, Y. Kozuka, T. Susaki, H. Takagi, and H. Hwang, Applied Physics Letters 90, 143507 (2007). 
[32] G. Koster, L. Klein, W. Siemons, G. Rijnders, J. S. Dodge, C.-B. Eom, D. H. Blank, and M. R. Beasley, Reviews of Modern Physics 84, 253 (2012).

[33] F. Chen, H. Wang, Q. Liu, W. Wu, and X.-G. Li, Applied Physics Letters 90, 082904 (2007).

[34] G. Koster, B. L. Kropman, G. J. Rijnders, D. H. Blank, and H. Rogalla, Applied Physics Letters 73, 2920 (1998).

[35] I. Vrejoiu, G. Le Rhun, L. Pintilie, D. Hesse, M. Alexe, and U. Gösele, Advanced Materials 18, 1657 (2006).

[36] X.-K. Wei, Y. Yang, L. J. McGilly, L. Feigl, R. E. Dunin-Borkowski, C.-L. Jia, L. Bellaiche, and N. Setter, Physical Review B 98, 020102 (2018).

[37] R.J.A Steenwelle, University of Twente, 2012.

[38] E. P. Houwman, K. Vergeer, G. Koster, and G. Rijnders, in Correlated Functional Oxides Springer, 2017 pp. 29-53.

[39] G. Gerra, A. Tagantsev, and N. Setter, Physical Review Letters 94, 107602 (2005).

[40] X. Lou, M. Zhang, S. Redfern, and J. Scott, Physical Review B 75, 224104 (2007).

[41] F. Chen, R. Schafranek, W. Wu, and A. Klein, Journal of Physics D: Applied Physics 44, 255301 (2011).

[42] R. Jacobs, J. Booske, and D. Morgan, Advanced Functional Materials 26, 5471 (2016).

[43] Z. Mengwei, K. Philipp, R. Aldin, V. Mehran, W. Zhanjie, A. Lambert, Applied Physics Letters 103, 141902 (2013).

[44] M. D. Nguyen, M. Dekkers, E. Houwman, R. Steenwelle, X. Wan, A. Roelofs, T. Schmitz-Kempen, and G. Rijnders, Applied Physics Letters 99, 252904 (2011). 


\title{
Chapter 5
}

\section{Complex plume stoichiometry during pulsed laser deposition of $\mathrm{SrVO}_{3}$ at low oxygen pressures}

\begin{abstract}
To control the pulsed laser deposition synthesis, knowledge on the relation between the plasma plume and the grown thin film is required. We show that the oxidation of species in the plasma plume still affects the $\mathrm{SrVO}_{3}$ growth at low oxygen partial pressures. Optical emission spectroscopy measurement for the plasma plume at different growth conditions were correlated to the film properties determined by Atomic force microscopy, X-ray diffraction and transport. At reducing oxygen pressures, the background argon pressure can affect the oxidation in the plasma plume, which in turn controls the growth kinetics, stoichiometry and electrical properties of the films.
\end{abstract}

This chapter is published in: J. Wang, G.Rijnders, and G. Koster, "Complex plume stoichiometry during pulsed laser deposition of SrVO3 at low oxygen pressures", Applied Physic Letters, 113, 2231032018. 


\section{Chapter 5: Complex plume stoichiometry during pulsed laser deposition of $\mathrm{SrVO}_{3}$ at low oxygen pressures}

\subsection{Introduction}

Transition metal oxides with the perovskite structure have received a lot of interest in recent years due to their broad range of properties, such as metal-to-insulator transitions, ferroelectricity and superconductivity. These properties open the way for novel applications, for example transistors, switches and sensors [1]-3].

The materials properties of thin film are related to surface morphology and crystal quality, which in turn are mostly determined by surface kinetics. Pulsed laser deposition (PLD) is a widely used thin film deposition technique. One of most cited reasons for its popularity is that it enables the deposition of a broad range of materials which can be stoichiometrically transferred from target to substrate. However, in reality the exact distribution and nature of species being transferred and their influence on surface kinetics and growing film are still little known. The most generally adopted model is that the kinetic energy of the arriving species is the key parameter to determine the type of the growth mechanism [4, 5]. The relation between the ambient gas pressure and kinetic propagation characteristics of the expanding plasma plume is well-known: the plasma propagation behaviour evolves from thermalized to drag with increasing background gas pressure [6, 7]. The model suggests that the increased kinetic energy of the species at lower background gas pressures improves surface diffusion which is favourable to the crystallinity and the smoothness of the films [8, 9]. More recent work has shown that oxidation of the arriving species also plays a role in controlling the smoothness and stoichiometry of the grown films [10]. In the pressure range where the kinetic transition occurs, the authors investigated the $\mathrm{SrTiO}_{3}$ growth at varying oxygen pressure in the range from 0.01 mbar to 0.1 mbar. Oppositely to kinetic model, this work showed that stoichiometric and smooth films were obtained at higher oxygen pressures. The Titanium atoms are oxidized to $\mathrm{TiO}_{2}$ in the plasma plume at increased oxygen pressure and $\mathrm{Ti}^{4+}$ is the most steady oxidation state for Titanium. Based on previous studies of plasma chemistry and thin film growth, which were conducted at relatively high absolute oxygen pressure, the question addressed in this study is whether oxidation of species plays any role at much lower oxygen pressure. $\mathrm{SrVO}_{3}$ is a good material system to study the influence of the growth parameters on oxide thin film characteristics such as stoichiometry and surface morphology at a low oxygen pressure range. $\mathrm{SrVO}_{3}$ can only be grown in very low oxygen (partial) pressure since over-oxidized $\mathrm{V}^{5+}$ hampers perovskite $\mathrm{SrVO}_{3}$ 
to be formed. $\mathrm{V}^{4+}$ in $\mathrm{SrVO}_{3}$ has tendency to dismutate: $\mathrm{V}^{4+}$ can be over-oxidized to $\mathrm{V}^{5+}$ at high oxygen pressure and oxygen vacancies can also be formed under reducing conditions [11, 12]. $\mathrm{SrVO}_{3}$ recently gains a lot of attention due to its high electrical conductivity [12, 13]. Although $\mathrm{SrRuO}_{3}$ has been widely used as an electrode layer in oxide thin film heterostructure and this material fulfils most requirements in many applications [14-18], a much lower resistance is still desired for high frequency applications to reduce conduct losses. $\mathrm{SrVO}_{3}$ has also been studied recently as a transparent conductor [19] and has been widely studied in theoretical modes as a correlated system [20, 21]. To investigate whether the nature of species has an influence on the thin film growth at low oxygen pressure, we grew the $\mathrm{SrVO}_{3}$ films at varying total pressures or varying oxygen partial pressures.

\subsection{Experimental}

For a typical used target-to-substrate (T-S) distance of $50 \mathrm{~mm}$, the change in kinetic propagation behaviour of the species occurs above 0.01 mbar [7, 10]. At low oxygen pressure, an argon pressure was introduced to control the propagation of the expanding plasma plume. All of thin films were grown using a PLD system equipped with reflection high energy electron diffraction (RHEED). During growth all films were monitored using RHEED to study the growth kinetics and in-plane crystal structure. A thermal and chemical treatment was applied to achieve the single $\mathrm{TiO}_{2}$ terminated $\mathrm{SrTiO}_{3}(100)$ (STO) substrates [22]. A $\operatorname{KrF}$ excimer laser $(\lambda=248 \mathrm{~nm})$ at fluency of $2 \mathrm{~J} / \mathrm{cm}^{2}$ and 1 $\mathrm{Hz}$ repetition rate was used. Temperature was kept at $600{ }^{\circ} \mathrm{C}$. Four samples in the first set were grown in the argon pressures of $0.01 \mathrm{mbar}, 0.02 \mathrm{mbar}, 0.025 \mathrm{mbar}$ and 0.04 mbar with the same oxygen partial pressure of $1 \times 10^{-5}$ mbar. The second set of samples were deposited in the 0.025 mbar argon pressure with different oxygen partial pressures of $1 \times 10^{-6}$ mbar, $5 \times 10^{-6}$ mbar and $1 \times 10^{-5}$ mbar. With a constant background total pressure, and only varying the oxygen partial pressure, we should be able to separate the effects of oxidation and plasma species kinetics. The third set of samples were deposited at varying target-to-substrate (T-S) distance from $28 \mathrm{~mm}$ to $50 \mathrm{~mm}$ with a constant background argon pressure of $0.035 \mathrm{mbar}$ and partial oxygen pressure of $1 \times 10^{-5}$ mbar.

Atomic force microscopy (AFM) (Bruker) in tapping mode was used for characterizing the topography of the obtained films, which indicates the type of the growth mecha- 


\section{Chapter 5: Complex plume stoichiometry during pulsed laser deposition of}

$\mathrm{SrVO}_{3}$ at low oxygen pressures

nism. X-ray diffraction (XRD) (Xpert panalytical MRD) was used to characterize crystal structure of the thin films. The out-of-plane lattice constant can be derived by performing $2 \theta / \omega$ symmetrical scans around the (002) Bragg reflection of $\mathrm{SrTiO}_{3}$ substrate to indicate the stoichiometry of grown films. Transport properties were measured in the van der Pauw geometry using a Quantum Design Physical Properties Measurement System (QD PPMS) in the $2 \mathrm{~K}-300 \mathrm{~K}$ temperature range.

To correlate the changes in nature of species being transferred with crystallinity and smoothness of the films, optical emission spectroscopy (OES) measurements for the $\mathrm{SrVO}_{3}$ plume were performed at the thin film growth conditions. An intensified charge coupled device (ICCD) camera (Andor New iStar) connected with a spectrograph (Andor's Shamarock) was used to collect the data. The targets of $\mathrm{SrO}, \mathrm{V}_{2} \mathrm{O}_{5}$ and $\mathrm{V}_{2} \mathrm{O}_{3}$ were also inspected to get information about the individual element in $\mathrm{SrVO}_{3}$. The wavelength scale was calibrated using reference database[23]. We focus on the wavelength in the range from $470 \mathrm{~nm}$ to $530 \mathrm{~nm}$ for neutral Strontium and in the range from $600 \mathrm{~nm}$ to 640 $\mathrm{nm}$ for oxidized Vanadium. A bandpass of $257 \mathrm{~nm}$ and a spectral resolution of $1.5 \mathrm{~nm}$ can be obtained by using a $1024 \times 1024$ pixel array and a 300 lines/mm grating. Each spectrum was taken at different delay time $\tau$ after the target ablated.

\subsection{Results and discussion}

Figure 5.1 shows AFM images and the corresponding cross-section profiles of the samples grown at argon pressures ranging from 0.01 mbar to 0.04 mbar with the oxygen partial pressure of $1 \times 10^{-5}$ mbar. The insets correspond to the RHEED diffraction patterns in the [01] direction after growth. The films grown at pressures below 0.025 mbar have an island morphology and the step-terrace structure of the substrate is barely visible (see Figure 5.1 a) and (b)). The corresponding RHEED patterns are so-called streaky patterns which are indicative of a still relatively two dimensional flat and crystalline surface. The peak-to-peak height difference is about $0.5 \mathrm{~nm}$ for these films as seen in the cross section profiles. On the other hand, the step-terrace structure is more clearly observed for the film grown at $0.025 \mathrm{mbar}$ (shown in Figure 5.1.(c)). Presumably step-flow-like growth has occurred at the latter condition. The RHEED specular intensity versus time for this film supports step-flow-like growth. The cross-section profile shows that the peak-topeak height difference is about $1 \mathrm{~nm}$. This value is higher than that in the previous two 

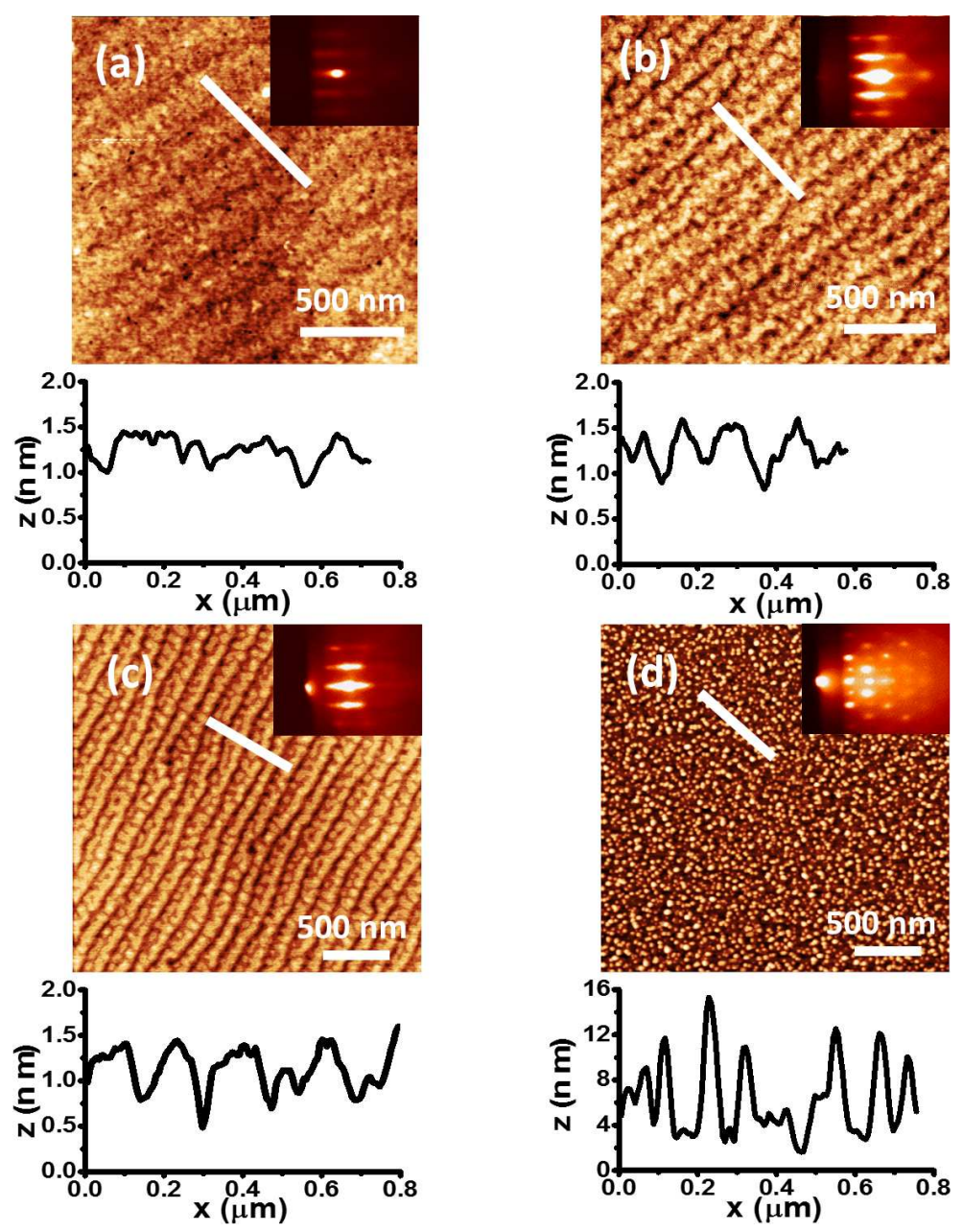

Figure 5.1: AFM images of $\mathrm{SrVO}_{3}$ thin film grown at the same oxygen partial pressure of $1 \times 10^{-5}$ mbar and varying argon background pressures of (a) $0.01 \mathrm{mbar}$, (b) 0.02 mbar, (c) 0.025 mbar and (d) 0.04 mbar. Each inset shows the RHEED pattern and a cross-section at each white line is shown below the AFM image. 


\section{Chapter 5: Complex plume stoichiometry during pulsed laser deposition of $\mathrm{SrVO}_{3}$ at low oxygen pressures}

samples, because in addition to the flat terraces, the image also reveals trenches at the edge of each terrace. Their origin is not fully understood, however, similar trenches have been seen in $\mathrm{SrRuO}_{3}$ thin films, which are related to the surface termination [14]. Finally, Figure 5.1. (d) shows that 3D islands are formed for the film deposited at 0.04 mbar, with heights of more than $4 \mathrm{~nm}$. It is also confirmed by RHEED showing a 3D transmission pattern.

Figure 5.2 shows AFM images of the films grown at varying oxygen partial pressures of $1 \times 10^{-6}$ mbar, $5 \times 10^{-6}$ mbar and $1 \times 10^{-5}$ mbar with the constant argon pressure of 0.025 mbar. AFM images show a layer-by-layer growth mode for the film grown at the $1 \times 10^{-6}$ mbar and $5 \times 10^{-6}$ mbar. At $1 \times 10^{-6}$ mbar, Figure 5.2 (a) shows that the initial terrace morphology of the substrate surface is still visible. However the morphology consists of very small islands on the terraces. The islands are too small to cover the terrace edge in the substrate. The cross-section profile shows that the peak-to-peak difference is about $1 \mathrm{~nm}$. The inset RHEED pattern shows a streaky pattern. The arriving species are more likely to be nucleated in Figure 5.2 (b). The size of islands in Figure 5.2 (b) is larger than that of islands in Figure 5.2 a). The large islands are easily to cover the terrace edges, causing substrate imprint is absent. The peak-to-peak difference is $1 \mathrm{~nm}$ as shown in the cross-section profile. The inset RHEED pattern also shows a so-called streaky pattern. Figure 5.2 (c), the same image as shown in Figure 5.1. (c), shows a clear step-terrace structure for the film grown at $1 \times 10^{-5}$ mbar. This is an evidence for a step-flow-like growth mode. The kikuchi lines are visible in the corresponding RHEED pattern, which indicates a highly-ordered surface.

Figure 5.3 shows AFM images and the corresponding cross-section profiles of the films grown at varying target-to-substrate (T-S) distance of $50 \mathrm{~mm}, 44 \mathrm{~mm}, 42 \mathrm{~mm}$ and $28 \mathrm{~mm}$. The oxygen partial pressure of $1 \times 10^{-5} \mathrm{mbar}$ and the argon pressure of 0.035 mbar (higher than the optimal value) were kept constant. Small islands are formed for the film grown at the T-S distance of $50 \mathrm{~mm}$ and $44 \mathrm{~mm}$ (Figure 5.3 (a) and (b)). The peak-to-peak height difference, as shown in the corresponding cross-section profiles, is 6 $\mathrm{nm}$ and $3 \mathrm{~nm}$ respectively. The smooth surface with the terrace stepped morphology was observed for the film grown at the T-S distance of $42 \mathrm{~mm}$ (Figure 5.3 (c)). Presumably the step-flow-like growth has occurred at this condition, which is similar as that for the film deposited at 0.025 mbar argon pressure with the T-S distance of $50 \mathrm{~mm}$. The peakto-peak height difference is about $0.5 \mathrm{~nm}$ as shown in the cross-section profile. The 

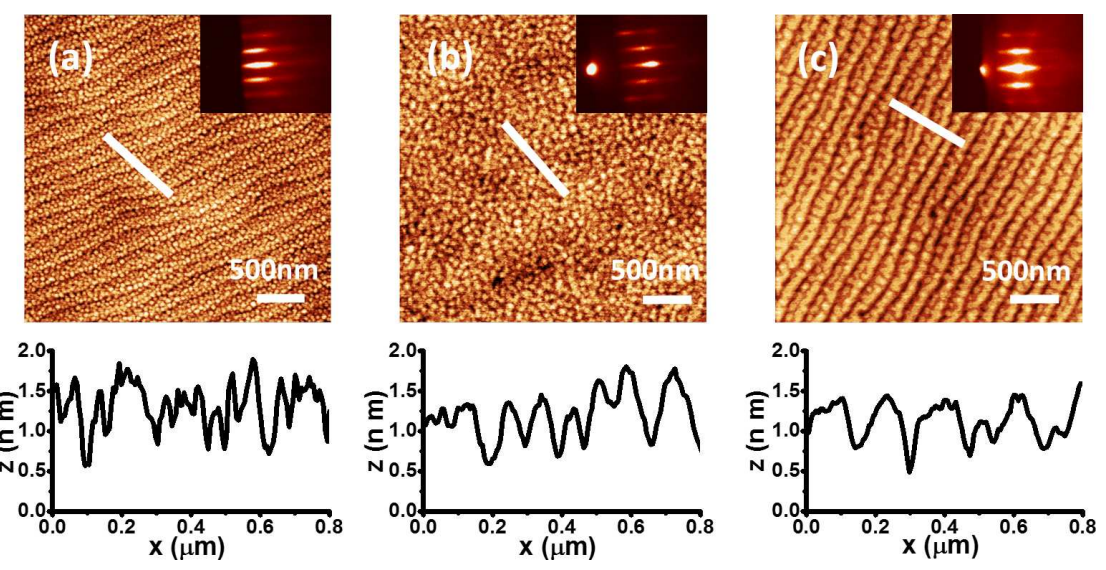

Figure 5.2: AFM images of $\mathrm{SrVO}_{3}$ thin film grown at oxygen partial pressures of (a) $1 \times 10^{-6}$ mbar, (b) $5 \times 10^{-6}$ mbar and (c) $1 \times 10^{-5}$ mbar with the same argon pressure of 0.025 mbar. Each inset shows the RHEED pattern and a cross-section at each white line is shown below the AFM image.

surface morphology of the film obtained at the T-S distance of $28 \mathrm{~mm}$ (Figure 5.3. (d)) is comparable to that of the film grown at 0.01 mbar argon pressure in the first set. The stepped terrace structure is barely visible and the peak-to-peak height difference is about $0.5 \mathrm{~nm}$.

Figure 5.4 a) shows XRD 001 scans around the (002) Bragg reflection of $\mathrm{SrTiO}_{3}$ for the films grown at varying argon pressures. AFM images of these samples were shown in Figure 5.1. The (002) film peaks of $\mathrm{SrVO}_{3}$ are indicated by black arrows. The measurements are fitted using the Stepanov model for quantitative analysis [24] and the corresponding out-of-plane lattice parameters are shown in Table 5.1. The reciprocal mapping around $\mathrm{SrTiO}_{3}$ (103) (See Figure 5.4(d)) shows that the $\mathrm{SrVO}_{3}$ film is fully in-plane strained by the $\mathrm{SrTiO}_{3}$ substrate. The equi-biaxial strain in the film plane due to lattice mismatch between STO (3.905 $⿱$ ) and SVO (3.842 $\AA$ ) is $1.64 \%$. Assuming the possion's ratio for $\mathrm{SVO}$ is 0.28 [12], the expected out-of-plane lattice parameter for stoichiometric SVO film is $3.793 \AA$. An increase of the film c-axis length corresponds to an increase unit cell volume which is caused by cation nonstoichiometry or point defects in the lattice [10, 12]. As the out-of-plane lattice parameter decreases with the increasing argon pressure, the film grown at higher pressure is closer to stoichiometry. The Laue fringes around the films peaks originating from the coherence between individual layers in the film are observed for the film grown at $0.01 \mathrm{mbar}, 0.02 \mathrm{mbar}$ and $0.025 \mathrm{mbar}$, which also 
Chapter 5: Complex plume stoichiometry during pulsed laser deposition of $\mathrm{SrVO}_{3}$ at low oxygen pressures
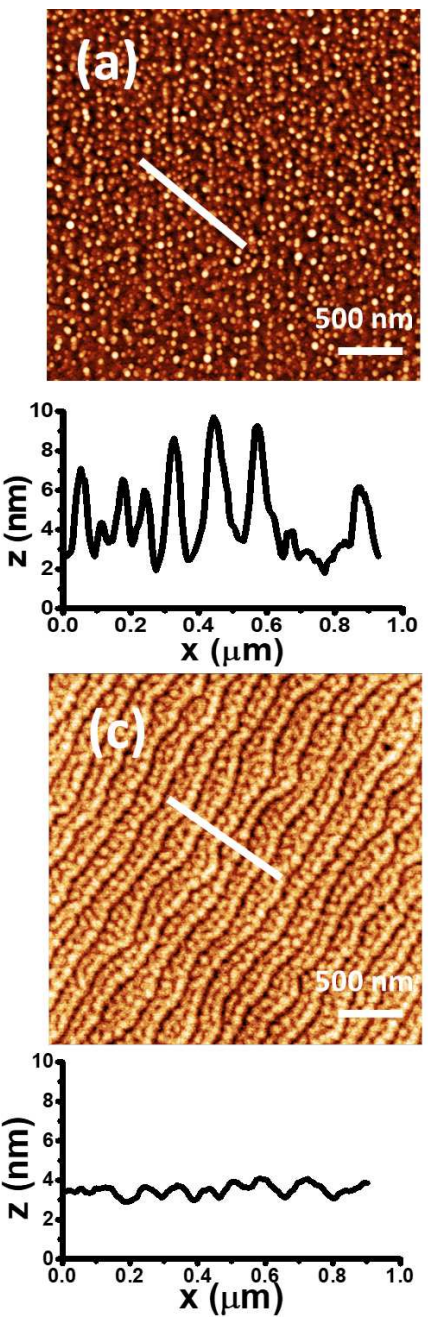
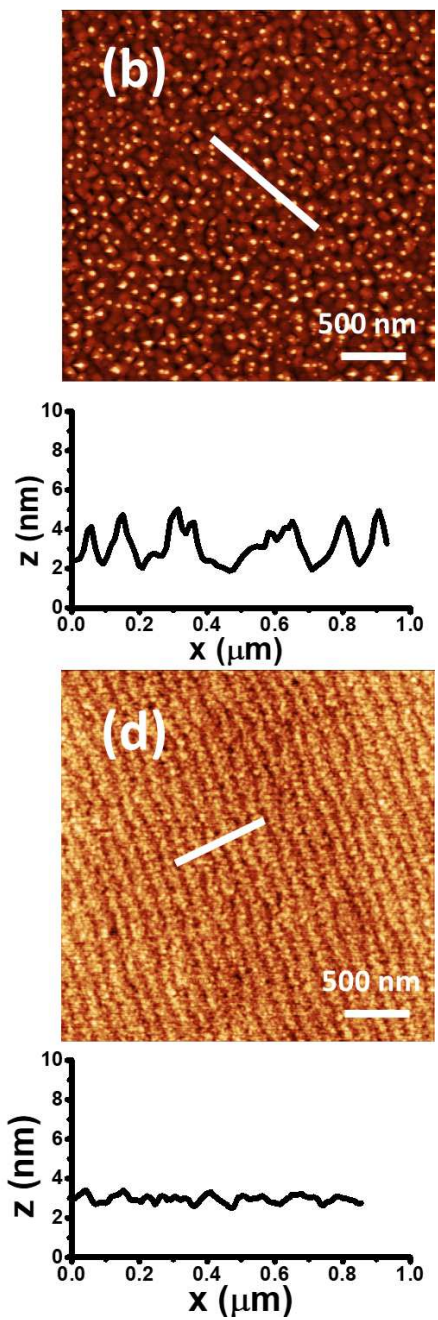

Figure 5.3: AFM images of $\mathrm{SrVO}_{3}$ thin film grown at total argon pressure of 0.035 mbar and oxygen partial pressures of $1 \times 10^{-5}$ mbar. The target-to-substrate distance was set at $50 \mathrm{~mm}$, (b) $44 \mathrm{~mm}$,(c) $42 \mathrm{~mm}$ and (d) $28 \mathrm{~mm}$. The cross-section of white line is shown below the each AFM image. 

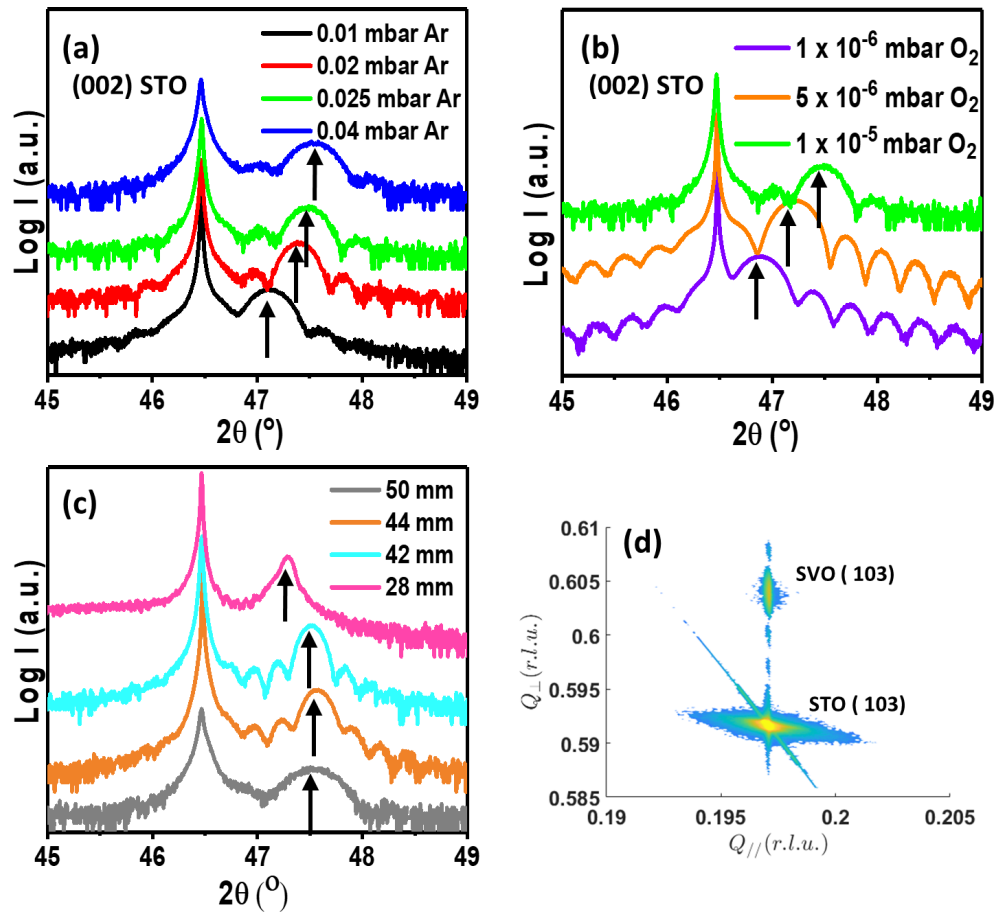

Figure 5.4: XRD 001 scans around the (002) Bragg reflection of the $\mathrm{SrTiO}_{3}$ for $\mathrm{SrVO}_{3}$ thin film grown at (a) oxygen partial pressure of $1 \times 10^{-5}$ mbar with varying argon pressures, (b) at argon pressure of 0.025 mbar with varying oxygen partial pressures and (c) at varying target-to-substrate distance. $\mathrm{SrVO}_{3}$ film peaks are indicated by black arrows. 


\section{Chapter 5: Complex plume stoichiometry during pulsed laser deposition of}

$\mathrm{SrVO}_{3}$ at low oxygen pressures

Table 5.1: Overview lattice parameters and thickness derived from the XRD scans for all samples.

\begin{tabular}{ccccc}
$\mathrm{P}_{\mathrm{Ar}} / \mathrm{P}_{\mathrm{O}_{2}}(\mathrm{mbar})$ & $\mathrm{D}_{\mathrm{T}-\mathrm{S}}(\mathrm{mm})$ & $\mathrm{C}_{\mathrm{axis}}(\AA)$ & $\mathrm{d}(\mathrm{nm})$ & No. of Pulses \\
\hline $0.01 / 1 \times 10^{-5}$ & 50 & $3.853 \pm 0.001$ & $31.0 \pm 0.5$ & 900 \\
$0.02 / 1 \times 10^{-5}$ & 50 & $3.833 \pm 0.001$ & $34.0 \pm 0.2$ & 950 \\
$\mathbf{0 . 0 2 5} / \mathbf{1} \times \mathbf{1 0}^{-\mathbf{5}}$ & $\mathbf{5 0}$ & $\mathbf{3 . 8 2 6} \pm \mathbf{0 . 0 0 1}$ & $\mathbf{3 1 . 0} \pm \mathbf{0 . 2}$ & $\mathbf{9 0 0}$ \\
$0.04 / 1 \times 10^{-5}$ & 50 & $3.819 \pm 0.001$ & $30.0 \pm 0.5$ & 900 \\
$0.025 / 1 \times 10^{-6}$ & 50 & $3.870 \pm 0.001$ & $30.0 \pm 0.2$ & 900 \\
$0.025 / 5 \times 10^{-6}$ & 50 & $3.846 \pm 0.001$ & $30.0 \pm 0.2$ & 900 \\
$0.035 / 1 \times 10^{-5}$ & 50 & $3.819 \pm 0.001$ & $30.0 \pm 0.5$ & 900 \\
$0.035 / 1 \times 10^{-5}$ & 44 & $3.819 \pm 0.001$ & $41.0 \pm 0.2$ & 900 \\
$\mathbf{0 . 0 3 5 / 1} \times \mathbf{1 0}^{-\mathbf{5}}$ & $\mathbf{4 2}$ & $\mathbf{3 . 8 2 3} \pm \mathbf{0 . 0 0 1}$ & $\mathbf{4 4 . 0} \pm \mathbf{0 . 2}$ & $\mathbf{9 0 0}$ \\
$0.035 / 1 \times 10^{-5}$ & 28 & $3.847 \pm 0.001$ & $90 \pm 1$ & 450
\end{tabular}

indicate a high degree of crystallinity. The thickness $d$ of the grown film, listed in Table 5.1. can also be derived from the spacing of the Laue fringes.

Figure 5.4 (b) shows the XRD 001 measurement of films grown at varying oxygen partial pressures. AFM images of these samples were shown in Figure 5.2 The out-ofplane lattice parameter and the thickness for the obtained films are shown in Table 5.1 using the same fitting algorithm. Again, an increased thin film c-axis length corresponds to an unit cell volume increased which results from point defects in the lattice. The XRD results suggest that the films grown in increasing oxygen partial pressure get closer to stoichiometric composition. Figure 5.4 (c) shows the XRD 001 scan of the films grown at varying target-to-substrate distance. AFM images of these samples were shown in Figure 5.3 . The (002) film peaks of SVO are clearly present and indicated by black arrows. The corresponding out-of-plane lattice parameter and the thickness for grown films are listed in Table 5.1 as well. The increased c-axis length of the film deposited at distance of 28 $\mathrm{mm}$ is caused by cation nonstoichiometry or point defects in the lattice. The c-axis length of the film grown at $42 \mathrm{~mm}$ is similar as that of the film grown at $50 \mathrm{~mm}$ with 0.025 mbar argon pressure and $1 \times 10^{-5}$ oxygen partial pressure. The thickness of the films increases with decreasing target-to-substrate distance because more material arrives on the substrate at each pulse.

The temperature dependence of electrical resistivity was measured in the temperature range $2 \mathrm{~K}-300 \mathrm{~K}$, as shown in Figure 5.5. a), (b) and (c). All the samples show metallic behaviour: the resistivity decreases with decreasing temperature. Furthermore, 

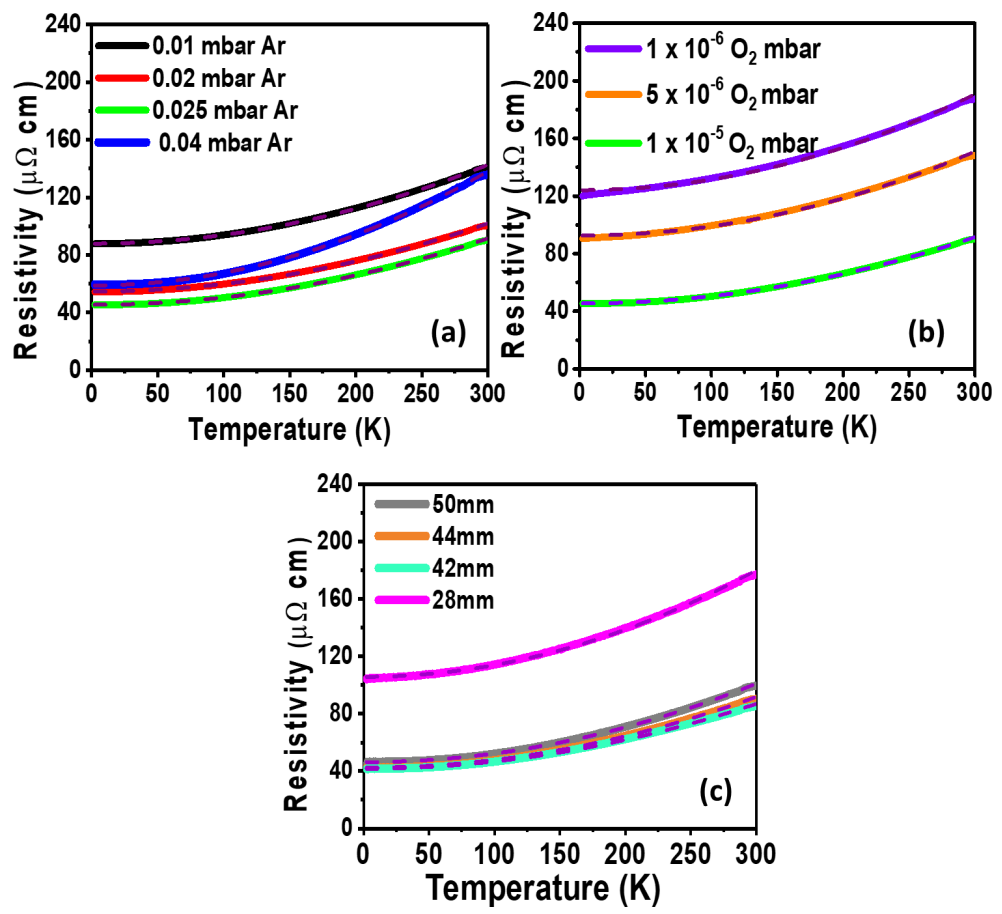

Figure 5.5: Temperature dependent resistivity $\rho$ for deposited $\mathrm{SrVO}_{3}$ films grown at (a) varying argon pressures (b) at varying oxygen partial pressures and (c) at varying target-to-substrate distance. The purple dashed line shows the fitting of $\rho=\rho_{0}+\mathrm{AT}^{2}$ for each film. 
Table 5.2: Overview electrical properties for all samples.

\begin{tabular}{ccccc}
$\mathrm{P}_{\mathrm{Ar}} / \mathrm{P}_{\mathrm{O}_{2}}(\mathrm{mbar})$ & $\mathrm{D}_{\mathrm{T}-\mathrm{S}}(\mathrm{mm})$ & $\rho_{0}(\mu \Omega \mathrm{cm})$ & $\mathrm{A}\left(\times 10^{-10} \Omega \mathrm{cm} \mathrm{K}^{-2}\right)$ & $\rho_{300 \mathrm{k}} / \rho_{2 \mathrm{~K}}$ \\
\hline $0.01 / 1 \times 10^{-5}$ & 50 & 86.2 & 5.95 & 1.61 \\
$0.02 / 1 \times 10^{-5}$ & 50 & 51.3 & 5.42 & 1.83 \\
$\mathbf{0 . 0 2 5 / 1} \times \mathbf{1 0}^{-\mathbf{5}}$ & $\mathbf{5 0}$ & $\mathbf{4 3 . 9}$ & $\mathbf{4 . 9 6}$ & $\mathbf{1 . 9 9}$ \\
$0.04 / 1 \times 10^{-5}$ & 50 & 46.3 & 6.08 & 2.14 \\
$0.025 / 1 \times 10^{-6}$ & 50 & 124.1 & 7.40 & 1.56 \\
$0.025 / 5 \times 10^{-6}$ & 50 & 92.5 & 6.48 & 1.63 \\
$0.035 / 1 \times 10^{-5}$ & 50 & 46.3 & 6.08 & 2.14 \\
$0.035 / 1 \times 10^{-5}$ & 44 & 42.4 & 5.49 & 2.13 \\
$\mathbf{0 . 0 3 5 / 1} \times \mathbf{1 0}^{-\mathbf{5}}$ & $\mathbf{4 2}$ & $\mathbf{4 1 . 7}$ & $\mathbf{5 . 0 2}$ & $\mathbf{2 . 0 5}$ \\
$0.035 / 1 \times 10^{-5}$ & 28 & 105.8 & 8.25 & 1.70
\end{tabular}

the electrical resistivity as a function of temperature can be fitted by a $\rho=\rho_{0}+\mathrm{AT}^{2}$ relation (see purple dashed line), which is characteristic of a Fermi liquid behaviour. The fitting parameters are reported in Table 5.2. The lowest resistivity of $85 \mu \Omega \mathrm{cm}$ at room temperature is obtained for the films with the smoothest surface and the best stoichiometry, which are grown at 0.025 mbar argon pressure with the oxygen partial pressure of $1 \times 10^{-5}$ mbar at T-S distance of $50 \mathrm{~mm}$ and grown at $0.035 \mathrm{mbar}$ argon pressure with oxygen partial pressure of $1 \times 10^{-5}$ mbar at T-S distance of $42 \mathrm{~mm}$. In order to be able to convincingly exclude a contribution from the substrate, a bare STO substrate, which has been subjected to growth conditions of SVO, but without the actual deposition taking place, was measured by insulation tester (Fluke 1507). The sample remained highly insulating with resistivity of $146 \mathrm{M} \Omega \mathrm{cm}$. In addition, the same SVO thin film has been grown on $\left(\mathrm{LaAlO}_{3}\right)_{0.3}\left(\mathrm{Sr}_{2} \mathrm{AlTa}_{6}\right)_{0.7}$ (LSAT) substrate, a material that should not be reducible under any condition, at the optimal growth conditions. The resistivity of the film at room temperature is about $65 \mu \Omega \mathrm{cm}$, which is even lower than the resistivity of the film grown on the STO substrate due to the less lattice mismatch $(90 \mu \Omega \mathrm{cm})$. We think this data can also be a strong evidence to rule out the contribution from the STO substrate.

To investigate the composition of the plasma plume at varying growth conditions, optical emission spectroscopy (OES) measurement was performed on the expanding plume. Although these measurements only interpret the results qualitatively, they can still indicate the relative abundance of species in different growth conditions. To help identifying the spectrum for individual elements $\left(\mathrm{Sr}\right.$ and $\mathrm{V}$ ) in $\mathrm{SrVO}_{3}$, plasma using different targets of $\mathrm{V}_{2} \mathrm{O}_{3}, \mathrm{~V}_{2} \mathrm{O}_{5}$ and $\mathrm{SrO}$ were imaged (shown in Figure 5.6. The original optical emis- 
sion spectroscopy data of the $\mathrm{V}_{2} \mathrm{O}_{3}$ plume at $\tau=4.5 \mu$ s in 0.025 mbar argon pressure is shown in Figure 5.6.a). The spectra are normalized by the maximum intensity of each plume expanding at 0.04 mbar and are shown in Figure 5.6 b), (c) and (d). In the plume of $\mathrm{V}_{2} \mathrm{O}_{3}, \mathrm{~V}_{2} \mathrm{O}_{5}$ (Figure 5.6 (b) and (c)), the peak at wavelength of about $620 \mathrm{~nm}$ is present after $4.5 \mu \mathrm{s}$. In Figure 5.7(d), the intensity of peaks at wavelength between $470 \mathrm{~nm}$ and $530 \mathrm{~nm}$ reduces after $5.5 \mu \mathrm{s}$. The images of $\mathrm{V}_{2} \mathrm{O}_{3}, \mathrm{~V}_{2} \mathrm{O}_{5}$ and $\mathrm{SrO}$ indicate that the spectra at wavelength between $470 \mathrm{~nm}$ and $530 \mathrm{~nm}$ corresponds to neutral Strontium and the spectra at wavelength between $600 \mathrm{~nm}$ and $640 \mathrm{~nm}$ corresponds to oxidized Vanadium.

The spectra of the oxidized Vanadium in the plasma plume of the $\mathrm{SrVO}_{3}$ target are normalized by the maximum intensity of the plume expanding at $0.04 \mathrm{mbar}$, as shown in Figure 5.7 The $\mathrm{SrVO}_{3}$ was ablated at varying total argon pressures of $0.01 \mathrm{mbar}$, 0.025 mbar and 0.04 mbar with the same oxygen partial pressure of $1 \times 10^{-5}$ mbar. At $\tau=1.5 \mu \mathrm{s}$, the intensity of all peaks corresponding to oxidized Vanadium are very low, since the species in plume mostly are neutral just after the target to be ablated. For the measurement at $0.01 \mathrm{mbar}$, the intensity of the peak at wavelength of $620 \mathrm{~nm}$ is not changing over time (see black line). At 0.025 mbar and 0.04 mbar, presented in red and blue line, the intensity of peak at $620 \mathrm{~nm}$ is rapidly increasing after $4.5 \mu \mathrm{s}$. At $\tau=5.5 \mu \mathrm{s}$, the intensity of this peak for 0.04 mbar is higher than that of the peak for 0.025 mbar (see blue and red lines). The amount of the oxidized Vanadium in the plume increases with the total argon pressure increasing. This phenomenon is likely to be caused by the plume confinement due to scattering resulting from the argon pressure increasing. In addition, the plume expands more slowly at higher pressure, causing more species to be oxidized in the plasma plume.

The results from the structural investigation and plasma plume analysis show the relation between the thin film characteristics and the species in the plume. The XRD characterization shows that the c-axis of the grown films was dependent on the total argon pressure. It indicates that the stoichiometry of the thin films is the function of the total pressure increasing. The growth kinetics was indicated by surface morphology study using AFM. At 0.025 mbar argon pressure, presumably step-flow-like growth mode has occurred, implying the improved surface diffusivity at this condition. However, the 3D growth mode occurred for the film grown at 0.04 mbar, indicating the limited mobility of particles at the substrate. The optimal room temperature resistivity of $85 \mu \Omega \mathrm{cm}$ was obtained for the film with the optimal crystalline structure and smooth surface morphology. 
(a)

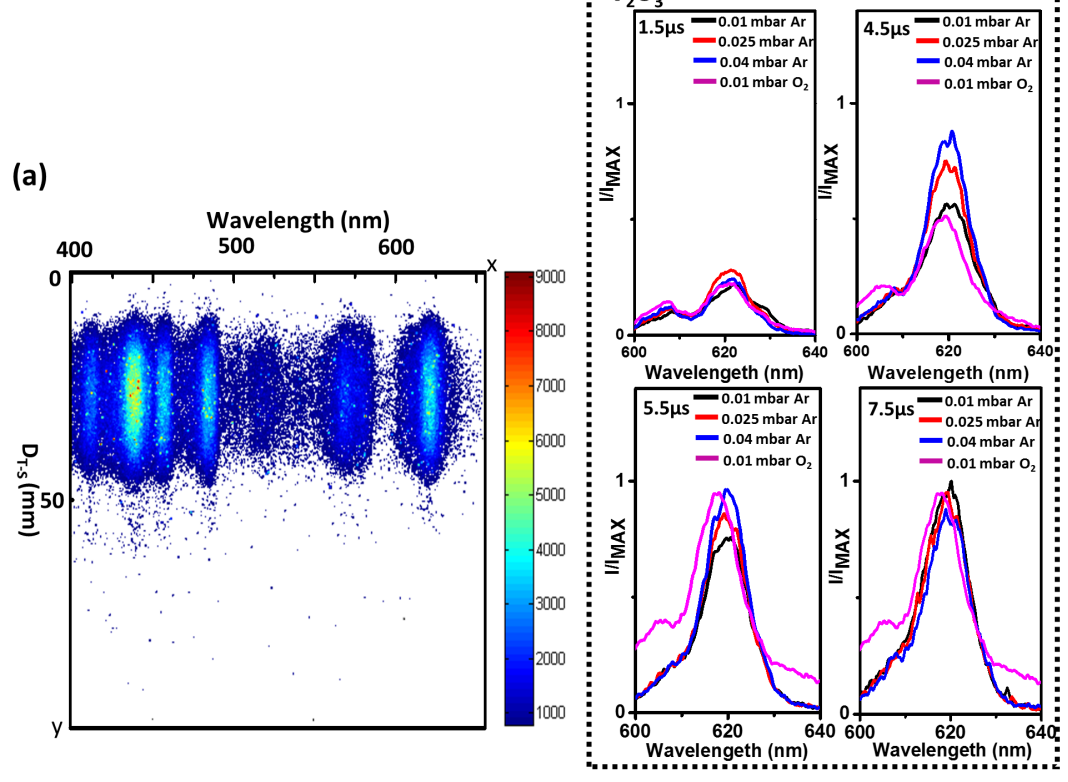

(b) $\mathrm{v}_{2} \mathrm{O}_{3}$

(c)

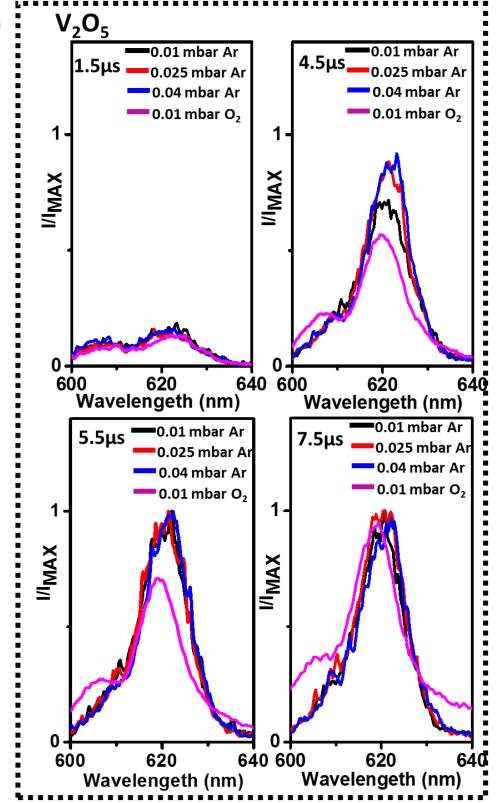

(d) $\mathrm{Sro}$

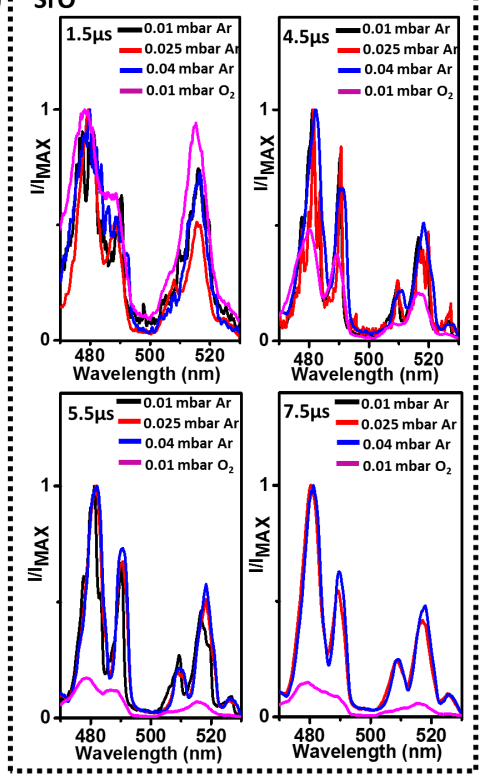

Figure 5.6: (a) The original optical emission spectroscopy data of the $\mathrm{V}_{2} \mathrm{O}_{3}$ plume at $\tau$ $=4.5 \mu \mathrm{s}$ in $0.025 \mathrm{mbar}$ argon pressure. The normalized spectra at wavelength in between $600 \mathrm{~nm}$ and $640 \mathrm{~nm}$ for the $\mathrm{V}_{2} \mathrm{O}_{3}$ and $\mathrm{V}_{2} \mathrm{O}_{5}$ plume are shown in (b) and (c) respectively. (d) is normalized spectra of $\mathrm{SrO}$ plume at wavelength in between $470 \mathrm{~nm}$ and $530 \mathrm{~nm}$. 


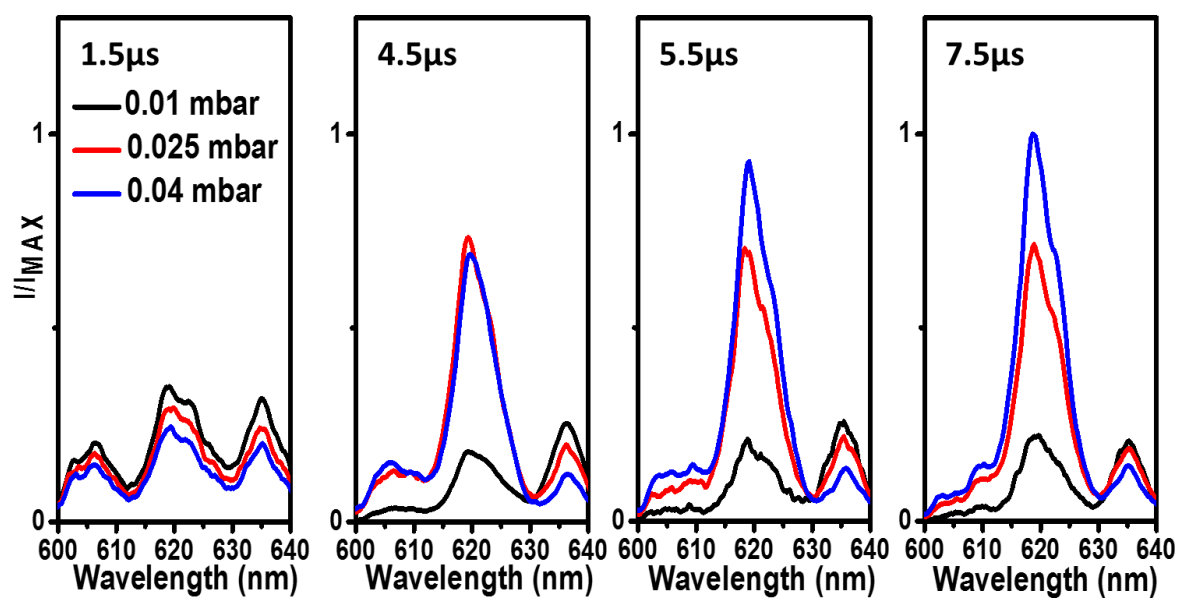

Figure 5.7: The normalized spectra of the oxidized Vanadium in the plasma plume expanding of the $\mathrm{SrVO}_{3}$ target.

The spectrum analysis indicates that the oxidized Vanadium in the plume was formed when the pressure increased to 0.025 mbar. An increased amount of oxidized species was observed at pressure of 0.04 mbar. These correlations strongly suggest that the oxidized species in plasma plume is a necessary requirement for stoichiometric growth thin film of $\mathrm{SrVO}_{3}$. The amount of oxidized species determine the surface diffusivity at the substrate for the films grown with the optimal at argon pressure of 0.025 mbar. Apparently, an excess of oxidized species at an argon pressure of 0.04 mbar can cause the over-oxidation. We speculate that mostly 4+ Vanadium is necessary to obtain the perovskite phase of $\mathrm{SrVO}_{3}$. The kinetic model proposed in previous works assume that the diffusion activation energy increases with increasing pressure [8, 9]. The model assumes that changing kinetic of arriving species affects the relaxation of the substrate. However, in this work surface smoothening and stoichiometric improvement are observed with the increasing background pressure up to 0.025 mbar. Therefore, we suggest that the enhanced surface diffusivity and improved stoichiometry are also dependent on oxidation of arriving species. A similar transition in the thin film stoichiometry and the surface morphology is observed for the films grown at varying oxygen partial pressures with the total pressure of 0.025 mbar. Since the kinetic energy is not changing, this supports the model of having the oxidation of arriving species to be an important parameter to affect the thin film growth. This suggests that oxidation of arriving species could determine the surface diffusion energies, but also could play a role in the competition between the formation 


\section{Chapter 5: Complex plume stoichiometry during pulsed laser deposition of $\mathrm{SrVO}_{3}$ at low oxygen pressures}

of different phases, either through preferred nucleation or kinetically enhanced growth of island. These are topics for future investigations.

To further substantiate this model, the structural property and surface morphology of the film grown at varying target-to-substrate (T-S) distances are are shown in Figure 5.3 and Figure 5.4 (c). The total argon pressure and the oxygen partial pressure was kept at $0.035 \mathrm{mbar}$ (higher than the optimal pressure observed in previous experiments) and $1 \times$ $10^{-5}$ mbar respectively. We observed the similar transition in the thin film stoichiometry and the surface morphology with increasing the T-S distance. An non-stoichiometry film was obtained at $28 \mathrm{~mm}$. The step-flow-like growth occurred at the film grown at 42 $\mathrm{mm}$, indicating the improved surface diffusivity by oxidized species. The 3D islands are observed for the film grown at $50 \mathrm{~mm}$, implying an excess of the oxidized species. The film grown at $42 \mathrm{~mm}$ with the smoothest surface and the best crystallinity has the lowest resistivity. The plasma plume study suggests that the amount of oxidized species in the plume increase with the plume propagation from the target to the substrate at this pressure (Figure 5.6. This result also supports that surface diffusivity and film stoichiometry is dependent on oxidation of the arriving species at the substrate.

\subsection{Conclusion}

From the correlation between the thin films properties determined by AFM and XRD and plasma plume composition analysed by OES measurements, we conclude that the surface diffusivity, growth kinetic and the films stoichiometry are controlled by oxidation of arriving species. At reducing oxygen pressures, the spectrum of expanding plume indicates that the oxidation species in the plasma plume can be controlled by the total argon pressure, which in turn controls the quality of the thin films, including the electrical properties of $\mathrm{SrVO}_{3}$. 


\section{Bibliography}

[1] M. Imada, A. Fujimori, and Y. Tokura, Reviews of Modern Physics 70, 1039 (1998).

[2] I. H. Inoue and M. J. Rozenberg, Advanced Functional Materials 18, 2289 (2008),

[3] H. W. Jang, A. Kumar, S. Denev, M. D. Biegalski, P. Maksymovych, C. W. Bark, C. T. Nelson, C. M. Folkman, S. H. Baek, N. Balke, C. M. Brooks, D. A. Tenne, D. G. Schlom, L. Q. Chen, X. Q. Pan, S. V. Kalinin, V. Gopalan, and C. B. Eom, Physical Review Letter 104, 197601 (2010).

[4] G. Koster, G. J. H. M. Rijnders, D. H. A. Blank, and H. Rogalla, Applied Physics Letters 74, 3729 (1999).

[5] D. H. Blank, G. Koster, G. A. Rijnders, E. van Setten, P. Slycke, and H. Rogalla, Journal of Crystal Growth 211, 98 (2000).

[6] S. Amoruso, A. Sambri, and X. Wang, Journal of Applied Physics 100, 013302 (2006)

[7] D. B. Geohegan, Thin Solid Films 220, 138 (1992).

[8] P. R. Willmott, R. Herger, C. M. Schlepütz, D. Martoccia, and B. D. Patterson, Physical Review Letter 96, 176102 (2006)

[9] J. E. Boschker, E. Folven, s. F. Monsen, E. Wahlström, J. K. Grepstad, and T. Tybell, Crystal Growth \& Design 12, 562 (2012).

[10] R. Groenen, J. Smit, K. Orsel, A. Vailionis, B. Bastiaens, M. Huijben, K. Boller, G. Rijnders, and G. Koster, APL Materials 3, 070701 (2015).

[11] S. Hui and A. Petric, Solid State Ionics 143, 275 (2001).

[12] J. A. Moyer, C. Eaton, and R. Engel-Herbert, Advanced Materials 25, 3578 (2013).

[13] Y. Lan, X. Chen, and M. He, Journal of Alloys and Compounds 354, 95 (2003).

[14] G. Koster, L. Klein, W. Siemons, G. Rijnders, J. S. Dodge, C.-B. Eom, D. H. A. Blank, and M. R. Beasley, Reviews of Modern Physics 84, 253 (2012) 
[15] Y. Kozuka, Y. Hikita, C. Bell, and H. Y. Hwang, Applied Physics Letters 97, 012107 (2010).

[16] A. Vailionis, W. Siemons, and G. Koster, Applied Physics Letters 93, 051909 (2008)

[17] M. Hiratani, C. Okazaki, K. Imagawa, and K. Takagi, Japanese Journal of Applied Physics 35, 6212 (1996).

[18] G. Herranz, V. Laukhin, F. Sánchez, P. Levy, C. Ferrater, M. V. García-Cuenca, M. Varela, and J. Fontcuberta, Physical Review B 77, 165114 (2008).

[19] L. Zhang, Y. Zhou, L. Guo, W. Zhao, A. Barnes, H. Zhang, C. Eaton, Y. Zheng, M. Brahlek, H. F. Haneef, N. J. Podraza, M. H. W. Chan, V. Gopalan, K. M. Rabe, and R. Engel-Herbert, Nature Materials 15 (2016).

[20] K. Yoshimatsu, K. Okabe, H. Kumigashira, S. Okamoto, S. Aizaki, A. Fujimori, and M. Oshima, Physical Review Letters 104 (2010).

[21] K. Yoshimatsu, K. Horiba, H. Kumigashira, T. Yoshida, A. Fujimori, and M. Oshima, Science 333, 319 (2011).

[22] G. Koster, B. L. Kropman, G. J. H. M. Rijnders, D. H. A. Blank, and H. Rogalla, Applied Physics Letters 73, 2920 (1998).

[23] Nist atomic spectra database lines form, https://physics.nist.gov/ .

[24] S. Stepanov, E. Kondrashkina, R. Köhler, D. Novikov, G. Materlik, and S. Durbin, Physical Review B 57, 4829 (1998). 


\title{
Chapter 6
}

\section{Dimensional-crossover-driven}

\section{Metal-insulator transition in}

\section{ultrathin $\mathrm{SrVO}_{3}$ films and}

\section{$\mathrm{SrVO}_{3} / \mathrm{SrTiO}_{3}$ superlattices}

\begin{abstract}
The metal-insulator transition (MIT) in strongly correlated oxides is a topic of great interest for their potential applications, such as Mott field effect transistors and sensors. Here we report the dimensional-driven MIT in high quality epitaxial $\mathrm{SrVO}_{3}$ (SVO) thin films grown by pulsed laser deposition. The critical thickness of 3 unit cells was achieved by suppressing stoichiometric effect under optimal growth conditions and excluding any surface effects by a $\mathrm{SrTiO}_{3}$ (STO) capping layer. The conductivity of SVO thin film embedded in SVO/STO superlattices is enhanced. We interpret that this conductivity enhancement is due to the interlayer coupling between SVO sublayers in the superlattice. This coupling effect is suppressed by increasing the thickness of STO sublayers in the superlattice. Magnetoresistance and Hall measurements indicate that the dominant driving force of MIT is the electron-electron interaction.
\end{abstract}




\subsection{Introduction}

Transition metal oxides are one of the most interesting classes of functional materials. The complex interplay between spin, charge and orbital generates a broad range of electrical and magnetic properties [1, 2]. Physical properties, which are different from those exhibited in their corresponding bulk forms, can emerge by introducing interface, surface, strain, and reduced dimensionality [3-6]. The most well known system, $\mathrm{LaAlO}_{3} / \mathrm{SrTiO}_{3}$, exhibits two dimensional electron gas with high mobility at the interface between two band-insulator [7]. The metal-insulator transition (MIT) in strongly correlated oxides has received a lot of interest. It has the potential to be used for novel electronic devices, such as Mott field effect transistors and sensors [8].

High conductivity has been reported for the $\mathrm{SrVO}_{3}(\mathrm{SVO})$ thin films. This material with a $3 \mathrm{~d}^{1}$ electronic configuration for Vanadium is a model strongly correlation system for studying MIT [9, 10]. According to the Mott-Hubbard theory, two controllable parameters for a Mott transition are filling control and bandwidth control [11]. In the filling-controlled MIT (FC-MIT), the chemical doping of a Mott insulator with half-filled band results in a transition to the metal. Previous study have demonstrated that the FCMIT could be induced in the $\mathrm{La}_{1-\mathrm{x}} \mathrm{Sr}_{\mathrm{x}} \mathrm{VO}_{3}$ by A-site substitution [12, 13]. Bandwidth controlled MIT system is determined by the competition between the on-site Coulomb repulsion $\mathrm{U}$ and the electronic bandwidth $\mathrm{W}$. The Mott transition occurs when $\mathrm{U} / \mathrm{W}$ is beyond a critical value. In perovskites, the bandwidth is affected by the angle of oxygen ions with the transition metal ion, and the bond length between the oxygen ion and the transition metal ion. The study of $\mathrm{Ca}_{1-\mathrm{x}} \mathrm{Sr}_{\mathrm{x}} \mathrm{VO}_{3}$ has shown that the bandwidth can be controlled by chemical A-site substitution with different ionic radius [14]. The angle of $\mathrm{V}-\mathrm{O}-\mathrm{V}$ is reduced from $180^{\circ}$ to $160^{\circ}$ by replacing $\mathrm{Sr}$ with $\mathrm{Ca}$ in $\mathrm{SrVO}_{3}$, resulting in the MIT.

The other approach to control the bandwidth is dimensional crossover by reducing the thickness of the films. The thickness at which the insulating behaviour occurs in the ground state is critical thickness $\left(t_{c}\right)$. Ultrathin SVO films have been studied by in situ photoemission spectroscopy (PES). The evolution of the electronic structure of SVO thin films has been observed. It is showed that a Mott-Hubbard band gap opening at the Fermi level is formed for the film with a thickness of 2-3 unit cells (u.c.). The insulating state was driven by the reduction of the bandwidth due to a dimensional crossover [15]. 
More recent works studied the MIT of SVO ultrathin films at dimensional crossover by ex situ transport measurements. The MIT transition occurred at $200 \mathrm{~K}$ for the film grown by $\mathrm{Gu}$ et al. with a thickness of $3 \mathrm{~nm}[16]$. Fouchet et al. have found the insulating behaviour in the temperature range from $2 \mathrm{~K}$ to $300 \mathrm{~K}$ for a film with a thickness of 2 $\mathrm{nm}$ [17]. The critical thickness shown in the literature is thicker than that shown in the in situ evolution of electronic structure study. Liao et al. [6] have shown that extrinsic factors, such as the oxygen vacancies, enhance the nonmetallic behaviour in LSMO thin films. It is reported that critical thickness of thin films grown at low oxygen pressure is higher than that of thin films grown at high oxygen pressure. A capping layer has also been used to improve the metallic behaviour in ultrathin films because the capping layer reduces the surface distortion and minimizes any effective surface off-stoichiometry. To gain more insight into the origin of the MIT transition of SVO thin films, it is very important to precisely control the thickness of the films and minimize extrinsic factors. In this work, the thickness of SVO thin films was controlled by counting the peak number of reflection high-energy electron diffraction (RHEED) intensity oscillations. The optimal growth conditions obtained in Chapter 5 was used and a $\mathrm{SrTiO}_{3}$ (STO) capping layer were introduced to exclude any surface effects.

Besides reducing the thickness of single thin films, the dimensional crossover driven MIT is also worth being studied in the ultrathin film embedded in superlattices. Typically, a superlattice can be used to understand the properties that are present in a single low dimensional system because the property of a single period can be enhanced by fabricating superlattice artificially. However, the properties of superlattices are not exactly the same as a single system. Sun et al [18] have shown the conductivity enhancement of ultrathin $\mathrm{LaNiO}_{3}$ films in superlattices. The interlayer coupling between each adjacent sublayer in the superlattice is still an issue and very important to understand. Ultrathin SVO layer with a STO capping layer is a typical strongly correlated system, showing dimensional driven MIT. The STO/SVO superlattice could be a good system to understand the interlayer coupling effect between metallic sublayers.

As we discussed in Chapter 5, SVO is a promising material to be an electrode in electronic devices due to its high conductivity. Unfortunately, SVO cannot be an electrode in PZT capacitors since the high oxygen pressure needed for the growth of a PZT layer can degrade the SVO layer. However, the study on electronic property of SVO thin film in the heterostructure is of importance, as SVO still has potential to be used for other 
electronic devices that have to be fabricated in low oxygen pressure.

\subsection{Experimental}

The growth mechanism of $\mathrm{SrVO}_{3}$ thin films has been discussed in Chapter 5. The stoichiometry of SVO thin films can be controlled by the argon pressure and the oxygen partial pressure. To minimize any stoichiometry effects on the metal-insulator transition, all SVO thin films were grown in the partial oxygen pressure of $1 \times 10^{-5}$ mbar with the background argon pressure of 0.025 mbar to ensure prefect $\mathrm{Sr}: \mathrm{V}=1: 1$ stoichiometry. SVO thin films were grown by pulsed laser deposition equipped with Reflection highenergy electron diffraction (RHEED). During the growth, the intensity of a specular spot in RHEED pattern can be monitored. The specular RHEED intensity is a measure of the surface step density. For the 2D nucleation and growth, oscillations of the RHEED intensity is caused by the periodic formation of growing islands, giving alternating step density. Therefore, one oscillation period corresponds to the deposition time of one unit cell in the case of layer-by-layer growth and can be used to determine the thickness of thin films.

First, a single SVO/STO bilayer system was grown. The thickness of SVO thin film was varied from 3 u.c. to 6 u.c.. After that, the 2 u.c. thick STO layer was used to cap all SVO ultrathin films. Next, in order to understand the coupling effect between metallic sublayers, superlattices $\left[(\mathrm{SVO})_{\mathrm{m}} /(\mathrm{STO})_{2}\right]_{10}(2 \leq \mathrm{m} \leq 4)$ and $\left[(\mathrm{SVO})_{4} /(\mathrm{STO})_{\mathrm{n}}\right]_{10}(1 \leq$ $\mathrm{n} \leq 3)$ were also grown. A thermal and chemical treatment was applied to achieve single $\mathrm{TiO}_{2}$ terminated $\mathrm{SrTiO}_{3}$ (100) (STO) substrates [19]. The substrate temperature was set at $600{ }^{\circ} \mathrm{C}$ by laser heating. A $248 \mathrm{~nm}$ wavelength $\mathrm{KrF}$ excimer laser was employed with a fluence of $2 \mathrm{~J} / \mathrm{cm}^{2}$ and a repetition frequency of $1 \mathrm{HZ}$. As the previous work has shown that a high fluence of $2 \mathrm{~J} / \mathrm{cm}^{2}$ for STO can compensate the stoichiometry of thin films grown at low oxygen partial pressures [20], the $\mathrm{SrTiO}_{3}$ layer was grown at the same growth condition as that of SVO thin films.

The surface morphology of grown films was investigated by atomic force microscopy (Bruker AFM) in a tapping mode. X-ray diffraction (XRD) was used to characterize crystal structure of SVO/STO superlattices (Xpert panalytical MRD). Although the ultrathin SVO layer is too thin to be seen in XRD measurement, the crystal structure can 

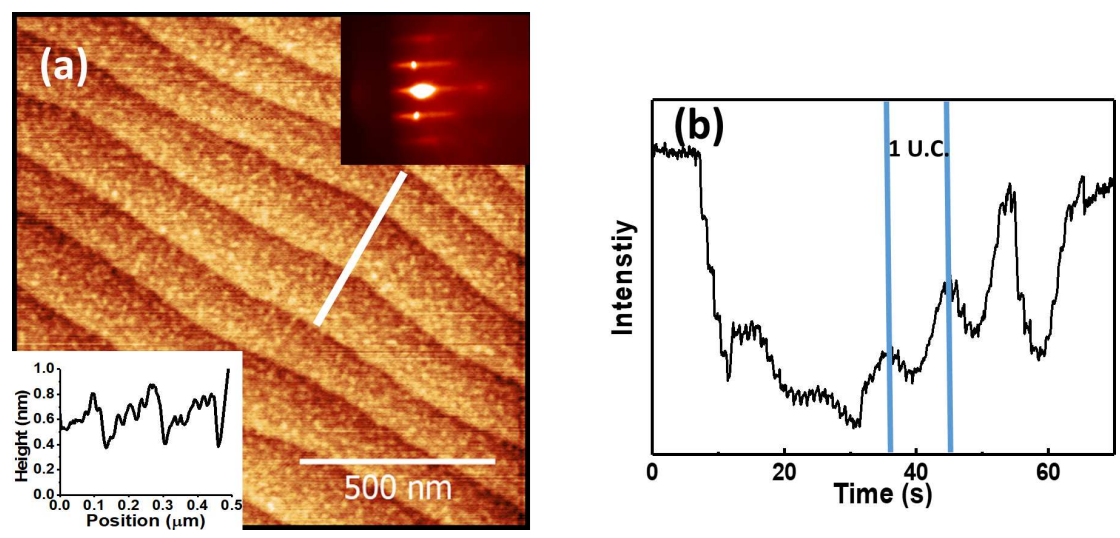

Figure 6.1: Tapping mode AFM image for the 6 u.c. SVO thin film capped by 2 u.c. STO layer. The step of $0.4 \mathrm{~nm}$ is shown in cross-section plot. The inset in Figure 1(a) is RHEED pattern of the grown film at room temperature. Figure 1(b) is RHEED specular spot intensity oscillation, indicating the thickness of the film.

be determined by RHEED, which has been fully discussed in Chapter 5 . The structural and chemical properties of the superlattice $\left[(\mathrm{SVO})_{2} /(\mathrm{STO})_{2}\right]_{10}$ were visualized by Cscorrected scanning transmission electron microscopy (STEM), equipped with a Gatan Enfina spectrometer for Electron Energy Loss Spectroscopy (EELS). The microscope was operated at $300 \mathrm{kV}$ with a $20 \mathrm{mrad}$ convergence angle. Transport properties of all the samples were measured by Physical Properties Measurement System (PPMS) using Van der Pauw method in the $2 \mathrm{~K}-300 \mathrm{~K}$ temperature range. Hall measurement and Magnetoresistance (MR) was performed in a perpendicular magnetic field from $-9 \mathrm{~T}$ to $9 \mathrm{~T}$ to understand the driving force behind the MIT.

\subsection{Results and conclusion}

Figure 6.1 (a) shows the tapping mode AFM image of a 2 u.c. STO capping layer on the 6 u.c. $\mathrm{SrVO}_{3}$ thin film on the STO substrate. The step height is about $0.4 \mathrm{~nm}$, which is the 1 u.c thickness of STO. the RHEED pattern expected with a 2D pattern, as shown in the inset of figure 6.1 (a), indicates a $2 \mathrm{D}$ flat surface. The oscillations of the RHEED specular spot intensity for the 6 u.c.. SVO thin film is shown in Figure 6.1 b). The thickness of all the films and superlattices are well controlled by the RHEED oscillations. 
The epitaxial growth of thick SVO films on (001)-oriented STO substrates and the physical properties of films have been shown in Chapter 5. Ultrathin single SVO/STO bilayer are too thin to be observed in XRD measurement. Figure 6.2 (a) and (b) show Xray diffraction around the $\left(\begin{array}{lll}0 & 0 & 2\end{array}\right)$ reflection of epitaxial superlattices $\left[(\mathrm{SVO})_{\mathrm{m}} /(\mathrm{STO})_{2}\right]_{10}$ $(2 \leq \mathrm{m} \leq 4)$ and $\left[(\mathrm{SVO})_{4} /(\mathrm{STO})_{\mathrm{n}}\right]_{10}(1 \leq \mathrm{n} \leq 3)$ respectively. In Figure 6.2 a $)$, the zeroth-order superlattice peak, which is close to the STO substrate peak, is observed for all superlattices. The averaged out-of-plane lattice constant derived from the superlattice peak decreases with increasing the thickness of SVO sublayers. The Laue fringes around the superlattice peaks originating from the coherence between individual sublayers indicate smooth interfaces between the SVO and STO layers. The first-order satellite peaks indicate that a long-range order is present in the superlattice $\left[(\mathrm{SVO})_{3} /(\mathrm{STO})_{2}\right]_{10}$ and $\left[(\mathrm{SVO})_{4} /(\mathrm{STO})_{2}\right]_{10}$. The thickness of SVO/STO bilayer can be estimated from the angular distance between the superlattice peak and the satellite peak. Since the atomic size of Vanadium and Titanium is similar, the contrast between SVO and STO is very weak. The intensity of first-order satellite peaks for the $\left[(\mathrm{SVO})_{2} /(\mathrm{STO})_{2}\right]_{10}$ superlattice is too weak to be observed. This low contrast also means that the SVO and STO are hard to distinguish in the TEM image of superlattice $\left[(\mathrm{SVO})_{2} /(\mathrm{STO})_{2}\right]_{10}$, as shown in Figure 6.2 (c). This TEM image shows high crystallinity of the superlattice $\left[(\mathrm{SVO})_{2} /(\mathrm{STO})_{2}\right]_{10}$. Chemical maps obtained by EELS of the $\mathrm{Ti} \mathrm{L}_{2,3}$ and $\mathrm{V} \mathrm{L}_{2,3}$ for the region in the rectangle of TEM image are also shown in Figure 6.2 (c), demonstrating atomically sharp ordered SVO/STO interfaces. This also shows that there is no perceptible atomic inter-diffusion at the interface between SVO and STO. In Figure 6.2 b), the zeroth-order superlattice peak are clearly seen for all superlattices. The averaged out-of-plane lattice constant derived from the superlattice peaks increases with increasing the thickness of STO sublayers. Again, the Laue fringes around the superlattice peaks indicate smooth interfaces between the SVO and STO layers. As the number of STO sublayers increase from 1 to 3 u.c., the first-order satellite peaks became sharper.

The electrical resistivity as a function of temperature ranging from $2 \mathrm{~K}$ to $300 \mathrm{~K}$ for a single SVO/STO bilayer system is shown in Figure 6.3 (a). The thickness of the SVO layer varies from 3 u.c. to 6 u.c. A thick SVO film, as shown in Chapter 5, shows metallic behaviour, the resistivity decreases with a decrease of the temperature. The electricity resistivity as a function of temperature can be expressed by a $\rho=\rho_{0}+\mathrm{AT}^{2}$ relation, where the residual resistivity $\rho_{0}$ is temperature independent, attributed to the electron-impurity 


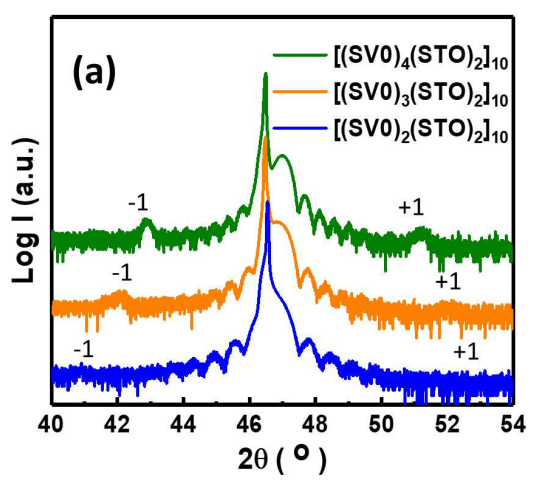

(c)

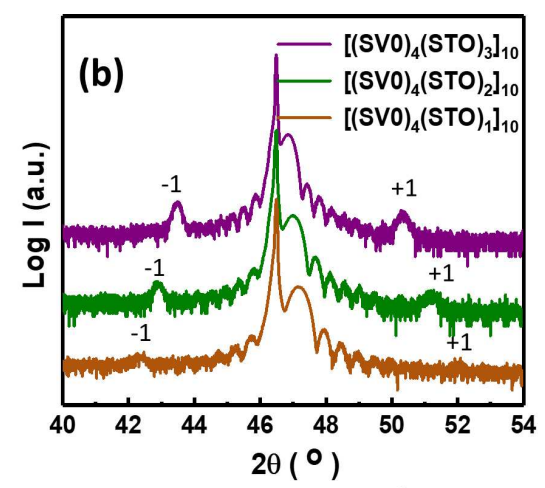

Ti V Tired, V Green
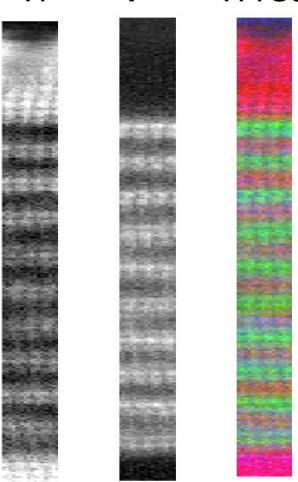

Figure 6.2: (a) $\mathrm{X}$-ray diffraction scan around (002) reflection of (a) $\left[(\mathrm{SVO})_{\mathrm{m}} /(\mathrm{STO})_{2}\right]_{10}(2 \leq \mathrm{m} \leq 4)$ and (b) $\left[(\mathrm{SVO})_{4} /(\mathrm{STO})_{\mathrm{n}}\right]_{10}(1 \leq \mathrm{n} \leq 3)$. (c) TEM image at low magnification showing the superlattice $\left[(\mathrm{SVO})_{2} /(\mathrm{STO})_{2}\right]_{10}$ structure and chemical maps obtained by EELS of the Ti $\mathrm{L}_{2,3}$ and $\mathrm{V} \mathrm{L}_{2,3}$ for the region in the red rectangle of TEM image. 
scattering. The coefficient A quantifies the electron-electron interaction relation. This dependence corresponds to the Fermi liquid behaviour in correlated electrons. The resistivity of SVO thin films with a reduced thickness, as shown in Figure 6.3 (a), is higher compared to that in the thick SVO film. The upturn occurs in the curve for SVO ultrathin films with thickness below 6 u.c. In the metallic regime, the temperature dependence of resistivity still follows the $\mathrm{T}^{2}$ law. The residual resistivity $\rho_{0}$ and coefficient $A$ for these films are shown in Table 6.1. The estimated value of residual resistivity $\rho_{0}$ and coefficient A increase with the decrease of the thin film thickness. The transition temperature $\left(\mathrm{T}_{\mathrm{MIT}}\right)$ for each film, as indicated by a black arrow in Figure 6.3 $\mathrm{a}$ ), is defined by the peak position at the $\mathrm{d} \rho / \mathrm{dT}$ curve. This temperature is $42 \mathrm{~K}$ for the 6 u.c. film and then increases to $100 \mathrm{~K}$ for the 4 u.c. film. The critical thickness of SVO is 3 u.c. at which the insulating behaviour presents in the whole temperature range. This thickness agrees well with the thickness measured by in-situ photoemission spectroscopy (PES) [15], whereas this is lower than critical thickness studied by transport measurement in previous works [16, 17]. As in the study of $\mathrm{La}_{2 / 3} \mathrm{Sr}_{1 / 3} \mathrm{MnO}_{3}$ (LSMO) thin film [6], the critical thickness can be influenced by stoichiometry of the film and surface effects. The transport properties of single SVO/STO bilayer indicate that our SVO films are close to stoichiometry and surface effects also play a role.

The temperature dependence resistivity in the range from $2 \mathrm{~K}$ to $300 \mathrm{~K}$ of the superlattices is shown in Figure 6.3 (b) and (c). Strikingly, the transport properties of the superlattice $\left[(\mathrm{SVO})_{4} /(\mathrm{STO})_{2}\right]_{10}$ are not the same as the single 4 u.c. SVO/2 u.c. STO bilayer system. The conductivity of this superlattice is enhanced (Figure 6.3 b)), and the metallic behaviour is present in the whole temperature range. The conductivity can be further improved by reducing the thickness of STO sublayers to 1 u.c. between the SVO sublayers (Figure 6.3 (c)). However, the MIT transition occurs at $64 \mathrm{~K}$ in the superlattice $\left[(\mathrm{SVO})_{4} /(\mathrm{STO})_{3}\right]_{10}$ (Figure 6.3 (c)). The MIT transition occurs also with further reducing the SVO thickness in SVO/STO superlattices. In Figure 6.3 b), the MIT temperature is $64 \mathrm{~K}$ for the superlattice $\Delta\left[(\mathrm{SVO})_{3} /(\mathrm{STO})_{2}\right]_{10}$ and $170 \mathrm{~K}$ for the superlattice $\left[(\mathrm{SVO})_{2} /(\mathrm{STO})_{2}\right]_{10}$. Again, the temperature dependence of resistivity in the metallic regime still follows the $T^{2}$ law. The residual resistivity $\rho_{0}$ and coefficient $\mathrm{A}$ for these films are also shown in Table 6.1 .

The conductivity enhancement in SVO/STO superlattices indicates that the interlayer coupling between the SVO sublayers plays a role. STO can be regarded as a barrier, 

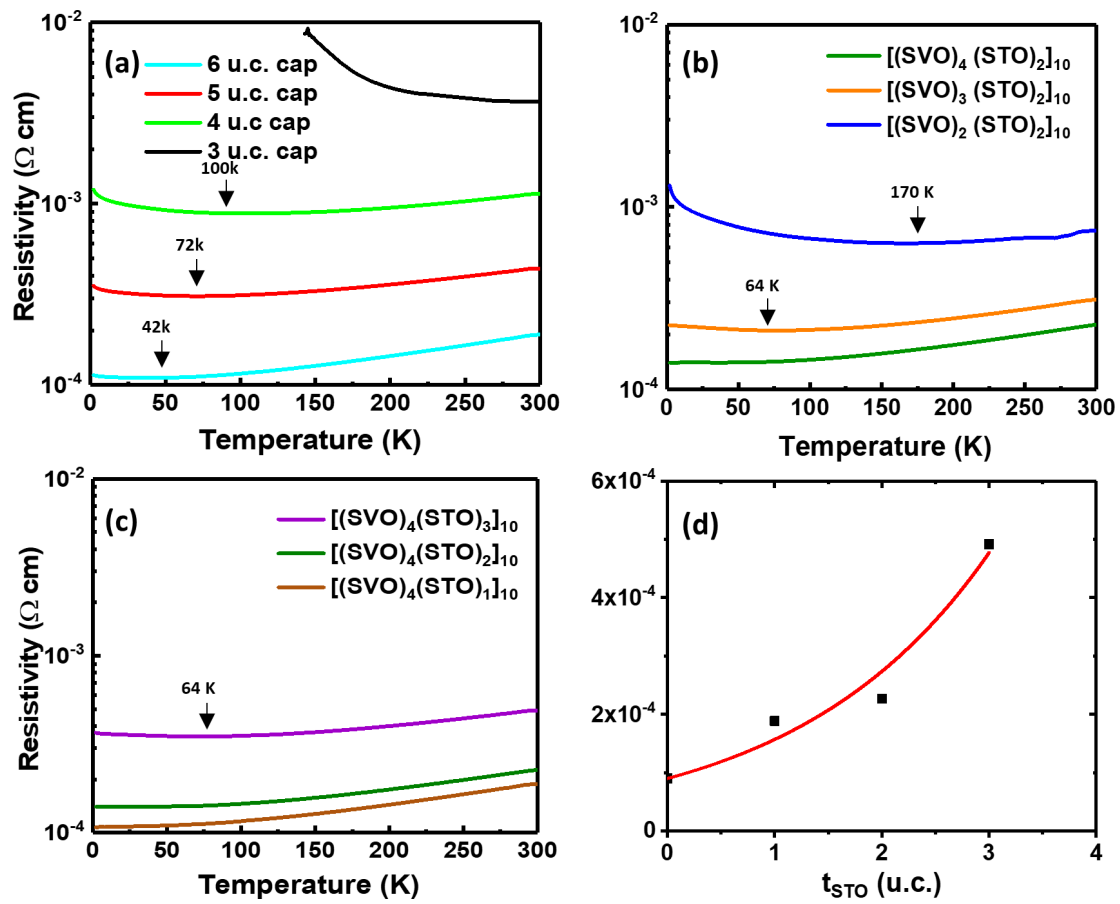

Figure 6.3: (a) Temperature dependent resistivity for films with different thickness in the range from 3 u.c. to 6 u.c. All the SVO films were capped by a 2 u.c. layer. The metal-insulator transition temperatures are indicated by a black arrow. The resistivity as a function of temperature for (b) $\left[(\mathrm{SVO})_{\mathrm{m}} /(\mathrm{STO})_{2}\right]_{10}(2 \leq \mathrm{m} \leq 4)$ and (c) $\left[(\mathrm{SVO})_{4} /(\mathrm{STO})_{\mathrm{n}}\right]_{10}(1 \leq \mathrm{n} \leq 3)$ superlattices. The metal-insulator transition temperature are also indicated by a black arrow. (d) Resistivity of superlattices $\rho$ as a function of the thickness of STO sublayer $\mathrm{t}_{\text {STO }}$. The data are fitted to $\rho=\rho_{0} \mathrm{e}^{\mathrm{t}_{\text {STO }} / 2.48}$ shown in a red solid line. 
Table 6.1: Overview electrical properties for single SVO/STO bilayer systems and SVO/STO superlattices.

\begin{tabular}{ccc} 
Thickness & $\rho_{0}\left(10^{-4} \Omega \mathrm{cm}\right)$ & $\mathrm{A}\left(\times 10^{-10} \Omega \mathrm{cm} \mathrm{K}^{-2}\right)$ \\
\hline 6 u.c SVO cap & 1.06 & 9.45 \\
5 u.c SVO cap & 2.94 & 16.3 \\
4 u.c SVO cap & 8.22 & 33.9 \\
{$\left[(\mathrm{SVO})_{2} /(\mathrm{STO})_{2}\right]_{10}$} & 5.85 & 14.1 \\
{$\left[(\mathrm{SVO})_{3} /(\mathrm{STO})_{2}\right]_{10}$} & 1.95 & 12.8 \\
{$\left[(\mathrm{SVO})_{4} /(\mathrm{STO})_{2}\right]_{10}$} & 1.36 & 9.30 \\
{$\left[(\mathrm{SVO})_{4} /(\mathrm{STO})_{3}\right]_{10}$} & 1.88 & 10.2 \\
{$\left[(\mathrm{SVO})_{4} /(\mathrm{STO})_{1}\right]_{10}$} & 0.90 & 7.66 \\
\hline
\end{tabular}

while the current between $\mathrm{SVO}$ sublayers pass through the $\mathrm{SrTiO}_{3}$ barriers. This tunnelling current would be suppressed by increasing the barrier thickness. In Figure 6.3 (c), the conductivity increases with the increasing thickness of the STO sublayers in the superlattices. Although the resistivity of the superlattice $\left[(\mathrm{SVO})_{4} /(\mathrm{STO})_{3}\right]_{10}$ is still lower than that of the single 4 u.c. SVO/STO bilayer system, the MIT behaves similarly to the single SVO/STO bilayer system when the superlattice consists of 3 u.c. STO sublayer. Figure 6.3 (d) shows the resistivity of the superlattices $\rho$ as a function of the thickness of

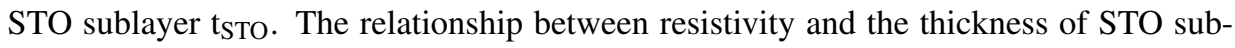
layer can be described by $\rho=\rho_{0} \mathrm{e}^{\mathrm{t}_{\mathrm{STO}} / 2.48}$. STO sublayers with the thickness of $6 \mathrm{u} . \mathrm{c}$ would be needed to suppress the coupling effect in superlattices. By reducing the dimensionality of SVO layer in superlattices, the transport properties is tuned from a metal to a Mott-insulator (Figure 6.3 (b)). The critical thickness of SVO is reduced by interlayer coupling effect in superlattices.

The results discussed above show that the temperature driven metal insulator transition exists in the SVO ultrathin films and superlattices. The critical thickness of SVO can be reduced by growing thin films at optimal conditions and removing any surface effects by using a capping layer. It is important to understand the driving force behind the observed MIT. First, the weak localization need to be considered. In a two dimensional (2D) system [21]:

$$
\sigma=\mathrm{s}_{0}+\mathrm{p} * \frac{\mathrm{e}^{2}}{\pi * \mathrm{~h}} \ln \left(\mathrm{T} / \mathrm{T}_{0}\right),
$$

where $\sigma$ is Drude conductivity, e is charge of electron, $h$ is Planck's constant, and $\mathrm{T}_{0}$ is related to the transport mean free path. If the main inelastic relaxation mechanism is electron-electron scattering $\mathrm{p}=1$, whereas electron-phonon scattering gives rise to $\mathrm{p}=3$. 

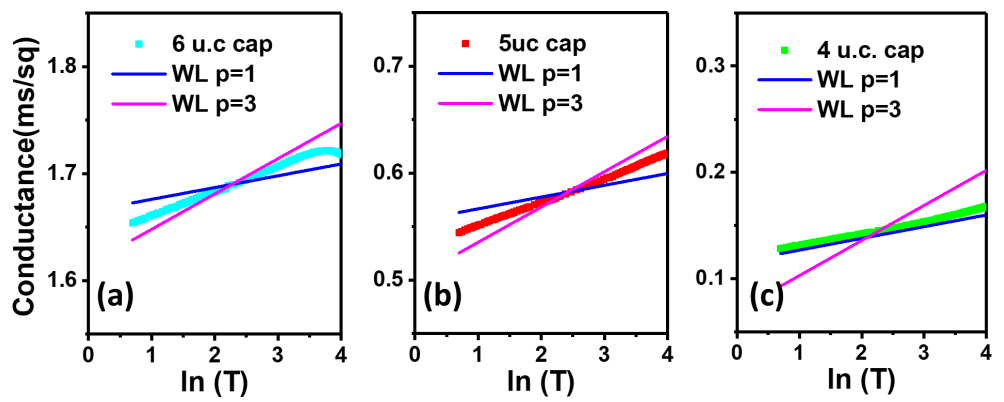

Figure 6.4: Sheet conductance at low temperature is presented as a function of $\operatorname{Ln}(\mathrm{T})$ for the single SVO/STO bilayer systems with (a) 6 u.c. SVO, (b) 5 u.c. SVO and (c) 4 u.c. SVO. A 2D model for the weak localization with $\mathrm{p}=1$ (blue line) and $\mathrm{p}=3$ (purple line).

The linear behaviour of the conductance as a function of $\ln (\mathrm{T})$ at low temperature for the single SVO/STO bilayer system is shown in figure 6.4. For the 6 u.c SVO and 5 u.c SVO, the weak localization mechanisms calculated from the Equation 6.1 with the electronelectron scattering $(\mathrm{p}=1)$ and the electron-phonon scattering $(\mathrm{p}=3)$ cannot describe the experiment data (Figure 6.4(a) and (b)). For the 4 u.c SVO the weak localization with $\mathrm{p}=1$ agrees with the data at low temperature. However, the fit deviates slightly for the temperature above $30 \mathrm{~K}(\operatorname{lnT}=3.4)$. In a 2D model established by Lee and Ramakrishnan [21], one point that need to be noted is that the electron-electron interaction would also affect the logarithmic temperature dependence of the conductivity. Both of these effects can be further clarified by analysing the magnetoresistance (MR).

To further understand the driving force behind the observed metal-insulator transition in the SVO ultrathin films, magneto-transport properties of the single SVO/STO bilayer and SVO/STO superlattice have been investigated by Magnetoresistance (MR) measurements. In figure 6.5 a), a positive magnetoresistance in a perpendicular magnetic field from $-9 \mathrm{~T}$ to $9 \mathrm{~T}$ was observed for the single 4 u.c. SVO/2 u.c. STO bilayer at temperature below the transition temperature. MR at a temperature higher than $5 \mathrm{~K}$, is proportional to $\mathrm{H}^{2}$ which can be attributed to a Lorentz force. The positive sign of MR does not correspond to the weak localization because the magnetic field suppresses the coherent interference for localization, leading to a negative MR. Instead, the positive MR over the entire range is an indication of electron-electron interaction. The Hall measurement of 4 u.c. capped SVO film is shown in figure 6.5 b). This figure shows that the carriers are electrons and their density slightly decreases as the temperature decreases. The carrier 

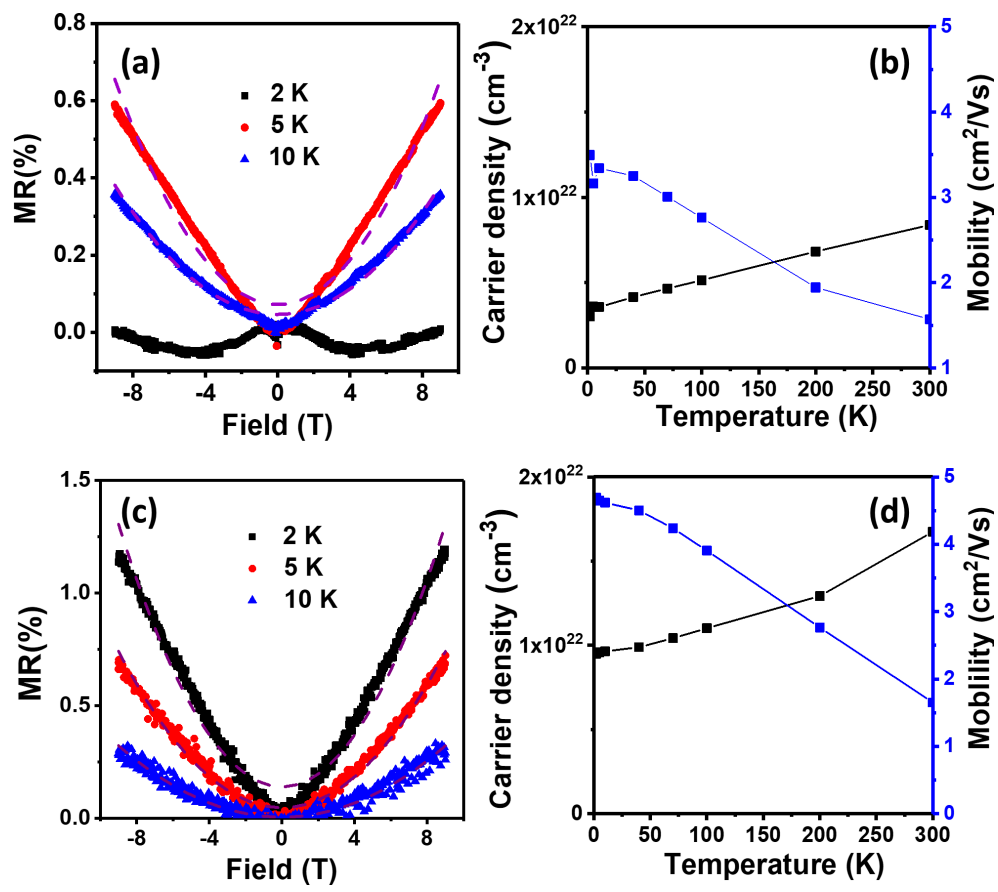

Figure 6.5: Magnetoresistance in perpendicular field for (a) the 2 u.c. STO capped 4 u.c. SVO film and (c) the superlattice $\left.\left[(\mathrm{SVO})_{4} /(\mathrm{STO})_{2}\right)\right]_{10}$ at low temperature. The parabolic fits to the dependency of $\mathrm{H}^{2}$ at each temperature are shown in purple dashed lines. Carrier density and mobility variation as a function of temperature for (b) the 2 u.c. STO capped 4 u.c. SVO film and (d) the superlattice $\left.\left[(\mathrm{SVO})_{4} /(\mathrm{STO})_{2}\right)\right]_{10}$. 
mobility increases with the decreasing temperature. The values of carrier density and the carrier mobility are similar to that of a thick SVO film. The Hall coefficient was found to increase logarithmically at a rate equal to twice that of the resistivity at low temperature for the localization effect [21]. The decrease of the carrier density with the decrease of the temperature observed here is not the dependency of Hall coefficient for the localization. For a lower magnetic field at $5 \mathrm{~K}$, a quick increase in MR is observed. The behaviour could be interpreted as the weak antilocalization (WAL), which originates from the destructive interference of coherently backscattered conductions due to the spin rotations. Interestingly, for the temperature at $2 \mathrm{~K}$, a competition of negative (small $\mathrm{H}$ ) and positive MR (large $\mathrm{H}$ ) is observed, which shows the interplay of electron-electron interaction and weak localization. In Figure 6.5 (c), MR in a perpendicular magnetic field at low temperature for the superlattice $\left.\left[(\mathrm{SVO})_{4} /(\mathrm{STO})_{2}\right)\right]_{10}$ is also proportional to $\mathrm{H}^{2}$. The positive sign indicates that the dominant driving force behind the MIT in the superlattice is electronelectron interaction as opposed to weak localization. The carrier density shown in Figure 6.5 (d) is higher than that in the single SVO/STO bilayer. This also can be caused by a still finite coupling between SVO sublayers in the superlattice.

\subsection{Conclusion}

The high quality epitaxial SVO ultrathin films show a metal-insulator transition driven by dimensionality effect. The critical thickness of 3 unit cells was achieved by suppressing stoichiometric effect under optimal growth conditions and excluding any surface effects by a $\mathrm{SrTiO}_{3}$ (STO) capping layer. A detailed investigation of transport measurements of SVO ultrathin films indicates that the dominant driving force of MIT is the electron-electron interaction.

Furthermore, epitaxial SVO/STO superlattices were fabricated. The conductivity of SVO layer is enhanced in the superlattice compared to the single SVO/STO bilayer. This behaviour can be interpreted as the interlayers coupling between SVO sublayers in the superlattice. The coupling effect can be suppressed by increasing the thickness of the STO barrier layers in the superlattice. 


\section{Bibliography}

[1] M. Imada, A. Fujimori, and Y. Tokura, Reviews of Modern Physics 70, 1039 (1998).

[2] I. H. Inoue and M. J. Rozenberg, Advanced Functional Materials 18, 2289 (2008)

[3] H. Y. Hwang, Y. Iwasa, M. Kawasaki, B. Keimer, N. Nagaosa, and Y. Tokura, Nature Materials 11, 103 (2012).

[4] D. G. Schlom, L.-Q. Chen, C.-B. Eom, K. M. Rabe, S. K. Streiffer, and J.-M. Triscone, Annual Review of Materials Research 37, 589 (2007).

[5] R. Scherwitzl, S. Gariglio, M. Gabay, P. Zubko, M. Gibert, and J.-M. Triscone, Physical Review Letters 106, 246403 (2011).

[6] Z. Liao, F. Li, P. Gao, L. Li, J. Guo, X. Pan, R. Jin, E. Plummer, and J. Zhang, Physical Review B 92, 125123 (2015).

[7] A. Ohtomo and H. Hwang, Nature 427, 423 (2004).

[8] Z. Yang, C. Ko, and S. Ramanathan, Annual Review of Materials Research 41, 337 (2011).

[9] Y. Lan, X. Chen, and M. He, Journal of Alloys and Compounds 354, 95 (2003).

[10] J. A. Moyer, C. Eaton, and R. Engel-Herbert, Advanced Materials 25, 3578 (2013).

[11] M. Imada, A. Fujimori, and Y. Tokura, Reviews of Modern Physics 70, 1039 (1998).

[12] S. Miyasaka, T. Okuda, and Y. Tokura, Physical Review Letters 85, 5388 (2000).

[13] T. M. Dao, P. S. Mondal, Y. Takamura, E. Arenholz, and J. Lee, Applied Physics Letters 99, 112111 (2011).

[14] M. J. Rozenberg, I. H. Inoue, H. Makino, F. Iga, and Y. Nishihara, Physical Review Letters 76, 4781 (1996).

[15] K. Yoshimatsu, T. Okabe, H. Kumigashira, S. Okamoto, S. Aizaki, A. Fujimori, and M. Oshima, Physical Review Letters 104, 147601 (2010).

[16] M. Gu, S. A. Wolf, and J. Lu, Advanced Materials Interfaces 1, 1300126 (2014). 
[17] A. Fouchet, M. Allain, B. Bérini, E. Popova, P.-E. Janolin, N. Guiblin, E. Chikoidze, J. Scola, D. Hrabovsky, Y. Dumont, et al., Materials Science and Engineering: B 212, 7 (2016).

[18] J. Son, J. M. LeBeau, S. J. Allen, and S. Stemmer, Applied Physics Letters 97, 202109 (2010).

[19] G. Koster, B. L. Kropman, G. J. H. M. Rijnders, D. H. A. Blank, and H. Rogalla, Applied Physics Letters 73, 2920 (1998).

[20] R. Groenen, J. Smit, K. Orsel, A. Vailionis, B. Bastiaens, M. Huijben, K. Boller, G. Rijnders, and G. Koster, APL Materials 3, 070701 (2015)

[21] P. A. Lee and T. Ramakrishnan, Reviews of Modern Physics 57, 287 (1985). 


\section{Summary}

Ferroelectric materials are used for non-volatile random access memory devices because these materials have switchability between two states, and they are non-volatile in nature. The performances, such as operating voltage, operating speed and the working stability, of these ferroelectric devices are important to be studied. $\mathrm{Pb}\left(\mathrm{Zr}_{\mathrm{x}} \mathrm{Ti}_{1-\mathrm{x}}\right) \mathrm{O}_{3}$ (PZT) is a well-known ferroelectric material because of its high degree of polarization, high Curie temperature and high electromechanical coupling coefficients in a wide temperature range. Typically, a layer of PZT is sandwiched between a pair of electrodes in capacitor geometry in such devices. Conductive oxide materials with the perovskite structure are a suitable template to epitaxially grow the subsequent ferroelectric PZT layer for high-performance devices. Currently, $\mathrm{SrRuO}_{3}$ (SRO) and $\mathrm{LaNiO}_{3}$ (LNO) are widely used as electrodes in PZT capacitors in the laboratory. However, attention needs to be given to the resistivity of these oxide electrodes, and the lattice mismatch between the electrode layers and PZT.

First, the lattice mismatch between commonly used electrode (SRO and LNO) and PZT is large, giving rise to defects at interfaces. $\mathrm{La}_{0.07} \mathrm{Ba}_{0.93} \mathrm{SnO}_{3}$ (LBSO) is a promising material to be an electrode because the lattice constant of this material is perfectly matched with PZT. The other issue is that the conductivity of commonly used electrode ( $\mathrm{SRO}$ and LNO) is relatively low compared to the metal (Pt), causing contact losses in the device. $\mathrm{SrVO}_{3}(\mathrm{SVO})$ gained a lot of attention because of its high conductivity (the same order as metal) and high carrier density. In this thesis, we focused on the growth and the characterization of two materials, SVO and LBSO. We started to investigate and understand the optimal growth parameters for these two materials. The performance of PZT ferroelectric devices with the LBSO electrode was then studied. Here, all the thin films and devices are fabricated by pulsed laser deposition (PLD), because it can deposit many kinds of materials in a broad range of gas pressures and also can be used to deposit on industrial size silicon wafers. The growth process of the PLD system is further discussed 
by studying the growth of SVO and LBSO.

Growth kinetics of LBSO thin films by pulsed laser deposition were investigated to control the morphological and structural properties in Chapter 3. Two sets of thin films were grown by varying growth temperature and laser spot size respectively with the constant oxygen pressure of 0.13 mbar. The first set of samples show that the surface morphology of LBSO thin films was improved by increasing the temperature up to $830{ }^{\circ} \mathrm{C}$. The white dots observed on the surface of the thin film grown at $850^{\circ} \mathrm{C}$ are an indication of tin evaporation and segregation. The second set of samples show that a small spot size is favourable for the crystallinity and smoothness of the films. Two kinetic parameters, diffusion coefficient controlled by growth temperature and mass flux tuned by spot size, affect the crystallinity and surface morphology of the films, which in turn control the properties of thin films. At the optimal conditions, the epitaxial LBSO thin films with a smooth surface and good crystallinity were obtained.

In Chapter 4, PZT thin films with excellent crystalline quality and chemical sharp interfaces of the bottom electrodes LBSO with the ferroelectric PZT were obtained. Compared to the device with the widely used electrode SRO, a large coercive field and strong fatigue behaviour were observed for the device with the LBSO bottom electrode. The fatigue can be resolved by introducing an only $2 \mathrm{~nm}$ SRO layer between the PZT and LBSO. The observed fatigue behaviour is explained by charge injection and subsequent trapping at the PZT/LBSO interface into the ferroelectric layer. Ultimately, the electric field induced by injected charge leads to polarization fatigue. Charge injection is much more likely to take place at the PZT/LBSO interface because of the low PZT/LBSO interfacial barrier as compared to the PZT/SRO interface and the low carrier density in LBSO as compared to that in SRO. This work clearly shows the work function and the carrier density of oxide electrodes in ferroelectric devices play an important role in the polarization switching and fatigue properties. A conductive oxide material with a high work function and high carrier density is required for PZT ferroelectric devices.

In Chapter 5, the growth mechanism of SVO thin films was studied by varying argon background pressures, partial oxygen pressures and target-to-substrate distance in pulsed laser deposition. The plasma plume of SVO at varying growth conditions was investigated by performing optical emission spectroscopy (OES) measurements. From the correlation between the thin films properties determined by AFM and XRD and plasma plume composition analysed by OES measurements, we conclude that the surface diffu- 
sivity, growth kinetics and the stoichiometry of the films are controlled by oxidation of arriving species. At reducing oxygen pressure, the total argon pressure can control the oxidation species in the plume, which in turn controls the quality of the thin film. At optimal growth conditions, the high conductive SVO thin films with a very smooth surface and good crystallinity were obtained. The conclusion of the growth study is that kinetic effects and oxidation species both make a contribution to determine the growth mode in PLD.

Although highly conductive SVO was obtained, the high oxygen pressure needed for PZT growth can degrade the desired phase of conductive SVO. It is still of importance to study the properties of SVO in a heterostructure since it has the potential to be used in devices that have to be grown in a low oxygen pressure. The metal-insulator transition (MIT) of $\mathrm{SrTiO}_{3}$ (STO) capped SVO ultrathin films and SVO/STO superlattices were studied in Chapter 6. We concluded that electron-electron interaction is the dominant driving force for MIT. The conductivity enhancement in SVO/STO superlattices compared to the single SVO/STO bilayer is explained by interlayers coupling effects. 


\section{Samenvatting}

Ferroelektrische materialen worden gebruikt voor niet-vluchtige RAM - geheugenapparaten omdat deze materialen schakelbaar zijn tussen twee toestanden en ze niet-vluchtig van aard zijn. De prestaties, zoals bedrijfsspanning, werkingssnelheid en de werkstabiliteit van deze ferro-elektrische apparaten zijn van belang om te worden bestudeerd. $\mathrm{Pb}\left(\mathrm{Zr}_{\mathrm{x}} \mathrm{Ti}_{1-\mathrm{x}}\right) \mathrm{O}_{3}(\mathrm{PZT})$ is een bekend ferro-elektrisch materiaal vanwege de grote polarisatie, hoge Curie-temperatuur en hoge elektromechanische koppelingscoëfficiënten in een breed temperatuurbereik. Typisch wordt een laag PZT ingeklemd door een paar elektroden in de condensatorgeometrie in dergelijke apparaten. Geleidend oxidematerialen met de perovskietstructuur vormen een goed sjabloon voor het epitaxiaal laten groeien van de daaropvolgende ferro-elektrische PZT-laag voor apparaten met hoge prestaties. Momenteel worden $\mathrm{SrRuO}_{3}(\mathrm{SRO})$ en $\mathrm{LaNiO}_{3}$ (LNO) veel gebruikt als elektroden in het laboratorium. Er moet echter worden gelet op de soortelijke weerstand van deze oxideelektroden en het verschil in roosterconstante tussen de elektrodelagen en PZT.

Ten eerste is het verschil in roosterconstante tussen de gewoonlijk gebruikte elektroden (SRO en LNO) en PZT groot, hetgeen aanleiding geeft tot defecten bij grensvlakken. $\mathrm{La}_{0.07} \mathrm{Ba}_{0.93} \mathrm{SnO}_{3}$ (LBSO) is een veelbelovend materiaal om als elektrode gebruikt te worden omdat de roosterconstante van dit materiaal perfect overeenkomt met PZT. Het andere probleem is dat de geleidbaarheid van de gewoonlijk gebruikte elektroden (SRO en LNO) relatief laag is in vergelijking met het metaal (Pt), waardoor contactverliezen in het apparaat ontstaan. $\mathrm{SrVO}_{3}(\mathrm{SVO})$ kreeg veel aandacht vanwege de hoge geleidbaarheid (in dezelfde ordegrootte als metaal) en de hoge ladingsdragerdichtheid. In dit proefschrift hebben we ons gericht op de groei en karakterisering van twee materialen, SVO en LBSO. We begonnen met het onderzoeken en begrijpen van de optimale groeiparameters voor deze twee materialen. De prestatie van PZT ferro-elektrische apparaten met de LBSO-elektrode werd vervolgens bestudeerd. Hier worden alle dunne films en apparaten gefabriceerd door gepulseerde laserdepositie (PLD), omdat het vele soorten 
materialen in een breed bereik van gasdrukken kan deponeren en ook kan worden gebruikt om te deponeren op silicium wafers van industriële afmeting. Het groeiproces van het PLD-systeem wordt verder besproken door de groei van SVO en LBSO te bestuderen.

De groeikinetiek van LBSO dunne films gemaakt door gepulseerde laserdepositie is onderzocht om de morfologische en structurele eigenschappen te controleren in Hoofdstuk 3. Twee sets dunne films werden gegroeid onder variërende groeitemperatuur en laserspotgrootte met een constante zuurstofdruk van 0,13 mbar. Uit de eerste reeks monsters blijkt dat de oppervlaktemorfologie van LBSO dunne films is verbeterd door de temperatuur te verhogen tot $830{ }^{\circ} \mathrm{C}$. De witte stippen waargenomen op het oppervlak van de dunne film gegroeid bij $850{ }^{\circ} \mathrm{C}$ zijn een indicatie van tinverdamping en segregatie. De tweede reeks monsters toont dat een kleine laserspotgrootte gunstig is voor de kristalliniteit en gladheid van de films. Twee kinetische parameters, diffusiecoëfficiënt geregeld door groeitemperatuur en massaflux afgestemd op de laserspotgrootte, beïnvloeden de kristalliniteit en oppervlaktemorfologie van de films, die op hun beurt de eigenschappen van dunne films bepalen. Bij de optimale omstandigheden werden de epitaxiale LBSO dunne films met een glad oppervlak en een goede kristalliniteit verkregen.

In hoofdstuk 4 werden PZT-dunne films met uitstekende kristallijne kwaliteit en chemisch scherpe grensvlakken van de onderste elektroden LBSO met de ferroelektrische PZT verkregen. Vergeleken met het apparaat met de veelgebruikte elektrode SRO, werden een groot coërcitief veld en sterk vermoeiingsgedrag waargenomen voor het apparaat met de LBSO bodemelektrode. De vermoeidheid kan worden opgelost door een enkel $2 \mathrm{~nm}$ dunne SRO-laag tussen de PZT en LBSO te introduceren. Het waargenomen vermoeidheidsgedrag wordt verklaard door ladingsinjectie en invangen op het PZT-LBSOgrensvlak in de ferro-elektrische laag. Uiteindelijk leidt het elektrische veld geïnduceerd door geïnjecteerde lading tot polarisatiemoeheid. Ladingsinjectie vindt veel waarschijnlijker plaats aan het PZT/LBSO interface vanwege de lage PZT/LBSO grensvlakbarrière in vergelijking met de PZT/SRO interface en de lage ladingsdichtheid in LBSO in vergelijking met die in SRO. Dit werk toont duidelijk dat de werkfunctie en de ladingsdragerdichtheid van oxide elektroden in ferroelektrische apparaten een belangrijke rol spelen bij de polarisatieschakeling en vermoeidheidseigenschappen. Voor PZT ferroelektrische apparaten is een geleidend oxidemateriaal met een hoge werkfunctie en een hoge ladingsdichtheid vereist.

In Hoofdstuk 5 werd het groeimechanisme van dunne films van SVO bestudeerd door 
argon-achtergronddrukken, partiële zuurstofdrukken en afstand tussen doelmateriaal en substraat in gepulseerde laserdepositie te variëren. De plasma-pluim van SVO bij variërende groeiomstandigheden werd onderzocht door metingen van optische emissiespectroscopie (OES) uit te voeren. Uit de correlatie tussen de eigenschappen van de dunne films bepaald door AFM, XRD en de geanalyseerd plasma-pluimssamenstelling met behulp van OES-metingen, concluderen we dat de oppervlaktediffusiviteit, groeikinetiek en de stoichiometrie van de films worden geregeld door oxidatie van aankomende ions. Bij het verlagen van de zuurstofdruk kan de totale argondruk de oxidatiespecies in de pluim regelen, die op zijn beurt de kwaliteit van de dunne film regelen. Bij optimale groeiomstandigheden werden de hooggeleidende SVO dunne films met een zeer glad oppervlak en een goede kristalliniteit verkregen. De conclusie van het groeionderzoek is dat kinetische effecten en oxidatiespecies een bijdrage leveren om de groeimodus in PLD te bepalen.

Hoewel sterk geleidende SVO werd verkregen, kan de hoge zuurstofdruk die nodig is voor PZT-groei de gewenste fase van geleidend SVO degraderen. Het is nog steeds van belang om de eigenschappen van SVO in een heterostructuur te bestuderen, omdat het potentieel heeft om te worden gebruikt in apparaten die moeten worden gegroeid in lage zuurstofdruk. De metaal-isolatorovergang (MIT) van $\mathrm{SrTiO}_{3}$ (STO) afgedekte SVO ultradunne films en SVO / STO superroosters werden bestudeerd in Hoofdstuk 6. We concludeerden dat elektron-elektron interactie de dominante drijvende kracht is voor MIT. De geleidbaarheidsverbetering in SVO / STO superroosters vergeleken met de enkele SVO / STO dubbellaag wordt verklaard door koppelingseffecten tussen de lagen. 


\section{全文总结}

铁电材料因其可以在两个极化状态下转换以及本质上不易消失的特性被广泛 应用到非易失性储存器中。装置的性能, 比如工作电压, 运行速度以及工作的稳 定性具有研究价值。 $\mathrm{Pb}\left(\mathrm{Zr}_{\mathrm{x}} \mathrm{Ti}_{1-\mathrm{x}}\right) \mathrm{O}_{3}$ (PZT) 因其具备很强的极化强度, 较高的 居里温度以及高的机电耦合系数而成为是一种被广泛使用的铁电材料。一般形况 下, 在电容器装置中, 一层铁电材料将夹在一对电极之间。导电的且具有钙钛 矿结构的氧化物做电极可以提供一个很好基底让PZT层可以外延的生长在电极材 料上, 从而使铁电装置有一个更好的性能。目前, 锶钓氧 $\mathrm{SrRuO}_{3}(\mathrm{SRO})$ 和镧镍 氧 $\mathrm{LaNiO}_{3}$ ( $\mathrm{LNO}$ ) 在实验室里被广泛的用作PZT铁电装置的电极。但是, 我们要 进一度关注到氧化物电极的电阻率和电极材料与PZT的晶格失配大小等问题。

首先, 常用的电极材 (SRO和LNO) 与PZT的晶格失配比较大。这会导 致PZT和电极的界面形成很多的缺陷。镧钡锡氧 $\mathrm{La}_{0.07} \mathrm{Ba}_{0.93} \mathrm{SnO}_{3}$ (LBSO)因为 和PZT的晶格可以完美的匹配被认为是一种很有潜力的材料。另外一个问题是常 用的氧化物电极材料 (SRO和LNO) 的导电率要比金属材料（比如, Pt）低一个 数量级, 从而导致较大的接触损失。锶钒氧 $\mathrm{SrVO}_{3}(\mathrm{SVO})$ 因其导电性可以与金 属达到同样一个数量级而获得了很大的关注。在这个论文中, 我们首先关注两种 材料, LBSO和SVO的生长和表征。我们研究和理解了两种材料的最优化的生长 条件。然后, 我们进一步研究了用以LBSO 作为电极的PZT铁电装置。这个工作 中, 所有的薄膜和装置都是有激光脉冲沉积所制备的。因为这个技术可以在很广 泛的气压下沉积多种的材料, 也可以将薄膜沉积在工业上用于批量生产的硅祄 底上。通过研究SVO 和LBSO 的生长, PLD系统的生长过程也进行了进一步的探 讨。

为了控制LBSO 薄膜的形态和结构的特性, 第三章我们研究了由脉冲激光沉 积所制备的LBSO 薄膜的生长动力。在同样的 $0.13 \mathrm{mbar}$ 的氧压下, 我们通过分别 改变生长温度和激光斑点的大小生长了两组样品。第一组样品表明LBSO的表面 形态将随着生长温度的升高而改善, 直到生长温度达到 $830^{\circ} \mathrm{C}$. 我们在 $850^{\circ} \mathrm{C}$ 生长 
的薄膜的表面发现了一些白点, 这表明了锡的挥发和聚积。第二组样品表面小的 激光斑点更有利于得到结晶度高和表面平整的LBSO薄膜。扩散系数和质量流量 这个两个动力学参数影响了薄膜的结晶性和表面的形貌, 从而控制着薄膜的性 质。其中生长温度可以改变扩散系数, 激光斑点大小可以调节质量流量。在最 优化的条件下, 我们可以得到且具有很好的的结晶度以及表面平整的外延生长 的LBSO薄膜。

第四章, 我们成功制备了生长在LBSO电极上且具有很好的结晶度的PZT薄 膜, 并且底电极LBSO和PZT有明确的界面。与使用SRO做电极的PZT装置不同, 用LBSO做电极的装置有一个更大的矫顽电场并且该装置还出现了极化疲劳的现 象。这种极化疲劳的现象可以通过在PZT与底电极LBSO之间加入 2 纳米的SRO解 决。我们认为这种极化疲劳现象可以用电荷从电极被注入紧接着被捕获到铁电层 中来解释。最终, 被注入的电子产生一个电场而引起的极化疲劳。电子的注入更 容易发生在PZT/LBSO界面, 因为PZT/LBSO与PZT/SRO界面相比有更低的界面势 垒而且 $\mathrm{LBSO}$ 与 $\mathrm{SRO}$ 相比载流子浓度更低。这一章节表明氧化物电极材料的功函 数和载流子浓度对极化转变和极化疲劳性有很大的影响。一个具有较高功函数和 较大的载流子浓度的材料是PZT铁电装置所需要的。

第五章, SVO的生长机制通过改变背底压强, 氧气的分压和靶材与祄底的距 离进行了研究。SVO的等离子体羽辉在不同的生长条件下通过光发射光谱的测量 进行了观察。通过原子力显微镜和X光衍射所确定的薄膜性质与通过光发射光谱 测量分析出的等离子体羽辉组分之间的相关性, 我们认为膜的表面扩散性, 生长 动力学和薄膜的化学计量可以通过到达物质的氧化程度来控制。在低氧压中, 氩 气的总压强可以控制羽辉中物质的氧化程度, 从而控制薄膜的质量。在最优的条 件下, 我们得到了具有很好结晶度, 表面光滑并且导电性很好的SVO薄膜。从生 长机制的研究中我们可以得出结论: 在PLD生长中, 抵达祄底表面的物质的动能 和氧化程度共同决定了生长模式。

尽管我们得到了导电性很好的SVO, 但是PZT生长所需要的高氧压会破 坏SVO的导电相。因为这个材料对一些需要低氧压生长的电子设备有潜在应用, 研究SVO在异质结中的性质依然很重要。第六章, 我们研究了被锶钛氧 $\mathrm{SrTiO}_{3}$

(STO) 封顶住的SVO薄膜和 SVO/STO超晶格的金属绝缘体转变。我们认为金属 绝缘体转变的主要是被电子与电子的相互作用驱使的。我们观察到 SVO/STO超晶 格与单独的SVO/STO双层系统相比有更好的导电率。这种导电率的提升可以用层 间耦合效应来解释。 


\section{Acknowledgements}

In the last part of my thesis I would like to express my gratitude to all people who have helped, supported and encouraged me in the last six years. This thesis would probably not be finished without those people. I have to say that I had the most unforgettable experience in my life in this city of Enschede.

First, I would like to express my heartfelt gratitude from the bottom of my heart to my supervisor Prof. Guus Rijnders and Prof. Gertjan Koster. Guus, I still remember the day when we met in the Skype for my interview. How time files. I am very much thankful to you for giving my opportunity to pursue my PhD in the IMS group. Thank you very much for giving me advices, encouragement and motivation to me all the way of my PhD. Gertjan, I am fortunate to have you as my daily supervisor. I am so grateful for your guidance in aspect of experiments performing and paper writing. Thank you for always being patient to discuss with me. I indeed learnt a lot from you. I would like to express my gratitude to Dr. Evert Houwman, who helped my to analyse the data and solve the challenge in our project. Thank you very much for your suggestions and writing corrections. I would also like to thank Prof. Mark Huijben for giving me advices to perform my experiments and to write my thesis.

I would also like to thank my committee members, Prof. dr. F. Bijkerk, Prof. dr. ir. A. Brinkman, Prof. dr. W.A. Groen, and Prof. dr. J.Verbeeck for spending time to evaluate this work.

I would also like to take this opportunity to express my gratitude to my master supervisor, Prof. Harold Zandivet, Prof. Detlef Lohse and Associate Prof. Xuehua Zhang for all their support and help. Harold, I am very much grateful for your advices and encouragement during my master. My master probably would not be achieved without your help.

I am thankful to my collaborator, Dr. Nicolas Gauquelin for taking the TEM images 
and giving me suggestions.

I gratefully acknowledge the technical support of Dominic, Frank, Laura and Harry for their wonderful job. Dominic, you can always solve almost all technical problems for helping me performing my experiments.

I would indeed to thank my colleagues and friends at IMS. I am very fortunate to work and experience several unforgettable events at IMS. It is a very nice and pleasure working place with you and all your support and help. First, I am thankful to my officemate in the first year of my Phd, Nirumpan, Alim, Werner. Because You guys created a nice atmosphere, I can quickly adapt to the new environment. Thanks to my officemate past and present, Laura, Phu, Shu and Yura for nice discussion and chat. I would also like to express my gratitude to all past and present IMSers, Bernald, Andre, Monica, Ufuk, Minh, Deekpak, Yorick, Daniel, Laura, Jaap, Thanh, Sina, Kit, Moritz, Marijn, Melvin, Tom, David, Petra, Arniban, Kurt, Ben, Tjeerd, Peter, Gerard, Pablo. I especially thank David for training me operating COMAT and XPS, Ben for coaching me using powder XRD, Kurt for training me using MRD, Werner for helping me using AFM, Marijn for helping me to translate the summary, and Minh and Thanh for helping me making PZT capacitor and using Ferroelectric tester. Laura, I am fortunate to work with in SpinBat project and also thanks for helping me to correct the writing of my thesis. I would also like to thank Marion, Jose and Karin for all your help. Marion, thank you for helping with all the paper work. You are always super-efficient. 感谢组里的中国同胞, 廖昭 亮, 李琳, 原会雨, 王洋, 陈斌斌, 倪澍, 黄斯昭和夏睿对我科研和生活上的帮 助以及和你们度过的愉快的午餐时间。

感谢在荷兰的每一位朋友, 很开心在这里和你们的相遇。李梁, 屠雨, 王 璐, 田建磊, 白馨蔚, 赵乙源从硕士一路走来有太多和你们的美好回忆。谢谢每 一位给过我帮助的朋友这几年来的支持和陪伴, 让我在荷兰的生活丰富多彩。

最后, 最重的是我要感谢我的家人。爸妈, 感谢你们用你们所有的爱对我的 支持和鼓励。感谢你们支持我出国让我能够看到这个世界的精彩。也感谢我的妹 妹徐琬让我了解荷兰和在国外一直的陪伴。

Jun Wang

王俊

June, 2019 
